\title{
Assessing the Relation between Corporate Social Responsibility and Firm Performance in the European Food and Beverage Industry
}

\section{Tadesse Getacher Engida}

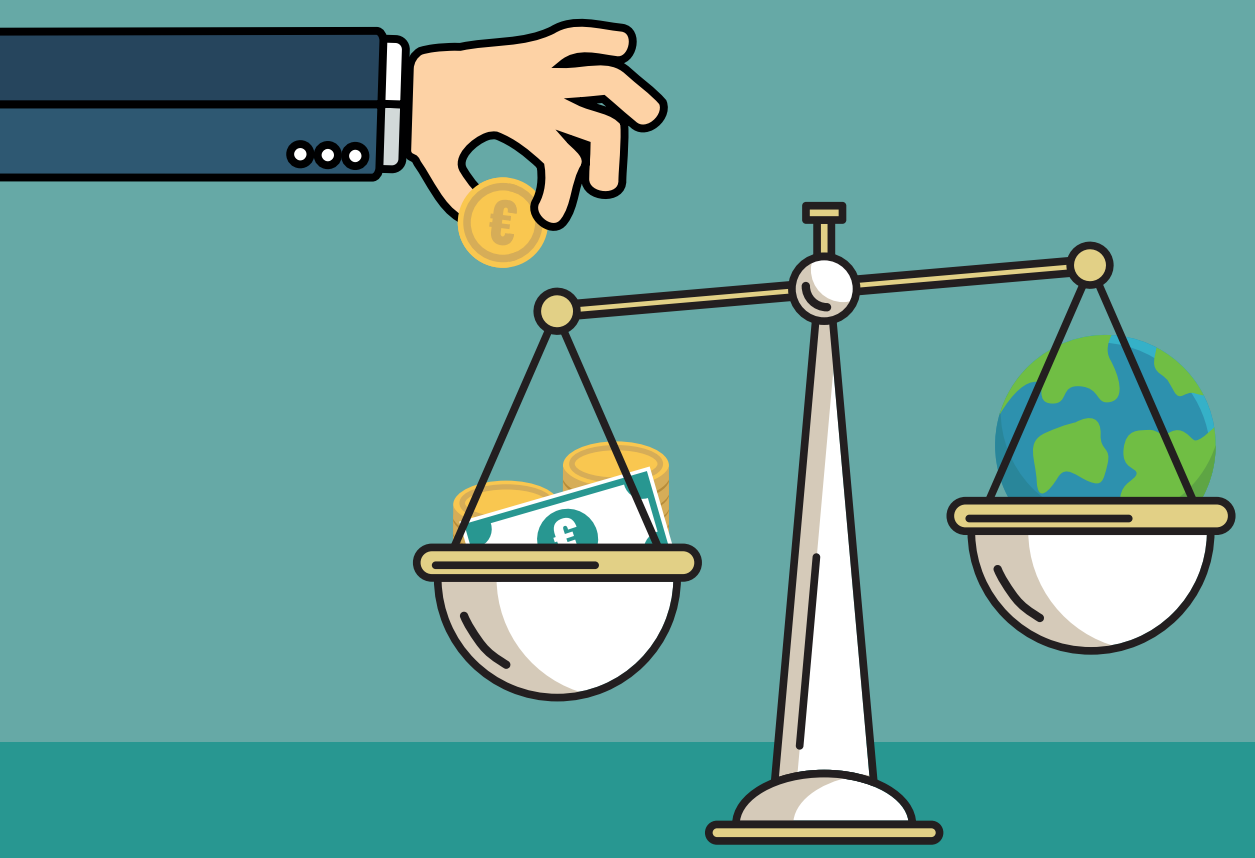




\section{Assessing the Relation between Corporate Social Responsibility and Firm Performance in the European Food and Beverage Industry}




\section{Thesis committee}

\section{Promotor}

Prof. Dr A.G.J.M. Oude Lansink

Professor of Business Economics

Wageningen University \& Research

\section{Co-promotor}

Dr X. Rao

Assistant professor, Business Economics Group

Wageningen University \& Research

\section{Other members}

Prof. Dr W.A. Dolfsma, Wageningen University \& Research

Prof. Dr L. Lauwers, Ghent University, Belgium

Prof. Dr J. Bos, Maastricht University

Dr A. Kanellopoulos, Wageningen University \& Research

This research was conducted under the auspices of the Wageningen School of Social Sciences (WASS). 


\section{Assessing the Relation between Corporate Social Responsibility and Firm Performance in the European Food and Beverage Industry}

\section{Tadesse Getacher Engida}

Thesis

submitted in fulfilment of the requirements for the degree of doctor

at Wageningen University

by the authority of the Rector Magnificus,

Prof. Dr A.P.J. Mol,

in the presence of the

Thesis Committee appointed by the Academic Board

to be defended in public

on Friday 20 December 2019

at 1.30 p.m in the Aula. 
Tadesse Getacher Engida

Assessing the Relation between Corporate Social Responsibility and Firm Performance in the European Food and Beverage Industry, 155 pages.

PhD thesis, Wageningen University, Wageningen, the Netherlands (2019)

With references, with summary in English

DOI: https://doi.org/10.18174/505655

ISBN: 978-94-6395-200-2 


\section{Abstract}

This thesis developed tools and generated insights that help accurately benchmark firms' performance in the presence of CSR. First, an aggregation method to construct a composite measure of CSR was described. The methods to integrate and aggregate individual indicators, which capture different facets of CSR help to manage and document sustainability improvements. Second, a dynamic by-production framework was developed with the aim of specifying a technology that best captures the link between production of desirable outputs(conventional and socially responsible outputs) and by-products (socially undesirable outputs). The framework captures the trade-offs between outputs and helps provide a more accurate representation of the production process. The empirical application focused on a sample of European food and beverage industry. The results provided insight into inefficiency related to the generation of CSR outputs and confirm the importance of accounting for adjustment costs in quasi-fixed inputs. Moreover, the results of the empirical application showed that there was a decline in dynamic Luenberger indicators mainly due to technical inefficiency change. This implies that firms should devise strategies to improve resource use and enhances the utilization of resources. Lastly, the relationship between CSR and investment inefficiency was examined using stochastic frontier approach which aptly characterizes CSR as having a downward pull on firm level investment efficiency. We applied the approach to a sample of European listed companies, providing robust evidence that high CSR performance reduces investment inefficiency. This result is in line with the view that high CSR firms are characterized by low information asymmetry and high stakeholder solidarity, which may represent a source of competitive advantage that helps to reducing investment inefficiency. The results imply that the implementation of CSR strategies is crucial to improve firm growth and safeguard interests of different stakeholders. This study contributes to a better understanding of the value of CSR and provides arguments for regulatory bodies to promote CSR activities.

Keywords: Corporate social responsibility, corporate sustainability, composite indicator, Principal Component Analysis, Data Envelopment Analysis, dynamic by-production model, technical inefficiency, dynamic Luenberger indicator, food and beverage manufacturing industry, stochastic frontier model, partly linear 



\section{Contents}

Chapter 1 General introduction 1

Chapter $2 \quad$ Measuring corporate sustainability performance - the case of 13

European food and beverage companies

Chapter $3 \quad$ A dynamic by-production framework to examine inefficiency 37

specific to corporate social responsibility

Chapter $4 \quad$ Measuring dynamic input- and output-specific productivity

change in the presence of socially responsible and

undesirable outputs

Chapter 5 Corporate social responsibility and investment inefficiency: An application of semi-parametric stochastic frontier estimations

Chapter 6 General discussion 



\section{Chapter 1}

General introduction 


\subsection{Background}

\section{The concept of CSR}

Almost all business decisions have social and environmental implications. Decisions such as how much to pay executives, what technologies to install in a new manufacturing facility, and how and when to retire old plants all have an effect on the firm's stakeholders and the natural environment. The threats that firms' growth pose to the environment and society are now clearer than ever. As pollution and environmental degradation worsen, the awareness of consumers and governments also increases (Harper \& Snowden, 2017; Ricci, Banterle, \& Stranieri, 2018). As a result business organizations today are increasingly encountering internal and external pressures to engage in corporate social responsibility (CSR) that extends beyond the economic interests of the firms (Yunus, 2011).

The concept of corporate social responsibility (CSR) relates to companies voluntarily integrating social and environmental concerns in their business decisions (European Commission, 2002) and has been argued to contain various components. Bowen(1979) defined CSR as “... an obligation to pursue policies to make decisions and to follow lines of action which are compatible with the objectives and values of society" (Douglas et al., 2004). CSR assumes that economic and legal duties of the companies should be extended by responsibilities to society. Carroll (1979) argues that Social Responsibility encompasses four components, i.e. economic, legal, ethical and discretionary (philanthropic) expectations that society has of a company and that companies have to decide which layer they focus on (Carroll, 1979).

Moreover, according to the World Business Council for Sustainable Development ${ }^{1}$, "Corporate Social Responsibility is the continuing commitment by business to contribute to economic development while improving the quality of life of the workforce and their families as well as of the community and society at large". In all of the above definitions, CSR is involving company's engagement with its stakeholders and its commitment to socially and environmentally responsible practices.

\section{CSR and sustainable development}

Sustainable development and corporate social responsibility are closely related business concepts that have greatly affected corporate governance in the early 21 st century. Corporations are being called upon to contribute to sustainable development, which aims to

\footnotetext{
${ }^{1}$ WBCSD Stakeholder Dialogue on CSR, The Netherlands, September 6-8, 1998.
} 
meet 'meet the needs of the present generation without compromising the ability of the next generations to meet their own needs(WCED, 1987:44). They are being asked to apply sustainable practice that involves the use of environmentally responsible and efficient operational practices. Sustainable practice refers to an organization's activities, typically considered voluntary, that demonstrate the inclusion of social and environmental concerns in business operations and in interactions with stakeholders. The most socially responsible organizations continue to enhance their current efforts and revise their short and long-term agendas, to stay ahead of rapidly changing challenges (Van Marrewijk, 2003). The quality of relationships that a company has with its employees and other key stakeholders, such as customers, investors, suppliers, public and governmental officials, activists, and communities, is crucial to its success, as is its ability to respond to the competitive conditions and corporate social responsibility. These major transformations require companies to approach their business in terms of sustainable development.

CSR represents sustainable development at the corporate level. Corporate sustainability essentially comprises activities related to corporate social responsibility (CSR) and is explained in light of environmental, social and governance (ESG) issues (Clark et al, 2015). ESG is a capital market term used by investors that represents the environmental, social and governance criteria to asses a company's responsible practices. CSR focuses on the corporate engagement realizing its responsibilities as a member of society and meeting the expectations of all stakeholders. It is, therefore, more logical to consider CSR as the enterprise's overall contribution (both positive and negative) to sustainable development, as reflected in Ward (2004) who defines corporate social responsibility as a "commitment of business to contribute to sustainable economic development - working with employees, their families, the local community and society at large to improve the quality of life, in ways that are both good for business and good for development' (Ward, 2004: 3).

CSR is definitely based on a sustainability mindset. CSR covers all the practices put in place by companies in order to uphold the principles of sustainable development and reach sustainable development path. In order to be a sustainable or responsible organization, companies need to be economically viable, have a positive impact on society, and respect and preserve the environment.

\subsection{Problem statement}

Corporate social responsibility is a relatively newly emerging theme in the discussion of business, the environment and the social responsibility of firms (Takala and Pallab, 2000). In recent years, there is growing pressure from various stakeholder groups to reduce adverse impacts of companies on environment and society (Molina-Azorín et al., 2009; Haniffa and 
Cooke, 2005). Governments in many countries have called for greater attention to the enforcement of CSR, aiming to support the sustainability of entrepreneurship as well as human welfare. Civil society and media are also increasingly requesting companies to consider the social and environmental consequences of their operations and to provide more transparency and openness with respect to their actions (Freeman et al., 2010). As a result, the business world has quickly incorporated the concept of corporate social responsibility (CSR), which covers not only aspects such as philanthropy and pollution but also a broad range of social, environmental, and governance metrics (Peloza, Loock, Cerruti, and Muyot, 2012, p. 76).

The need to broaden the focus of sustainability in business performance beyond that of economic and financial performance has also led to the establishment of independent advisory firms with the aim of sustainability assessments. Researchers have also shown an increased interest in developing methods for developing composite measures of corporate sustainability performance (Dočekalová and Kocmanová, 2016, Lee and Saen, 2012, Singh et al., 2007). However, many of these methods are not suitable for large correlated data and the aggregation of multidimensional constructs using expert opinions to determine weights of indicators. This creates the need to address the subjective weighing of multiple indicators when constructing a composite measure for the corporate sustainability performance.

The implementation of socially responsible activities such as environmental programs and community programs may mitigate undesirable outputs such as pollution and waste but divert resources away from the production of marketable output. Therefore, it is important to incorporate CSR into a production framework to capture these trade-offs among the inputs and outputs (desirable, undesirable). Research exploring productivity change and/or efficiency in the presence of CSR is still limited (Puggioni and Stefanou, 2016; Guillamon-Saorin et al., 2018; Sun and Stuebs, 2013; Wang et al., 2014). These articles aim at analysing efficiency and productivity change for all inputs simultaneously, ignoring differences in inputs. In addition, these studies are generally performed in a static context, ignoring the presence of adjustment costs associated with investments, such as search costs of new capital, costs of installing new equipment, costs of learning to use new equipment. Therefore, developing a framework that accounts for adjustment costs and captures the trade-offs between inputs and outputs in a dynamic context helps provide a more accurate representation of the production process when evaluating firm's performance.

Several researchers have investigated the benefits of CSR and found evidence that CSR contributes to business value through revenue generation (McWilliams and Siegel, 2001), cost control (Roberts and Dowling, 2002), risk management (Choi and Wang, 2009) and improved information quality(Cho et al., 2013, Lopatta et al., 2016). CSR improves the quality of 
information by providing incremental information beyond usual accounting measures such as revenue and costs (Cho et al., 2013, Lopatta et al., 2016). According to Cho et al. (2013) and Dhaliwal et al. (2011), firms that are relatively highly involved in CSR disclose more information with respect to their action on the social and environmental consequences of their operations compared to low CSR firms. Such disclosure improves information quality that helps to address information asymmetry and reduces investment inefficiency. Therefore, it is important to provide empirical insights on the relationship between CSR and investment inefficiency.

The empirical applications in this dissertation focus on the food and beverage industry in Europe. The food sector strongly depends on natural, human and physical resources (Genier et al., 2009). This sector is also viewed critically by diverse stakeholders including consumers and government as food is part of basic human needs, and consumers tend to have strong opinions about what they eat (Hartmann, 2011). Moreover, the food industry in Europe is the largest manufacturing industry in terms of turnover, value added and employment (Food drink Europe, 2015). These special characteristics justify a close examination of the joint profit-CSR sustainability of the European food industry.

\subsection{Objective of the thesis}

The overall objective of this thesis is to assess the relationship between CSR and firm performance with a focus on the European food and beverage industry.

This overall objective is met by addressing the following specific objectives:

1. To assess corporate sustainability performance in the European food and beverage industry,

2. To estimate dynamic inefficiency in the presence of socially responsible and undesirable output in the European food and beverage industry,

3. To estimate input- and output-specific productivity change in the presence of socially responsible and undesirable output in the European food and beverage industry,

4. To assess the relationship between corporate social responsibility and investment inefficiency.

\subsection{Outline of the thesis}

The thesis contains six chapters including a general introduction (Chapter 1) and a general discussion (Chapter 6). The outline of the dissertation is presented in Table 1.1. 
Table 1.1. Outline of the thesis

\begin{tabular}{|c|c|c|}
\hline Chapter & & Method \\
\hline \multirow[t]{3}{*}{1} & General Introduction & \\
\hline & Measuring corporate sustainability & \\
\hline & performance in the European food & \\
\hline \multirow[t]{3}{*}{2} & and beverage companies & PCA and DEA \\
\hline & A dynamic by-production framework & \\
\hline & to examine inefficiency specific to & Directional distance functions \\
\hline \multirow[t]{4}{*}{3} & corporate social responsibility & and DEA \\
\hline & Measuring dynamic input- and output- & \\
\hline & specific productivity change in the & \\
\hline & presence of socially responsible and & A Luenberger Indicator of \\
\hline \multirow[t]{2}{*}{4} & undesirable outputs & Productivity change and DEA \\
\hline & Role of social responsibility in & A semi-parametric stochastic \\
\hline 5 & explaining the investment inefficiency & frontier \\
\hline 6 & General Discussion & \\
\hline
\end{tabular}

Chapter 2 develops a method to measure corporate sustainability performance. The method combines Principal Component Analysis (PCA) and Data Envelopment Analysis (DEA) to aggregate multiple dimensions of sustainability performance. The method is applied to panel data of companies in the European food and beverages sector. This chapter also shows how the composite measure of corporate sustainability can be complemented by a decomposition analysis to identify priorities for sustainability improvements.

Chapter 3 develops a dynamic by-production framework and derives technical inefficiency estimates in the presence of socially responsible and undesirable output. Static production approaches fail to account for adjustment costs associated with investments in quasi fixed inputs. The dynamic by-production framework accounts for [1] adjustment costs in quasi fixed inputs and [2] resources diverted from the production of desirable outputs to CSR activities as well as the mitigation effects of CSR as it reduces undesirable outputs. The results provide insights into technical inefficiency related to the generation of CSR outputs and confirm the importance of dynamic framework that accounts for adjustment costs in quasi-fixed inputs.

Chapter 4 estimates input and output-specific productivity changes in the presence of a socially responsible output and an undesirable output. The productivity estimation accounts for the role of corporate social responsibility and adjustment costs in quasi-fixed inputs. Measuring productivity change sheds lights on the evolution of a firm and its degree of competitiveness over time. We further decompose productivity change into technical change, technical 
inefficiency change and scale inefficiency change to provide insights in the sources of productivity change.

Chapter $\mathbf{5}$ assesses the role of social responsibility in explaining investment inefficiency. Both the theoretical and empirical literature show that there exist friction that lead firms to deviate from optimal levels of investment. This friction is commonly known as investment inefficiency and literature suggests the sources of the friction include information asymmetry (Myers and Majluf, 1984). Studies in corporate social responsibility have found evidence that CSR contributes to business value through improved information quality among other channels (Cho et al., 2013, Lopatta et al., 2016). Building on this, we explore the effects of CSR on investment inefficiency.

Chapter 6 discusses the overall findings and implications of the four research chapters. This discussion includes critical reflections with regard to the methodologies and data and provides policy and business implications. Finally, the chapter provides the overall conclusions and gives recommendations for future research. 


\section{References}

Carroll, A. B. (1979). A three-dimensional conceptual model of corporate social performance. Academy of Management Review, 4, 497-505.

Clark, G. L., Feiner, A., \& Viehs, M. (2015). From the stockholder to the stakeholder: How sustainability can drive financial outperformance. Available at SSRN 2508281.

Cho, S. Y., Lee, C., and Pfeiffer Jr, R. J. (2013). Corporate social responsibility performance and information asymmetry. Journal of Accounting and Public Policy, 32(1):71-83.

Choi, J. and Wang, H. (2009). Stakeholder relations and the persistence of corporate financial performance. Strategic management journal, 30(8):895-907.

Douglas, A., Doris, J., \& Johnson, B. (2004). Corporate social reporting in Irish financial institutions. The TQM Magazine , 16(6), 387-395.

Dočekalová, M.P., Kocmanová, A., 2016. Composite indicator for measuring corporate sustainability. Ecological Indicators 61, 612-623

Dhaliwal, D. S., Li, O. Z., Tsang, A., and Yang, Y. G. (2011). Voluntary nonfinancial disclosure and the cost of equity capital: The initiation of corporate social responsibility reporting. The accounting review, 86(1):59-100.

European Commission (2002). Communication from the Commission concerning corporate social responsibility: a business contribution to sustainable development . Commission of the European Communities.

Food drink Europe. (2015). European Food and Drink Industry (2014-2015): Data and trends. Available at [http://www.fooddrinkeurope.eu/uploads/publications_documents/Data_and_Trends_201 4-20151.pdf] [Accessed 15 August 2019]

Freeman, R.E., Harrison, J.S., Wicks, A.C., Parmar, B.L., De Colle, S., 2010. Stakeholder Theory: the State of the Art. Cambridge University Press.

Friedman, M. (1962).Capitalism and Freedom. Chicago: University of Chicago Press.

Genier, C., Stamp, M. and Pfitzer, M. (2009). Corporate social responsibility for agro-industries development. In: C. Da Silva, D. Baker, A. Shepherd, C. Jenane and S. Miranda-da-Cruz (eds), Agro industries for Development. Oxfordshire, UK: CAB

Guillamon-Saorin, E., Kapelko, M., and Stefanou, S. (2018). Corporate social responsibility and operational inefficiency: A dynamic approach. Sustainability, 10(7):2277.

Harper, C., Harper, CL, \& Snowden, M. (2017). Environment and society: Human perspectives on environmental issues. Routledge.

Haniffa, R.M., Cooke, T.E., 2005. The impact of culture and governance on corporate social reporting. Journal of Accounting and Public Policy 24 (5), 391e430Hartmann, M. (2011). Corporate social responsibility in the food sector. European Review of Agricultural Economics, 38(3), 297-324.

Lee, K.-H., Saen, R.F., 2012. Measuring corporate sustainability management: a data envelopment analysis approach. Inter. J. Prod. Econ. 140 (1), $219 e 226$.

Lopatta, K., Buchholz, F., and Kaspereit, T. (2016). Asymmetric information and corporate social responsibility. Business \& Society, 55(3):458-488. 
McWilliams, A. and Siegel, D. (2001). Corporate social responsibility: A theory of the firm perspective. Academy of management review, 26(1):117-127.

Molina-Azorín, JF, Claver-Cortés, E., Lopez-Gamero, MD, \& Tarí, JJ (2009). Green management and financial performance: a literature review. Management Decision , 47 (7), 1080-1100.

Peloza, J., Loock, M., Cerruti, J., \& Muyot, M. (2012). Sustainability: How stakeholder perceptions differ from corporate reality. California Management Review, 55(1), 74-97.

Puggioni, D., \& Stefanou, S. E. (2016). The Value of Being Socially Responsible. A DEA Approach for Analyzing Efficiency and Recovering Shadow Prices of CSR Activities (No. 333-2016-14692).

Ricci, EC, Banterle, A., \& Stranieri, S. (2018). Trust to go green: an exploration of consumer intentions for eco-friendly convenience food. Ecological Economics, 148 , 54-65.

Roberts, P. W., \& Dowling, G. R. (2002). Corporate reputation and sustained superior financial performance. Strategic Management Journal, 23(12), 1077-1093.

Singh, RK, Murty, HR, Gupta, SK, \& Dikshit, AK (2007). Development of a composite sustainability performance index for steel industry. Ecological Indicators , 7 (3), 565-588.

Sun, L., \& Stuebs, M. (2013). Corporate social responsibility and firm productivity: Evidence from the chemical industry in the United States. Journal of Business Ethics , 118 (2), 251 263.

Takala, T., \& Pallab, P. (2000). Individual, collective and social responsibility of the firm. Business ethics: A European review , 9 (2), 109-118.

Van Marrewijk, M. (2003). Concepts and definitions of CSR and corporate sustainability: Between agency and communion. Journal of Business Ethics, 44 (2-3), 95-105.

Wang, W.-K., Lu, W.-M., Kweh, Q. L., and Lai, H.-W. (2014). Does corporate social responsibility influence the corporate performance of the us telecommunications industry? Telecommunications Policy, 38(7):580- 591.

WCED. (1987). Our Common Future: Report of the World Commission on Environment and Development.

Yunus, M. (2010). Building social business: The new kind of capitalism that serves humanity's most pressing needs . PublicAffairs. 


\section{Chapter 2}

\section{Measuring corporate sustainability performance- the case of European food and beverage industry}

Tadesse Getacher Engida ${ }^{\text {a, b, }}$ Xudong Rao ${ }^{a}$, Paul B.M. Berentsen ${ }^{\text {a }}$, Alfons G.J.M. Oude Lansink a

${ }^{a}$ Wageningen University \& Research, Business Economics Group, Hollandseweg 1, 6706 KN Wageningen, The Netherlands

${ }^{b}$ College of Business and Economics, Mekelle University, Mekelle, Ethiopia

Published in Journal of Cleaner Production (2018) 195: 734-743. 


\begin{abstract}
Measuring corporate sustainability performance is necessary to guide sustainability improvements. Although many indicators exist that capture the different dimensions of sustainability, a composite indicator that integrates across all indicators is important as it helps to summarize multi-dimensional issues and provide synthesized information. This study discusses and evaluates a method that builds on a combination of principal component analysis and data envelopment analysis for developing a composite indicator of corporate sustainability. Principal component analysis is used to reduce the number of indicators and remove correlations among the indicators. The composite indicator of sustainability for each company is then obtained by using data envelopment analysis with a bootstrapping procedure. The method is illustrated for companies in the European food and beverages sector, using data from Sustainalytics. The study also shows how the composite indicator of sustainability can be complemented by a decomposition analysis to identify priorities for sustainability improvements. The approach is valuable for stakeholders who aim to enhance corporate sustainability.
\end{abstract}

Keywords: Corporate sustainability, Indicator, Composite indicator, Principal component analysis, Data envelopment analysis 


\subsection{Introduction}

Business entities face fierce competitions from rival companies as they engage in growing and swift paced businesses. As a result of the dynamics of the competitions they face, they begin to grapple with challenges that need to be overcome to continuously operate in such a competitive arena. In doing so, their endeavours to sustain their functionality might have a spilling over consequence that could potentially have a multifarious effect upon their social milieu. Thus, companies face growing pressure from various stakeholder groups to consider the social and environmental consequences of their operations (Haniffa and Cooke, 2005; Molina-Azorín et al., 2009; SustainAbility and Poor, 2004). Moreover, a change in values and preferences of more affluent citizens, especially in Western societies, raises the relevance of corporate sustainability and responsibility (Moon and Vogel, 2008). Stakeholder groups, such as civil society and media progressively demand companies to take the social and environmental consequences of their operations in to consideration and to provide more transparency and openness with regard to their actions (Freeman et al., 2010).

The increasing societal demand with respect to corporate social responsibility and sustainability affects all sectors of the economy. However, given the characteristics of an industry, the pressure on companies to take up corporate social responsibility(CSR) likely differs. The food sector is linked to several societal concerns. Food safety, for example, is a key concern for any society as it demands the attention and awareness of the government and all stakeholders in the industry (Kong, 2012). Some other societal concerns are ethical issues relating to procurement processes because of the danger of power abuse and unfair practices, while others with relevance in other areas of the economy have a specific demand from the food sector, for example, labour rights, animal welfare (Hartmann, 2011; Heyder and Theuvsen, 2012). CSR in the food industry is particularly important due to its wide range of potential benefits including ensuring food safety.

In order to document and show the current status and improvement in corporate sustainability, sustainability indicators are crucial. The need to broaden the focus of sustainability in business performance beyond that of financial performance has also led to the establishment of independent advisory firms with aim of sustainability assessments. These sustainability assessments or standards are extensive, including large number of indicators to capture different facets of sustainability. For example, Sustainalytics ${ }^{2}$ collects information on over 150

\footnotetext{
${ }^{2}$ Sustainalytics is a global leader in sustainability research and analysis, serving investors and financial institutions around the world.
} 
indicators by evaluating companies' management systems, practices and policies related to environmental, social and governance risk.

Methods to integrate and aggregate individual indicators, which capture different facets of sustainability help to manage and document sustainability improvements. A composite indicator for measuring corporate sustainability has implications in several aspects. At firm level, the composite indicator help firms to evaluate their performance against their peers and identify priorities for sustainable improvements. The composite sustainability indicator is also increasingly important in business decision making given the pressure from stakeholders and the need for improving firm image (Lee and Saen, 2012). At the aggregate level, the distribution of the composite indicators helps to evaluate the overall sustain-ability performance. Composite indicators can summarize complex, multi-dimensional concepts while maintaining the underlying information base (Saisana and Tarantola, 2002). Composite indicators are also easier to interpret than a set of individual indicators and facilitate communication with the general public and other stakeholders. Conversely, some researchers argue against using composite indicators because of the weighting process (Sharpe, 2004) or because "work in data collection and editing is wasted or hidden behind a single number of dubious significance" (Saisana et al., 2005).

Recently, researchers have shown an increased interest on methods for developing composite measures of corporate sustainability (Docekalova and Kocmanova, 2016; Lee and Saen, 2012; Singh et al., 2007). However, many of these methods are not suitable for large correlated data or use subjective weights.

The objective of this study is to describe and evaluate a method for developing a composite indicator that address problems arise in corporate sustainability assessments. The method is suitable for large correlated data and applies a model to decide weights endogenously. As an empirical application, we apply the method to European food and beverage companies using a data from Sustainalytics. The underlying concept of the method is to first apply principal component analysis(PCA) to reduce the large number of sustainability indicators into a smaller number of principal components and then use these components in data envelopment analysis (DEA) to construct a composite indicator of sustainability. By employing the combined PCA and DEA, we offer a new approach to measure corporate sustainability performance. The new approach is suitable especially when sustainability assessments include large number of highly correlated indicators that capture different dimensions of sustainability and the study findings contribute to the body of knowledge in corporate sustainability measurement.

The remainder of this chapter is organized as follows. Section 2 elaborates the method for constructing a composite measure by discussing issues arising when PCA and DEA are used. 
Following, section 3 is the empirical illustration that describes the data and presents the results. It discusses how the composite indicators can be constructed and how specific priorities are identified to improve corporate sustainability. And Section 4 offers concluding comments.

\subsection{Methodological approach}

Data envelopment analysis (DEA) has become an important technique in economics and management disciplines to analyse efficiency and productivity (Bogetoft and Otto, 2010; Cooper et al., 2007). DEA benchmarks the performance of individual decision making units (DMUs) against a frontier based on the observed practices or outcomes of other DMUs (Cooper et al., 2007). In our context, DEA estimates the efficiency value for each DMU to incorporate many aspects of sustainability and to produce a single composite measure of sustainability. DEA is suitable for the construction of composite indicators, as it was previously applied to measure well being and quality of life (Domínguez-Serrano and Blancas, 2011; Jurado and Perez-Mayo, 2012), human development (Despotis, 2005), farm sustainability (Dong et al., 2015). The advantage of DEA is that the method allows each DMU to grant greater weight to its specific best performing features. Stakeholders cannot dispute about an unfair weighting since it uses the most favourable weighting according to the relative performance of the DMU in any particular dimension.

Assessments of corporate sustainability usually embrace a large number of correlated variables capturing different dimensions of sustainability. Definitely, large numbers of correlated variables limit the value of DEA. Given a constant number of DMUs, as the number of variables increases, the frontier becomes defined by a larger number of DMUs, so that an increasing number of DMUs are ranked as efficient and the ability to differentiate among DMUs decreases (Adler and Yazhemsky, 2010). In addition, correlation among the variables also influences efficiency evaluations by reducing the discriminating power of DEA (Jolliffe, 2002). For these reasons, PCA can be used as it helps to reduce the large number of highly correlated variables to small number of uncorrelated principal components (Jolliffe, 2002). Another limitation in DEA is the assumption that requires data to be free of measurement error or statistical noise; as a result, DEA tends to be sensitive to measurement errors than parametric techniques. The results of a DEA using real life data are inevitably affected by statistical noise. However, the principal components are less vulnerable to the statistical noise present in reallife data (Jolliffe, 2002; Poldaru and Roots, 2014).

To develop a composite indicator and evaluate corporate sustainability, a two stage analysis that combined PCA and DEA is employed in this study. The two stage analysis begins with PCA. In the second stage, a bootstrap DEA is used to construct composite indicator of corporate sustainability. 


\subsubsection{Principal component analysis (PCA)}

PCA is a statistical procedure that uses orthogonal transformation of the covariance or correlation matrix to transform observations of possibility correlated indicators (variables) in to uncorrelated principal components (Li et al., 2012; OECD., 2008). Each principal component is a linear combination of the original variables. The quality of PCA is that data can be compressed by limiting the number of dimensions after observing the patterns in the data (Jolliffe, 2002).

The principal components represent uncorrelated variables and are ordered in a way that the first few keep most of the variation in all of the original variables (Jolliffe, 2002). The highest factor loadings are allocated to the individual indicators that have the largest variation across the observations. If most of the variation in population can be captured by the first few components, then these components can replace the original variables with minimal loss of information. This in turn helps to improve the discriminatory power of the DEA model (Adler and Golany, 2001). The principal components are also less vulnerable to the impact of measurement errors (statistical noise). Hence, principal components can be used to substitute the original variables simultaneously or to replace certain groups of variables in a DEA structure (Adler and Golany, 2001; Poldaru and Roots, 2014). The mathematical expression of the model follows.

Let the random vector $X=\left\lfloor x_{1}, x_{2}, \cdots, x_{p}\right\rfloor$ possess the covariance matrix $V$ with eigenvalues $\eta_{1} \geq \eta_{2} \geq \cdots \eta_{P} \geq 0$ and normalized eigenvectors $I_{1} \geq I_{2} \geq \cdots I_{P}$.

Consider the linear combinations, where the superscript $t$ represents the transpose operator, as specified in (1).

$$
\begin{aligned}
& X_{P C_{i}}=I_{i}^{t} X=I_{1 i} X_{1}+I_{2 i} X_{2}+\ldots+I_{p i} X_{p} \\
& \operatorname{Var}\left(X_{P C_{i}}\right)=I_{i}^{t} V I=\eta_{i}, i=1,2, . ., p \\
& \operatorname{Cov}\left(X_{P C_{i}}, X_{P C_{k}}\right)=I_{i}^{t} V I_{k}=0, i=1,2, . ., p, k=1,2, . ., p, i \neq k
\end{aligned}
$$

The principal components, $X_{P C_{1}}, X_{P_{2}}, \ldots, X_{P C_{p}}$, are the uncorrelated linear combinations ranked by their variances in descending order. The complete set of principal components is as large as the original set of variables. $L_{x}$ is the matrix of all $I_{i}$ whose dimensions drop from $m \times m$ to $h \times m$, as PCs are dropped ( $X_{P C}$ becomes an $h \times n$ matrix). 
Generally, DEA requires strictly positive inputs and outputs although elements of principal components can be negative. To resolve this, all the components used in the DEA have been increased, where necessary, by the most negative value in the vector plus one, thus strictly positive data is assured (Adler and Yazhemsky, 2010; P oldaru and Roots, 2014). The linear monotone increasing data transformation to avoid the negative values is specified as follows:

$$
y_{i j}=X_{P C_{i j}}+Q
$$

where $Q=-\min _{1 \leq i \leq h} \min _{1 \leq j \leq n}\left\{P C_{i j}\right\}+1$.

$i$ indexes the principal components with $h$ number of selected principal components

$j$ indexes the firm with $n$ number of firms in the sample

\subsubsection{DEA model and bootstrapping of DEA estimates}

The DEA approach aims to measure relative efficiency, which is based on the comparison with other DMUs in the sample. DEA identifies inefficient DMUs and efficient DMUs, which are considered as benchmarks. The inefficient DMUs have a value of inefficiency derived by the distance to the frontier developed from benchmark DMUs. The DEA approach in this study followed the research line started by Lovell et al. (1995) and promoted by Cherchye et al. (2004), who proposed the concept of estimating composite indicators using optimization techniques. The main difference between the DEA constructing composite indicator and the basic DEA efficiency model is that the former only looks at achievements (outputs), without explicitly considering the resources (inputs) used (Cherchye et al., 2004). The purpose of using a DEA model to obtain a composite indicator is to aggregate a set of indicators, i.e. selected principal components in our case, into a single summary measure of corporate sustainability. DEA helps to avoid any possible controversies related to the selection of weights since it decides weights endogenously and it uses the most favourable weighting scheme according to the relative performance of a firm in any particular indicator. This helps to address the limitations of corporate sustainability assessments that use expert opinions to determine weights of indicators.

Mathematically, the DEA model for driving the composite indicator Cjo for a firm jo is determined by solving the following mathematical programming problem.

$$
C_{j}=\max \theta
$$

subject to 


$$
\theta y_{i k} \leq \sum_{j} \lambda_{j} y_{i j}, \quad i=1,2, \ldots, h, \lambda_{j} \geq 0, \quad j=1,2, \ldots, n
$$

where $y_{j}=y_{1 j}, y_{2 j}, \ldots, y_{h j}$ represent selected principal component scores for the firm $j, j$ indexes the firms in the analysis, $n$ is the total number of firms in the sample, $i$ indexes the principal components, $h$ is the total number of selected principal components, and $\lambda_{j}$ are the assigned weights for each firm.

After computing the composite indicator, bootstrapping is used to obtain unbiased performance estimates. Bootstrapping the DEA estimates helps to test the sensitivity of DEA scores to sampling variation (Aliev and Ebadi, 2012). The basic idea of bootstrapping is to resample from the original data to produce replicate datasets from which statistical inference can be made (Efron, 1982). The bootstrapping method corrects the DEA estimates for sampling bias and allows the construction of confidence intervals, which can be used to test whether the estimates differ significantly (Simar and Wilson, 1998). The bootstrapping procedure adopted in this study was implemented using the statistical package $R$ including the FEAR library, developed by Wilson (2008). Horta et al. (2012) specify the following steps for bootstrapping and obtaining the sample bias corrected estimates and the confidence interval of the estimates:

1) Compute the performance estimates $\hat{C}_{j}$ for each $\mathrm{DMU} j=1, \ldots, n$ by solving the model in Equation (3).

2) Use Kernel density estimation and the reflection method to generate a random sample of size $n$ from $\left\{\hat{C}_{j}, j=1, \ldots, n\right\}$, resulting in $\left\{C_{j b}^{*}, j=1, \ldots, n\right\}$.

3) Generate a pseudo dataset $\left\{\left(x_{j}^{*}, y_{j}^{*}\right), j=1, \ldots, n\right\}$ in order to form a bootstrap technology.

4) Compute the bootstrap estimate of performance $C_{j b}^{*}$ of $\hat{C}_{j}$ for each $j=1, \ldots, n$.

5) Repeat steps 2 to $4 B$ times $(B=2000)$ to obtain a set of estimates $\left\{C_{j b}^{*}, b=1, \ldots, B\right\}$.

When the bootstrapped values are computed, the bias of $\hat{C}_{j}$ is obtained: $\widehat{\operatorname{bias}}_{B}\left(\hat{C}_{j}\right)=$ $B^{-1} \sum_{b=1}^{B} \hat{C}_{j b}^{*}-\hat{C}_{j}$. The bias-corrected estimates of $C_{j}$ are then:

$\widehat{\hat{C}}_{J}=\hat{C}_{j}-\widehat{b l a s}_{B}\left(\hat{C}_{j}\right)=2 \hat{C}_{j}-B^{-1} \sum_{b=1}^{B} \hat{C}_{j b}^{*} \quad$. To obtain the confidence intervals for $C_{j}$, the values $\left(\hat{C}_{j b}^{*}-\hat{C}_{j}\right)$ for $b=1, \ldots, B$ are sorted in increasing order, and $((\alpha / 2) \times 100) \%$ of the elements are deleted at either end of the sorted array. Subsequently, $-\hat{b}_{\alpha}^{*}$ and $-\hat{a}_{\alpha}^{*}\left(\hat{a}_{\alpha}^{*} \leq \hat{b}_{\alpha}^{*}\right)$ need to be set equal to the end points of the sorted array. The estimated $(1-\alpha) \%$ confidence interval is then: $\hat{C}_{j}+\hat{a}_{\alpha}^{*} \leq C_{j} \leq \hat{C}_{j}+\hat{b}_{\alpha}^{*}$. 
To summarize the proposed method for measuring and evaluating corporate sustainability, PCA is applied to reduce large number of highly correlated indicators into a smaller number of principal components. The principal components, which are orthogonal linear combinations of original indicators, are used in DEA to construct a composite indicator of corporate sustainability.

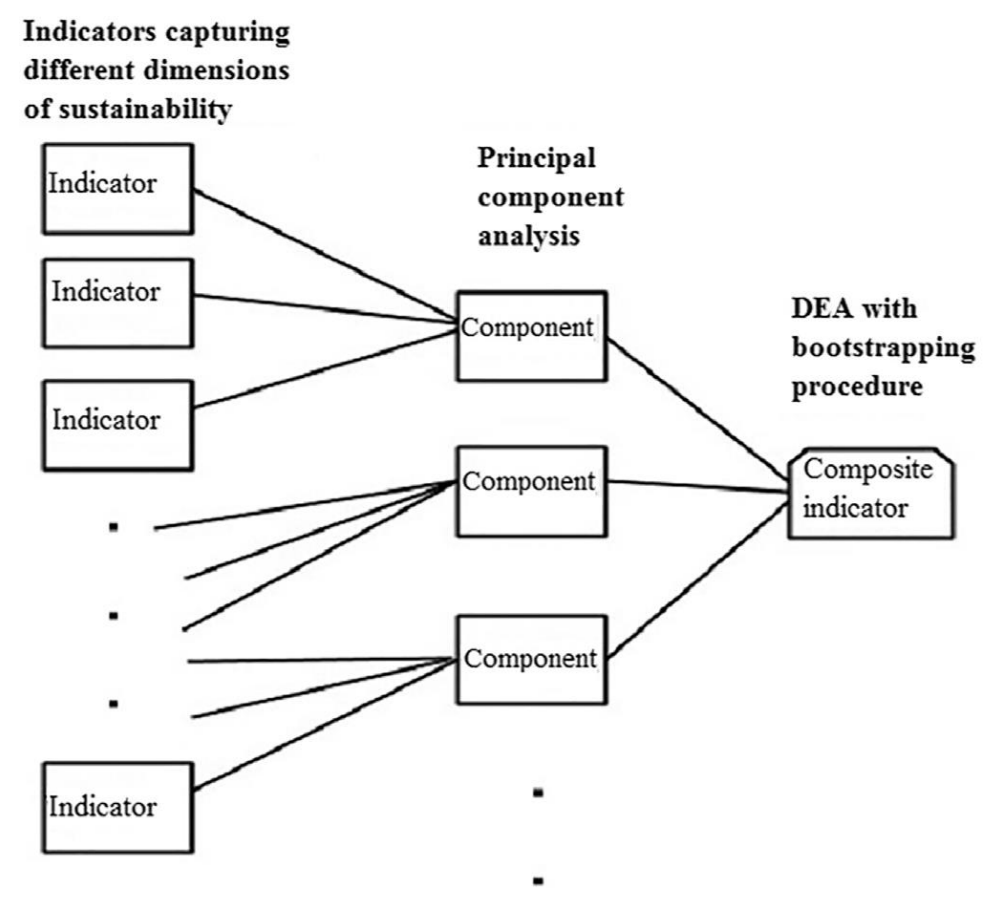

Fig. 2.1. Graphic representation of the method for constructing composite indicator.

The schematic representation of the method is shown on Fig. 2.1. This method is illustrated using data on indicators that capture different dimensions of Sustianability in the case of European food and beverage companies.

\subsection{Empirical application}

\subsubsection{Data}

The database of Sustainalytics was consulted to obtain data for the empirical applications. The database contain a large number of indicators that reflect the different dimensions of sustainability. Fig. 2.2 illustrates the structure of Sustainalytics database, which includes three main dimensions: environmental, social and governance. In the environmental dimension, the sub categories are operations, contractors \& supply chain, and products and services. In the social dimension, these include: employees, contracts \&supply chain, consumers, society \& community, philanthropy. In the governance dimension, the categories include: business ethics, corporate governance and public policy. Within each of the categories, several indicators are identified, such as policy on bribery and board independence. At the indicator level, a 
comprehensive set of metrics are analysed and scored. The assessment of the score is done by in house specialists based on information from sources such as available annual reports, financial reports, CSR reports, CSR websites, news releases, public news sources such as Bloomberg, (local) newspapers and NGOs.

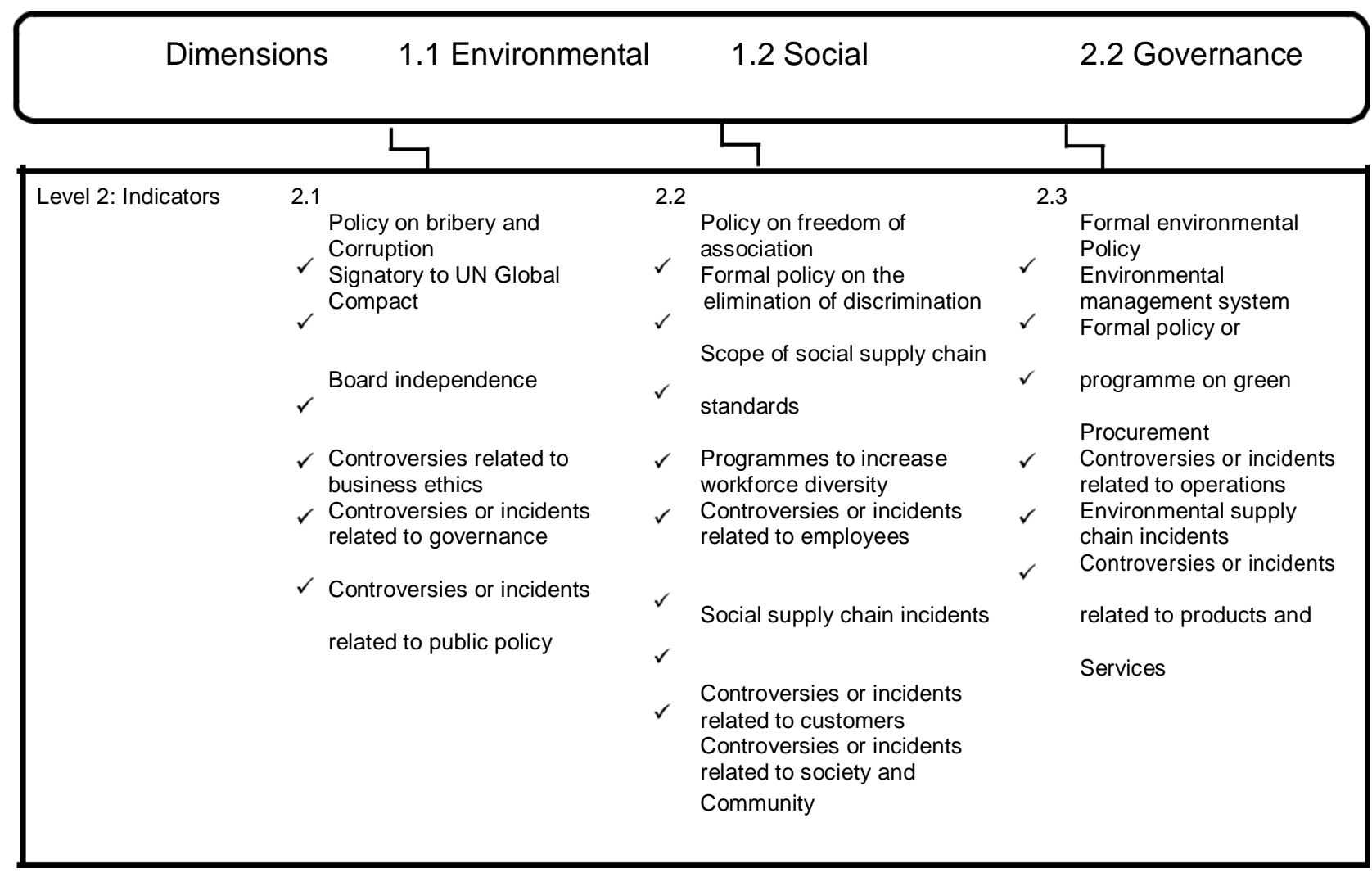

Fig. 2.2. Indicators reflecting different dimensions of sustainability.

The data provided by Sustainalytics is in the form of scores. For each firm within a sector, a score is provided for the indicators across the three dimensions (Environment, Social and Governance). Raw scores range between 0 and 100, where 0 denotes a very poor performance and 100 denotes an excellent performance.

In this study, we use scores of twenty indicators, which reflect the three dimensions of corporate sustainability, to construct our proposed composite indicator of corporate sustainability. Table 2.1 shows the descriptive statistics (mean and standard deviation) of the twenty indicators. These indicators form the basis for subsequent analysis. 
Table 2.1. Descriptive statistics (Mean and standard deviation (S.D) of the scores for each indicators of corporate sustainability $(n=84)$.

\begin{tabular}{|c|c|c|c|c|}
\hline Dimensions & Indicators & Symbol & Mean & S.D \\
\hline \multirow[t]{6}{*}{ Governance } & Policy on bribery and corruption & g1 & 61.90 & 34.60 \\
\hline & Signatory to UN Global Compact & g2 & 38.10 & 48.85 \\
\hline & Board independence & g3 & 44.35 & 43.97 \\
\hline & Controversies related to business ethics & g4 & 92.01 & 14.25 \\
\hline & Controversies or incidents related to governance & g5 & 97.67 & 7.64 \\
\hline & Controversies or incidents related to public policy & g6 & 99.48 & 3.07 \\
\hline \multirow[t]{9}{*}{ Social } & Policy on freedom of association & s1 & 55.89 & 44.16 \\
\hline & Formal policy on the elimination of discrimination & s2 & 47.14 & 34.63 \\
\hline & Scope of social supply chain standards & s3 & 62.80 & 42.78 \\
\hline & Programmes to increase workforce diversity & s4 & 26.49 & 27.81 \\
\hline & Controversies or incidents related to employees & s5 & 95.86 & 10.80 \\
\hline & Social supply chain incidents & s6 & 93.19 & 14.73 \\
\hline & Controversies or incidents related to customers & s7 & 94.23 & 11.57 \\
\hline & Controversies or incidents related to society and & & & \\
\hline & community & s8 & 98.31 & 6.83 \\
\hline \multirow[t]{7}{*}{ Environment } & Formal environmental policy & e1 & 51.01 & 34.58 \\
\hline & Environmental management system & e2 & 59.52 & 31.96 \\
\hline & Formal policy or programme on green procurement & e3 & 43.10 & 31.39 \\
\hline & Controversies or incidents related to operations & e4 & 98.57 & 6.53 \\
\hline & Environmental supply chain incidents & e5 & 99.02 & 4.28 \\
\hline & Controversies or incidents related to products and & & & \\
\hline & services & e6 & 99.99 & 0.11 \\
\hline
\end{tabular}

\subsubsection{Principal component analysis}

The first stage of the analysis is to transform the twenty indicators that capture the different dimensions of sustainability into a new set of uncorrelated principal components, with the first few retaining most of the variation present in the original indicators.

Prior to conducting the PCA, the KMO (Kaiser-Meyer-Olkin) measure of sampling adequacy and Bartlett's test of sphericity is calculated to check that PCA was an appropriate method. PCA is appropriate if the KMO value is greater than 0.50, and if Bartlett's test rejects the hypothesis that there are no correlations between indicators at $\mathrm{p}<0.05$. The KMO measure of sampling adequacy was 0.75 , which is well above the minimum threshold. Kaiser (1974) characterizes measures around 0.70 as middling, suggesting that the sample size is adequate for PCA. Bartlett's test of sphericity was also significant (769.23; $p<0.001)$, suggesting that the correlation matrix is significantly different from an identity matrix. In other words, at least one of the correlations between the indicators is significantly different from zero.

The general rule to determine the number of principal components for an analysis is that the cumulative weight of the principal components should constitute at least $70 \%$ of the variance in the original data (Jolliffe, 2002). As shown in Table 2, the first seven principal components, PC1 to PC7, together constituted $74.1 \%$ of the variance in the original data. These seven components also had the highest eigenvalues. The corresponding seven eigenvalues have 
been used in this analysis without losing significant information from the original set of indicators.

The loading factors in Table 2.2 show that indicators, such as g1, g2, g4, s1, s2, s3, s4,s7,e1,e2 and $\mathrm{e} 3$ are mainly associated with component PC1, whereas g5 and s6 are associated with component PC2. The indicators $\mathrm{g} 6$, s5, e4 and e5 are mainly associated with component PC3, s8 is mainly associated with component PC5 and e6 is associated with component PC7. The indicators that are highly correlated with other indicators and that have large variations across observations are loaded on the first principal component.

Table 2.2. Squared cosines of the variables (loading factors)

\begin{tabular}{|c|c|c|c|c|c|c|c|c|}
\hline Variables & Symbol & $\mathrm{PC1}$ & PC2 & PC3 & PC4 & PC5 & PC6 & PC7 \\
\hline Policy on Bribery and Corruption & g1 & 0.409 & 0.000 & 0.004 & 0.075 & 0.071 & 0.035 & 0.014 \\
\hline Signatory to UN Global Compact & g2 & 0.337 & .225 & 0.041 & 0.096 & 0.070 & 0.001 & 0.013 \\
\hline Board Independence & g3 & 0.117 & 0.108 & 0.052 & 0.161 & 0.024 & 0.001 & 0.003 \\
\hline $\begin{array}{l}\text { Business Ethics Related Controversies } \\
\text { or Incidents }\end{array}$ & g4 & 0.345 & 0.042 & 0.033 & 0.084 & 0.104 & 0.213 & 0.002 \\
\hline $\begin{array}{l}\text { Governance Related Controversies or } \\
\text { Incidents }\end{array}$ & g5 & 0.086 & 0.284 & 0.138 & 0.058 & 0.007 & 0.243 & 0.012 \\
\hline $\begin{array}{l}\text { Public Policy Related Controversies or } \\
\text { Incidents }\end{array}$ & g6 & 0.087 & 0.210 & 0.281 & 0.012 & 0.075 & 0.159 & 0.014 \\
\hline Policy on Freedom of Association & s1 & 0.347 & 0.136 & 0.006 & 0.015 & 0.014 & 0.047 & 0.115 \\
\hline $\begin{array}{l}\text { Formal Policy on the Elimination of } \\
\text { Discrimination }\end{array}$ & s2 & 0.487 & 0.189 & 0.011 & 0.060 & 0.003 & 0.001 & 0.034 \\
\hline $\begin{array}{l}\text { f Social Supply Chain } \\
\text { ds }\end{array}$ & s3 & 0.537 & 0.094 & 0.018 & 0.011 & 0.008 & 0.000 & 0.000 \\
\hline $\begin{array}{l}\text { ammes to Increase Workforce } \\
\text { sity }\end{array}$ & s4 & 0.545 & 0.001 & 0.008 & 0.025 & 0.070 & 0.009 & 0.015 \\
\hline $\begin{array}{l}\text { Employee Related Controversies or } \\
\text { Incidents }\end{array}$ & s5 & 0.176 & 0.084 & 0.381 & 0.000 & 0.020 & 0.017 & 0.000 \\
\hline upply Chain Incidents & s6 & 0.288 & 0.436 & 0.017 & 0.016 & 0.031 & 0.011 & 0.000 \\
\hline $\begin{array}{l}\text { Customer Related Controversies or } \\
\text { Incidents }\end{array}$ & s7 & 0.433 & 0.191 & 0.028 & 0.070 & 0.013 & 0.091 & 0.038 \\
\hline $\begin{array}{l}\text { Society \& Community Related } \\
\text { Controversies or Incidents }\end{array}$ & s8 & 0.040 & 0.089 & 0.102 & 0.148 & 0.332 & 0.030 & 0.000 \\
\hline Form & e1 & & & 0.045 & 0.002 & 0.116 & 0.002 & 0.062 \\
\hline Enviro & e2 & 0.347 & 0.102 & 0.000 & 0.113 & 0.034 & 0.002 & 0.092 \\
\hline $\begin{array}{l}\text { Formal Policy or Programme on Green } \\
\text { Procurement }\end{array}$ & e3 & 0.594 & 0.027 & 0.009 & 0.058 & 0.004 & 0.003 & 0.048 \\
\hline $\begin{array}{l}\text { Operations Related Controversies or } \\
\text { Incidents }\end{array}$ & e4 & 0.120 & 0.119 & 0.411 & 0.000 & 0.070 & 0.023 & 0.001 \\
\hline Environmental Supply Chain Incidents & e5 & 0.126 & 0.094 & 0.406 & 0.023 & 0.052 & 0.011 & 0.000 \\
\hline $\begin{array}{l}\text { Products \& Services Related } \\
\text { Controversies or Incidents }\end{array}$ & e6 & 0.037 & 0.008 & 0.003 & 0.187 & 0.028 & 0.131 & 0.503 \\
\hline Eigenvalue & & & 2.570 & 1.993 & 1.213 & 1.147 & 1.030 & 0.967 \\
\hline Cumulative proportion & & 0.295 & 0.423 & 0.523 & 0.584 & 0.641 & 0.693 & 0.741 \\
\hline
\end{tabular}

Values in bold correspond for each variable to the factor for which the squared cosine is the largest. 
Before rotation, most variables loaded highly on the first principal component and the remaining components were less relevant. The loading factors changed considerably after the rotation of the component structure, as shown in Table 2.3.

Table 2.3: Squared cosines of the variables after Oblimin rotation (loading factors after Oblimin rotation)

\begin{tabular}{|c|c|c|c|c|c|c|c|c|}
\hline Variables & & D1 & D2 & D3 & D4 & D5 & D6 & D7 \\
\hline Policy on Bribery and Corruption & g1 & 0.198 & 0.015 & 0.015 & 0.183 & 0.301 & 0.273 & 0.016 \\
\hline Signatory to UN Global Compact & g2 & 0.096 & 0.289 & 0.033 & 0.017 & 0.035 & 0.111 & 0.420 \\
\hline Board Independence & g3 & 0.000 & 0.194 & 0.042 & 0.002 & 0.266 & 0.414 & 0.082 \\
\hline $\begin{array}{l}\text { Business Ethics Related Controversies or } \\
\text { Incidents }\end{array}$ & g4 & 0.285 & 0.144 & 0.041 & 0.051 & 0.000 & 0.022 & 0.456 \\
\hline $\begin{array}{l}\text { Governance Related Controversies or } \\
\text { Incidents }\end{array}$ & g5 & 0.364 & 0.076 & 0.028 & 0.081 & 0.033 & 0.000 & 0.418 \\
\hline $\begin{array}{l}\text { Public Policy Related Controversies or } \\
\text { Incidents }\end{array}$ & g6 & 0.518 & 0.047 & 0.029 & 0.269 & 0.091 & 0.044 & 0.002 \\
\hline Policy on Freedom of Association & s1 & 0.582 & 0.148 & 0.018 & 0.158 & 0.018 & 0.067 & 0.009 \\
\hline $\begin{array}{l}\text { Formal Policy on the Elimination of } \\
\text { Discrimination }\end{array}$ & s2 & 0.145 & 0.437 & 0.003 & 0.005 & 0.131 & 0.235 & 0.043 \\
\hline Scope of Social Supply Chain Standards & s3 & 0.032 & 0.335 & 0.028 & 0.006 & 0.173 & 0.314 & 0.111 \\
\hline $\begin{array}{l}\text { Programmes to Increase Workforce } \\
\text { Diversity }\end{array}$ & s4 & 0.189 & 0.166 & 0.027 & 0.016 & 0.101 & 0.149 & 0.352 \\
\hline $\begin{array}{l}\text { Employee Related Controversies or } \\
\text { Incidents }\end{array}$ & s5 & 0.312 & 0.001 & 0.008 & 0.138 & 0.296 & 0.217 & 0.027 \\
\hline Social Supply Chain Incidents & s6 & 0.106 & 0.176 & 0.040 & 0.007 & 0.160 & 0.251 & 0.260 \\
\hline $\begin{array}{l}\text { Customer Related Controversies or } \\
\text { Incidents }\end{array}$ & s7 & 0.001 & 0.345 & 0.064 & 0.013 & 0.081 & 0.177 & 0.319 \\
\hline $\begin{array}{l}\text { Society \& Community Related } \\
\text { Controversies or Incidents }\end{array}$ & s8 & 0.048 & 0.087 & 0.016 & 0.002 & 0.374 & 0.397 & 0.076 \\
\hline Formal Environmental Policy & e1 & 0.163 & 0.090 & 0.163 & 0.000 & 0.078 & 0.262 & 0.242 \\
\hline Environmental Management System & e2 & 0.000 & 0.037 & 0.107 & 0.022 & 0.478 & 0.179 & 0.178 \\
\hline $\begin{array}{l}\text { Formal Policy or Programme on Green } \\
\text { Procurement }\end{array}$ & e3 & 0.112 & 0.149 & 0.008 & 0.029 & 0.235 & 0.283 & 0.183 \\
\hline $\begin{array}{l}\text { Operations Related Controversies or } \\
\text { Incidents }\end{array}$ & e4 & 0.161 & 0.010 & 0.032 & 0.085 & 0.458 & 0.248 & 0.006 \\
\hline Environmental Supply Chain Incidents & e5 & 0.409 & 0.001 & 0.014 & 0.171 & 0.232 & 0.143 & 0.031 \\
\hline $\begin{array}{l}\text { Products \& Services Related Controversies } \\
\text { or Incidents }\end{array}$ & e6 & 0.357 & 0.005 & 0.004 & 0.000 & 0.123 & 0.235 & 0.277 \\
\hline
\end{tabular}

For each variable, values in bold correspond to the factor for which the squared cosine is the largest.

The first principal component was correlated with the scores of Public Policy Related Controversies or Incidents (g6), Policy on Freedom of Association (s1), Employee Related Controversies or Incidents (s5), Environmental Supply Chain Incidents (e5) and Products Services Related Controversies or Incidents (e6). The second principal component was correlated with the scores of Formal Policy on the Elimination of Discrimination (s2), Scope of Social Supply Chain Standards (s3) and Customer Related Controversies or Incidents (s7). This component addresses part of the social dimension of sustainability. 
There are no indicators that load highly on the third and fourth components. The fifth principal component was associated with three original indicators: Policy on Bribery and Corruption (g1), Environmental Management System (e2) and Operations Related Controversies or Incidents (e4). This is a reasonable because bribery and corruption cost a company that undermines business performance and diverts resources from legitimate sustainable development initiatives such as programs on environment management systems (Utting, 2002).

\subsubsection{Composite measure of corporate sustainability: DEA model and bootstrapping of DEA estimates}

The second stage of the analysis was to estimate a composite indicator of sustainability performance for each company. The composite indicator was based on a comparison with a pooled frontier representing the best practices observed using the seven principal components instead of the twenty original indicators. Using this approach, each company is evaluated by the composite indicator of sustainability that allows companies to compare themselves to their peers.

Table 2.4 reports the summary results for the composite indicator of corporate sustainability obtained using DEA model with bootstrapping procedure. For the bootstrapping procedure, the steps described in the methodological section were applied. The bootstrap estimates were produced using $B=2000$ bootstrap replications. The purpose of bootstrapping is to test the sensitivity of the variations in the model and assess the robustness of the DEA estimates. Table 2.4 shows the mean, maximum and minimum values of the original DEA estimates, the bias corrected estimates, bias, standard deviation and 95\% confidence intervals for the bias corrected estimates.

Table 2.4: Mean, maximum and minimum values of the original and bootstrapped corporate sustainability scores $(n=84)$

\begin{tabular}{lcccccc}
\hline & $\begin{array}{c}\text { Original } \\
\text { DEA } \\
\text { estimates }\end{array}$ & $\begin{array}{c}\text { Bias- } \\
\text { corrected } \\
\text { estimates }\end{array}$ & Bias & $\begin{array}{c}\text { Standard } \\
\text { deviation }\end{array}$ & $\begin{array}{c}\text { Lower } \\
\text { bound }\end{array}$ & $\begin{array}{c}\text { Upper } \\
\text { bound }\end{array}$ \\
\hline Mean & 0.9386 & 0.9151 & 0.0235 & 0.0150 & 0.8899 & 0.9368 \\
Minimum & 0.7453 & 0.7344 & 0.0100 & 0.0044 & 0.7201 & 0.7440 \\
Maximum & 1.0000 & 0.9798 & 0.0748 & 0.0651 & 0.9542 & 0.9990 \\
\hline
\end{tabular}

The bootstrapped results for all DMUs are presented in Appendix 2A.1. The bootstrapped results show that the bias-corrected estimates had relatively narrow confidence intervals, i.e. the lower and upper bounds of the intervals were relatively close. In addition, the results indicate substantial bias. Since the bias estimates are large relative to the standard error estimates, the bias corrected scores are preferred to the original estimates (Fried et al., 2008). 
Therefore, the bias corrected estimates are the composite indicators used to assess corporate sustainability performance.

Fig. 2.3 is a Kernel density distribution of the composite indicator of sustainability, which is the overall sustainability score for the sampled companies, showing the distribution between the minimum score of 0.73 and the maximum score of 0.98 . The density distribution shows a clustering of scores between 0.95 and 0.98 (the mode is 0.96 ) and a strong skew to the left that creates a tail of lower scoring companies. Among the companies, sustainability leaders are clustered to the right, close to the maximum score of 0.98 , while companies with scores in the left hand tail lower the group performance.

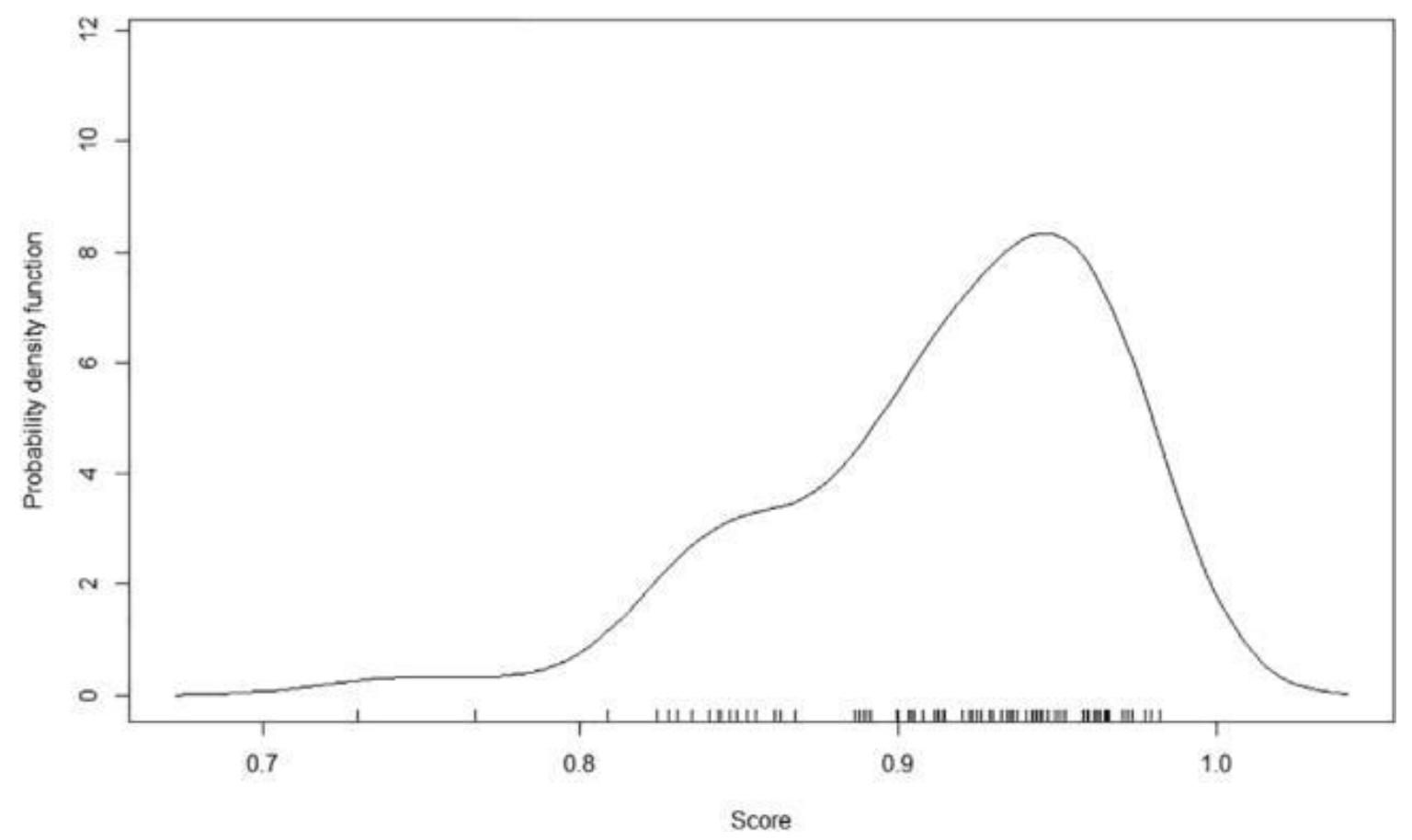

Fig. 2.3. Kernel density estimate of the composite indicator of sustainability ( $n=84)$.

\subsubsection{Decomposition analysis}

A decomposition analysis extends the analysis to investigate the contribution of a set of indicators to the aggregated composite measure (OECD., 2008). Investigating the existence of significant differences in specific indicators between highest and lowest performing companies in the composite measure is important since this can help to identify the specific indicators that need priorities so as to improve the overall sustainability performance of the later. In this study, the group of high performers contained companies with the $10 \%$ highest composite sustainability scores and a group of low performers, which contained companies with the $10 \%$ lowest composite sustainability scores. A Mann-Whitney $U$ test is conducted to determine whether there was a significant difference in the sustainability scores between these 
two groups. The result of the test $\left(U \frac{1}{4} 0.000, Z 1 / 43.580, p<0.05\right)$ shows that the high performers had significantly higher composite sustainability scores than the low performers.

The differences in the individual indicators between these two groups were then explored. Table 2.5 shows the mean scores of indicators for the two groups: low performers and the high performers. The high performers had higher scores for many of the indicators in the environmental, social and governance dimensions than the low performers. The MannWhitney test revealed that the high performers scored significantly higher on the following indicators: Policy on Bribery and Corruption (g1), Signatory to UN Global Compact (g2), Board Independence (g3), Policy on Freedom of Association (s1), Formal Policy on the Elimination of Discrimination (s2), Scope of Social Supply Chain Standards (s3), Formal Environmental Policy (e1), Environmental Management System (e2) and Formal Policy or Programme on Green Procurement (e3). Therefore, initiatives that target these indicators would help to improve the composite sustainability score of the low performers. To further complement the sustainability assessment of the companies in the European food and beverages companies, an investigation is made on whether there is a difference in composite sustainability scores between private and public companies.

Table 2.5. Mean scores for the low performers and high performers and Mann-Whitney $U$ test values indicating significant differences between these two groups. ${ }^{a}$

\begin{tabular}{|c|c|c|c|c|}
\hline Variables(Indicators) & Symbol & $\begin{array}{c}\text { Low } \\
\text { performers } \\
(10 \%)\end{array}$ & $\begin{array}{c}\text { High } \\
\text { performers } \\
(10 \%) \\
\end{array}$ & $\begin{array}{c}\text { Mann- } \\
\text { Whitney } \\
\text { U }\end{array}$ \\
\hline Policy on Bribery and Corruption & g1 & 5.56 & 80.56 & $1.00^{* * *}$ \\
\hline Signatory to UN Global Compact & g2 & 11.11 & 55.56 & $22.50^{*}$ \\
\hline Board Independence & g3 & 11.11 & 63.89 & $12.50^{* *}$ \\
\hline Business Ethics Related Controversies or Incidents & g4 & 99.89 & 81.78 & 36.00 \\
\hline Governance Related Controversies or Incidents & g5 & 100.00 & 99.78 & 53.50 \\
\hline Public Policy Related Controversies or Incidents & 96 & 100.00 & 99.89 & 45.00 \\
\hline Policy on Freedom of Association & s1 & 33.33 & 86.11 & $19.50^{\star *}$ \\
\hline Formal Policy on the Elimination of Discrimination & s2 & 11.11 & 75.00 & $3.50^{* *}$ \\
\hline Scope of Social Supply Chain Standards & s3 & 5.56 & 83.33 & $1.00^{* * *}$ \\
\hline Programmes to Increase Workforce Diversity & s4 & 11.11 & 27.78 & 24.00 \\
\hline Employee Related Controversies or Incidents & s5 & 100.00 & 89.56 & $72.00^{* *}$ \\
\hline Social Supply Chain Incidents & s6 & 100.00 & 95.56 & 49.50 \\
\hline Customer Related Controversies or Incidents & s7 & 100.00 & 93.11 & $63.00^{\star *}$ \\
\hline Society \& Community Related Controversies or Incidents & s8 & 97.78 & 99.78 & 44.00 \\
\hline Formal Environmental Policy & e1 & 14.44 & 83.33 & $1.50^{* \star *}$ \\
\hline Environmental Management System & $\mathrm{e} 2$ & 15.56 & 88.89 & $0.00^{\star *}$ \\
\hline Formal Policy or Programme on Green Procurement & e3 & 3.33 & 62.22 & $0.00^{* * *}$ \\
\hline Operations Related Controversies or Incidents & e4 & 99.89 & 99.56 & 54.00 \\
\hline Environmental Supply Chain Incidents & e5 & 100.00 & 99.89 & 45.00 \\
\hline Products \& Services Related Controversies or Incidents & e6 & 99.89 & 100.00 & 36.00 \\
\hline
\end{tabular}

a The group of low performers contained companies with the $10 \%$ lowest overall sustainability scores; the group of high performers contained companies with the $10 \%$ highest overall sustainability scores. 
The results of the Mann-Whitney $U$ test revealed a statistically significant difference $(U 1 / 4288.5$, $\left.Z 1 / 42,140, p^{1 / 4} 0.031<0.05\right)$ between the composite sustainability scores of publicly listed companies (median was 0.9246 ) and private companies (median was 0.9605). The rank average of the sustainability score for public companies was 40.06 , whereas the companies in the private group had a rank average of 55.81. The analyses showed that the group of private companies had a better sustainability performance than publicly listed companies. This result is also confirmed by the density plot shown on Fig. 2.4. Private companies may view corporate sustainability initiatives as a mechanism for enhancing their competitiveness and may present corporate sustainability results in a favourable way. It is possible that the reaction of some of crucial stakeholders to a more sustainability initiatives (i.e. consumers more satisfied by product quality or social characteristics, more motivated workers) could have positive effects on corporate performance. This contentions is also referred as porter hypothesis which suggests that meeting the needs of various stakeholders will lead to greater competitiveness (Clark et al., 2015; McWilliams and Siegel, 2011).

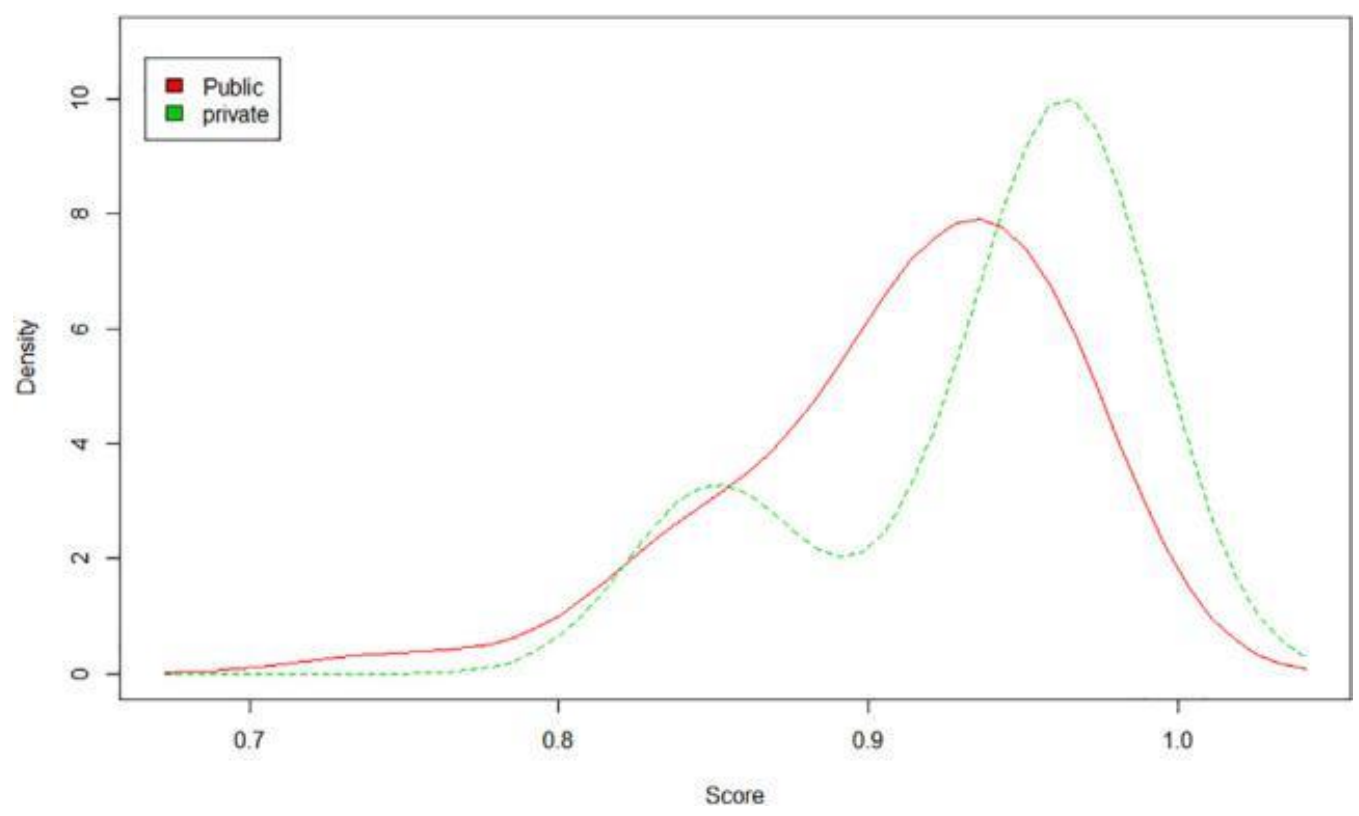

Fig. 2.4. Kernel density estimate of the composite indicator of sustainability for private and public listed companies.

\subsection{Conclusion}

There has been renewed interest in measuring corporate sustainability. An integrated composite measure of corporate sustainability is important as it can provide synthesized information about the sustainability performance of companies and can guide sustainability improvements. The methods for developing and evaluating composite indicator of corporate sustainability in most recent literature poses major methodological challenges: either the aggregation is not suitable for large correlated data or use subjective weights. In this study, 
we developed and evaluated a method to construct a composite indicator of corporate sustainability. The novelty of the method lies in the combination of PCA and DEA for assessing corporate sustainability and this method is suitable for large correlated indicators that are commonly included in sustainability assessments.

The major contribution of this study is to construct a framework that uses PCA to pre-process the data and then applies DEA with bootstrapping procedure to construct a composite indicator of corporate sustainability. This method has the following merits. PCA is less vulnerable to the statistical noise present in real life data and it addresses one of the limitations of DEA that assumes data to be free of measurement error (statistical noise). The DEA decides weights endogenously; this avoids any possible controversies related to the selection of weights, as DEA uses the most favourable weighting scheme according to the relative performance of a firm in any particular dimension.

Measuring and evaluating corporate sustainability in the food sector while meeting the growing food demand is crucial. Hence, the method is illustrated and evaluated using empirical data on European food and beverage companies, obtained from Sustainalytics. In this specific case, the application of PCA reduced the twenty original indicators to seven principal components, which accounted for $74.08 \%$ of the total variance. Applying DEA to the resulting principal components and bootstrapping DEA estimates helps to obtain the composite indicator of corporate sustainability. The results rank each company in terms of sustainability performance by the composite indicators. A decomposition analysis is also made to identify specific priorities for companies to improve sustainability performance.

This study shows how the combined PCA and DEA method can be applied to evaluate and communicate corporate sustainability performance. The method can also be used in similar assessments to construct a composite indicator when the assessments include large number of highly correlated indicators. However, the method computes a relative measure, and thus shows only the performance of a company relative to the other companies included in the analysis. 


\section{References}

Adler, N., Golany, B., 2001. Evaluation of deregulated airline networks using data envelopment analysis combined with principal component analysis with an application to Western Europe. European J. Operat. Res. 132 (2), 260-273.

Adler, N., Yazhemsky, E., 2010. Improving discrimination in data envelopment analysis: PCADEA or variable reduction. European J. Operat. Res. 202 (1), 273-284.

Aliev, F., Ebadi, S., 2012. Ranking efficient DMUs by bootstrapping method, prob-lems of cybernetics and informatics (PCI). In: 2012 IV International Conference. IEEE, pp. 1-3.

Bogetoft, P., Otto, L., 2010. Benchmarking with Dea, Sfa, and R. Springer Science \& Business Media.

Cherchye, L., Moesen, W., Puyenbroeck, T., 2004. Legitimately diverse, yet compa-rable: on synthesizing social inclusion performance in the EU. JCMS: J. Common Market Stud. 42 (5), 919-955.

Clark, G.L., Feiner, A., Viehs, M., 2015. From the Stockholder to the Stakeholder: How Sustainability Can Drive Financial Outperformance.

Compact, U.N.G., 2015. Guide to Corporate Sustainability. https://www.unglobalcompact.org/library/1151 (Accessed 25 December 2016).

Cooper, W., Seiford, L.M., Tone, K., 2007. Data Envelopment Analysis: A Comprehensive Text with Models, Applications, References and DEA-Solver Software. Kluwer Academic Publishers, Boston

Despotis, D., 2005. A reassessment of the human development index via data envelopment analysis. J. Operat. Res. Soc. 56 (8), 969-980.

Docekalova, M.P., Kocmanova, A., 2016. Composite indicator for measuring corporate sustainability. Ecological Indicators 61, 612-623.

Domínguez-Serrano, M., Blancas, F.J., 2011. A gender wellbeing composite indicator: the best-worst global evaluation approach. Social Indicators Research 102 (3), 477-496.

Dong, F., Mitchell, P.D., Colquhoun, J., 2015. Measuring farm sustainability using data envelope analysis with principal components: the case of Wisconsin cranberry. J. Environ. Manag. 147, 175-183.

Dunn, P., Sainty, B., 2009. The relationship among board of director characteristics, corporate social performance and corporate financial performance. Inter. J. Manag. Finance 5 (4), 407-423.

Efron, B., 1982. The Jackknife, the Bootstrap, and Other Resampling Plans. Siam. Freeman, R.E., Harrison, J.S., Wicks, A.C., Parmar, B.L., De Colle, S., 2010. Stakeholder Theory: the State of the Art. Cambridge University Press.

Fried, H.O., Lovell, C.K., Schmidt, S.S., 2008. The Measurement of Productive Efficiency and Productivity Growth. Oxford University Press.

Haniffa, R.M., Cooke, T.E., 2005. The impact of culture and governance on corporate social reporting. Journal of accounting and public policy 24 (5), 391-430.

Hartmann, M., 2011. Corporate social responsibility in the food sector. European Rev. Agri. Econ. 38 (3), 297-324. 
Heyder, M., Theuvsen, L., 2012. Determinants and effects of corporate social re-sponsibility in German agribusiness: a PLS model. Agribusiness 28 (4), 400-420.

Horta, I., Camanho, A., da Costa, J.M., 2012. Performance assessment of construction companies: a study of factors promoting financial soundness and innovation in the industry. International Journal of Production Economics 137 (1), 84-93.

Jo, H., Harjoto, M.A., 2012. The causal effect of corporate governance on corporate social responsibility. Journal of business ethics 106 (1), 53-72.

Jolliffe, I.T., 2002. Principal component analysis and factor analysis. Principal Comp. Analysis 150-166.

Jurado, A., Perez-Mayo, J., 2012. Construction and evolution of a multidimensional well-being index for the Spanish regions. Social Indicat. Res. 107 (2), 259-279.

Kong, D., 2012. Does corporate social responsibility matter in the food industry? Evidence from a nature experiment in China. Food Policy 37 (3), 323-334.

Lee, K.-H., Saen, R.F., 2012. Measuring corporate sustainability management: a data envelopment analysis approach. Inter. J. Prod. Econ. 140 (1), 219-226.

Li, T., Zhang, H., Yuan, C., Liu, Z., Fan, C., 2012. A PCA-based method for construction of composite sustainability indicators. The Inter. J. Life Cycle Assess. 17 (5), 593-603.

Lovell, C.K., Pastor, J.T., Turner, J.A., 1995. Measuring macroeconomic performance in the OECD: a comparison of European and non-European countries. European J. Operat. Res. 87 (3), 507-518.

McWilliams, A., Siegel, D.S., 2011. Creating and capturing value: strategic corporate social responsibility, resource-based theory, and sustainable competitive advantage. J. Manag. 37 (5), 1480-1495.

Molina-Azorín, J.F., Claver-Cortes, E., Lopez-Gamero, M.D., Tarí, J.J., 2009. Green management and financial performance: a literature review. Manag. Dec. 47 (7), 10801100.

Moon, J., Vogel, D., 2008. Corporate Social Responsibility, Government, and Civil Society. The Oxford handbook of corporate social responsibility. OECD, 2008. Handbook on Constructing Composite Indicators: Methodology and User Guide.

Poldaru, R., Roots, J., 2014. A PCAeDEA approach to measure the quality of life in Estonian counties. Socio-Econ. Plan. Sci. 48 (1), 65-73.

Saisana, M., Tarantola, S., 2002. State-of-the-art Report on Current Methodologies and Practices for Composite Indicator Development. Citeseer).

Saisana, M., Saltelli, A., Tarantola, S., 2005. Uncertainty and sensitivity analysis techniques as tools for the quality assessment of composite indicators. J. Royal Statist. Soc. Series A (Statist. Soc.ty) 168 (2), 307-323.

Sharpe, A., 2004. Literature Review of Frameworks for Macroindicators. Centre for the Study of Living Standards Ottawa.

Simar, L., Wilson, P.W., 1998. Sensitivity analysis of efficiency scores: How to bootstrap in nonparametric frontier models. Manag. Sci. 44 (1), 49-61. 
Singh, R.K., Murty, H., Gupta, S., Dikshit, A., 2007. Development of composite sus-tainability performance index for steel industry. Ecological Indic. 7 (3), 565-588.

SustainAbility, S., Poor, U., 2004. Risk \& opportunity: Best practice in non-financial reporting. SustainAbility (London).

Utting, P., 2002. Regulating business via multistakeholder initiatives: A preliminary assessment. Voluntary approaches to corporate responsibility: Readings and a resource guide, p. 61130 .

Wilson, P.W., 2008. FEAR: A software package for frontier efficiency analysis with R. Socioecon. Plann. Sci. 42 (4), 247-254. 


\section{Appendix 2A Supplementary material}

Appendix 2A.1 Results of original and bootstrapped sustainability scores ( $B=2000)$

\begin{tabular}{|c|c|c|c|c|c|c|}
\hline DMU & $\begin{array}{l}\text { Original } \\
\text { DEA } \\
\text { estimates }\end{array}$ & $\begin{array}{l}\text { Bias- } \\
\text { corrected } \\
\text { estimates }\end{array}$ & Bias & St. dev. & $\begin{array}{l}\text { Lower } \\
\text { bound }(\mathrm{Cl})\end{array}$ & $\begin{array}{l}\text { Upper } \\
\text { bound } \\
\text { (CI) }\end{array}$ \\
\hline 1 & 1.0000 & 0.9696 & 0.0304 & 0.0175 & 0.9402 & 0.9977 \\
\hline 2 & 1.0000 & 0.9267 & 0.0733 & 0.0641 & 0.8434 & 0.9975 \\
\hline 3 & 1.0000 & 0.9605 & 0.0395 & 0.0377 & 0.8884 & 0.9989 \\
\hline 4 & 1.0000 & 0.9605 & 0.0395 & 0.0377 & 0.8884 & 0.9989 \\
\hline 5 & 1.0000 & 0.9746 & 0.0254 & 0.0165 & 0.9450 & 0.9990 \\
\hline 6 & 1.0000 & 0.9746 & 0.0254 & 0.0165 & 0.9450 & 0.9990 \\
\hline 7 & 1.0000 & 0.9646 & 0.0354 & 0.0278 & 0.9183 & 0.9989 \\
\hline 8 & 1.0000 & 0.9646 & 0.0354 & 0.0278 & 0.9183 & 0.9989 \\
\hline 9 & 1.0000 & 0.9658 & 0.0342 & 0.0178 & 0.9412 & 0.9979 \\
\hline 10 & 1.0000 & 0.9604 & 0.0396 & 0.0368 & 0.8908 & 0.9990 \\
\hline 11 & 1.0000 & 0.9604 & 0.0396 & 0.0368 & 0.8908 & 0.9990 \\
\hline 12 & 1.0000 & 0.9252 & 0.0748 & 0.0651 & 0.8408 & 0.9978 \\
\hline 13 & 1.0000 & 0.9629 & 0.0371 & 0.0207 & 0.9296 & 0.9977 \\
\hline 14 & 1.0000 & 0.9501 & 0.0499 & 0.0287 & 0.9189 & 0.9978 \\
\hline 15 & 1.0000 & 0.9270 & 0.0730 & 0.0645 & 0.8435 & 0.9978 \\
\hline 16 & 1.0000 & 0.9259 & 0.0741 & 0.0650 & 0.8417 & 0.9978 \\
\hline 17 & 1.0000 & 0.9704 & 0.0296 & 0.0147 & 0.9477 & 0.9978 \\
\hline 18 & 0.9998 & 0.9707 & 0.0291 & 0.0150 & 0.9473 & 0.9977 \\
\hline 19 & 0.9992 & 0.9798 & 0.0194 & 0.0132 & 0.9542 & 0.9981 \\
\hline 20 & 0.9992 & 0.9798 & 0.0194 & 0.0132 & 0.9542 & 0.9981 \\
\hline 21 & 0.9979 & 0.9717 & 0.0262 & 0.0136 & 0.9479 & 0.9956 \\
\hline 22 & 0.9923 & 0.9671 & 0.0252 & 0.0127 & 0.9461 & 0.9900 \\
\hline 23 & 0.9893 & 0.9659 & 0.0234 & 0.0124 & 0.9455 & 0.9872 \\
\hline 24 & 0.9876 & 0.9668 & 0.0208 & 0.0143 & 0.9392 & 0.9855 \\
\hline 25 & 0.9856 & 0.9593 & 0.0263 & 0.0142 & 0.9342 & 0.9834 \\
\hline 26 & 0.9794 & 0.9624 & 0.0170 & 0.0103 & 0.9409 & 0.9777 \\
\hline 27 & 0.9758 & 0.9599 & 0.0159 & 0.0093 & 0.9410 & 0.9738 \\
\hline 28 & 0.9753 & 0.9507 & 0.0246 & 0.0135 & 0.9255 & 0.9733 \\
\hline 29 & 0.9725 & 0.9555 & 0.0170 & 0.0073 & 0.9429 & 0.9703 \\
\hline 30 & 0.9713 & 0.9459 & 0.0254 & 0.0154 & 0.9215 & 0.9695 \\
\hline 31 & 0.9686 & 0.9443 & 0.0243 & 0.0121 & 0.9262 & 0.9665 \\
\hline 32 & 0.9683 & 0.9484 & 0.0199 & 0.0096 & 0.9319 & 0.9664 \\
\hline 33 & 0.9675 & 0.9488 & 0.0186 & 0.0141 & 0.9192 & 0.9663 \\
\hline 34 & 0.9663 & 0.9413 & 0.0250 & 0.0134 & 0.9184 & 0.9640 \\
\hline 35 & 0.9653 & 0.9342 & 0.0311 & 0.0191 & 0.9053 & 0.9631 \\
\hline 36 & 0.9640 & 0.9365 & 0.0274 & 0.0146 & 0.9131 & 0.9620 \\
\hline 37 & 0.9605 & 0.9471 & 0.0134 & 0.0066 & 0.9342 & 0.9584 \\
\hline 38 & 0.9594 & 0.9348 & 0.0246 & 0.0139 & 0.9119 & 0.9573 \\
\hline 39 & 0.9592 & 0.9386 & 0.0206 & 0.0122 & 0.9168 & 0.9572 \\
\hline 40 & 0.9579 & 0.9428 & 0.0152 & 0.0070 & 0.9299 & 0.9559 \\
\hline 41 & 0.9577 & 0.9394 & 0.0184 & 0.0085 & 0.9246 & 0.9557 \\
\hline 42 & 0.9549 & 0.9361 & 0.0189 & 0.0096 & 0.9191 & 0.9530 \\
\hline
\end{tabular}




\begin{tabular}{|c|c|c|c|c|c|c|}
\hline DMU & $\begin{array}{l}\text { Original } \\
\text { DEA } \\
\text { estimates }\end{array}$ & $\begin{array}{l}\text { Bias- } \\
\text { corrected } \\
\text { estimates }\end{array}$ & Bias & St. dev. & $\begin{array}{l}\text { Lower } \\
\text { bound }(\mathrm{Cl})\end{array}$ & $\begin{array}{l}\text { Upper } \\
\text { bound } \\
\text { (CI) }\end{array}$ \\
\hline 43 & 0.9539 & 0.9246 & 0.0293 & 0.0226 & 0.8790 & 0.9520 \\
\hline 44 & 0.9532 & 0.9404 & 0.0128 & 0.0064 & 0.9272 & 0.9512 \\
\hline 45 & 0.9468 & 0.9359 & 0.0109 & 0.0070 & 0.9203 & 0.9455 \\
\hline 46 & 0.9413 & 0.9257 & 0.0156 & 0.0081 & 0.9103 & 0.9392 \\
\hline 47 & 0.9384 & 0.9124 & 0.0260 & 0.0146 & 0.8900 & 0.9361 \\
\hline 48 & 0.9362 & 0.9225 & 0.0137 & 0.0066 & 0.9100 & 0.9343 \\
\hline 49 & 0.9345 & 0.9115 & 0.0230 & 0.0129 & 0.8884 & 0.9321 \\
\hline 50 & 0.9326 & 0.9136 & 0.0190 & 0.0125 & 0.8901 & 0.9309 \\
\hline 51 & 0.9299 & 0.9162 & 0.0136 & 0.0065 & 0.9037 & 0.9277 \\
\hline 52 & 0.9282 & 0.9142 & 0.0140 & 0.0079 & 0.8971 & 0.9260 \\
\hline 53 & 0.9245 & 0.9040 & 0.0206 & 0.0105 & 0.8864 & 0.9225 \\
\hline 54 & 0.9198 & 0.9073 & 0.0124 & 0.0062 & 0.8950 & 0.9179 \\
\hline 55 & 0.9198 & 0.9080 & 0.0117 & 0.0058 & 0.8961 & 0.9179 \\
\hline 56 & 0.9191 & 0.9058 & 0.0134 & 0.0072 & 0.8919 & 0.9172 \\
\hline 57 & 0.9182 & 0.9066 & 0.0115 & 0.0046 & 0.8981 & 0.9161 \\
\hline 58 & 0.9178 & 0.8937 & 0.0242 & 0.0114 & 0.8753 & 0.9156 \\
\hline 59 & 0.9174 & 0.8932 & 0.0242 & 0.0129 & 0.8737 & 0.9154 \\
\hline 60 & 0.9138 & 0.9003 & 0.0134 & 0.0054 & 0.8907 & 0.9118 \\
\hline 61 & 0.9122 & 0.8940 & 0.0181 & 0.0122 & 0.8702 & 0.9112 \\
\hline 62 & 0.9122 & 0.8940 & 0.0181 & 0.0122 & 0.8702 & 0.9112 \\
\hline 63 & 0.9114 & 0.8915 & 0.0199 & 0.0096 & 0.8753 & 0.9093 \\
\hline 64 & 0.9099 & 0.8894 & 0.0205 & 0.0123 & 0.8659 & 0.9079 \\
\hline 65 & 0.9080 & 0.8963 & 0.0117 & 0.0060 & 0.8842 & 0.9062 \\
\hline 66 & 0.8976 & 0.8838 & 0.0138 & 0.0071 & 0.8704 & 0.8958 \\
\hline 67 & 0.8827 & 0.8574 & 0.0253 & 0.0146 & 0.8317 & 0.8807 \\
\hline 68 & 0.8820 & 0.8653 & 0.0167 & 0.0084 & 0.8480 & 0.8798 \\
\hline 69 & 0.8810 & 0.8657 & 0.0153 & 0.0074 & 0.8531 & 0.8791 \\
\hline 70 & 0.8712 & 0.8612 & 0.0100 & 0.0045 & 0.8522 & 0.8693 \\
\hline 71 & 0.8660 & 0.8490 & 0.0171 & 0.0079 & 0.8350 & 0.8641 \\
\hline 72 & 0.8637 & 0.8460 & 0.0177 & 0.0091 & 0.8307 & 0.8619 \\
\hline 73 & 0.8625 & 0.8462 & 0.0164 & 0.0079 & 0.8324 & 0.8606 \\
\hline 74 & 0.8617 & 0.8491 & 0.0126 & 0.0060 & 0.8373 & 0.8597 \\
\hline 75 & 0.8597 & 0.8463 & 0.0134 & 0.0067 & 0.8328 & 0.8579 \\
\hline 76 & 0.8588 & 0.8488 & 0.0100 & 0.0045 & 0.8397 & 0.8570 \\
\hline 77 & 0.8550 & 0.8443 & 0.0107 & 0.0055 & 0.8332 & 0.8532 \\
\hline 78 & 0.8506 & 0.8395 & 0.0111 & 0.0050 & 0.8295 & 0.8487 \\
\hline 79 & 0.8427 & 0.8318 & 0.0109 & 0.0044 & 0.8239 & 0.8408 \\
\hline 80 & 0.8413 & 0.8288 & 0.0125 & 0.0069 & 0.8148 & 0.8396 \\
\hline 81 & 0.8356 & 0.8243 & 0.0114 & 0.0047 & 0.8154 & 0.8337 \\
\hline 82 & 0.8252 & 0.8110 & 0.0142 & 0.0073 & 0.7963 & 0.8233 \\
\hline 83 & 0.7871 & 0.7661 & 0.0210 & 0.0129 & 0.7451 & 0.7857 \\
\hline 84 & 0.7453 & 0.7344 & 0.0109 & 0.0069 & 0.7201 & 0.7440 \\
\hline
\end{tabular}




\section{Chapter 3}

\section{A dynamic by-production framework to examine inefficiency specific to corporate social responsibility}

Tadesse Getacher Engida a, , Xudong Rao ${ }^{a}$, Alfons G.J.M. Oude Lansink ${ }^{\text {a }}$

${ }^{a}$ Wageningen University \& Research, Business Economics Group, Hollandseweg 1, 6706 KN Wageningen, The Netherlands 


\section{Abstract}

This study integrates corporate social responsibility (CSR) into a formal dynamic by-production framework and examines the factors associated with CSR performance. It provides a useful framework to benchmark performance, accounting for resources diverted from the production of desirable outputs (conventional outputs) to socially responsible outputs as well as the mitigation effects of socially responsible output as it reduces undesirable outputs. The framework captures the correct trade-offs between outputs and helps provide a more accurate representation of the production process. The results provide insight into inefficiency related to the generation of CSR outputs and confirm the importance of accounting for adjustment costs in quasi-fixed inputs.

Keywords: Corporate social responsibility, dynamic by-production model, data envelopment analysis, inefficiency, food and beverage manufacturing industry 


\subsection{Introduction}

Over the last two decades, an increasing number of companies have included social and environmental factors in their business decisions by adopting corporate-related policies and practices (Eccles \& Krzus, 2010). The business world has quickly embraced the concept of corporate social responsibility (CSR), which encompasses not only aspects such as philanthropy and pollution but also a broad range of social, environmental, and governance metrics (Peloza et al, 2012). Incorporating data on CSR that includes socially responsible activities and undesirable output (such as environmental and social risks) helps a firm move towards decisions that are better for the business and the society as they provide incremental information beyond usual accounting measures such as sales. In other words, emphasis on CSR and undesirable output can broaden a firm's view of what needs to be achieved in pursuit of long-term viability of the business and societal interest. Rodger and George (2016) confirm the feasibility to preserve the positive dynamics of "competing" stakeholders. While simultaneously improving collaboration between stakeholders such as industry, landowners, and environmentalists, it is feasible to optimize return on profits for companies, to provide royalties to landowners, and to satisfy environmentalists.

Existing research has centered mainly on the financial implications of engaging in corporate social responsibility. Baron (2001) and McWilliams and Siegel (2001) were the first to suggest that firms undertake CSR activities expecting a net benefit from them. CSR is treated as a way for firms to compete for socially responsible consumers by either linking their social contribution to product sales or adding social attributes and features to their products. Empirical finance literature appears to document a negative association between CSR and systemic risk and cost of equity capital, and a positive association between CSR and firm value and shareholder wealth (Oikonomou et al., 2012; Margolis et al., 2009; Galema et al., 2008; Dimson et al., 2015).

This study takes a different prospective and investigates the process through which CSR is created by incorporating it into a production framework. This helps to understand the way CSR is produced and the implications of CSR production that include the impact of CSR on other outputs. CSR activities imply a shift of productive resources from the production of marketable outputs to socially desirable outputs and to a reduction of undesirable outputs. Socially responsible activities such as environmental programs and community programs appear to mitigate undesirable outputs while diverting resources that could have been employed in the production of marketable output. Therefore, it is important to incorporate CSR into a production framework that captures the trade-offs among inputs, desirable output, CSR, and undesirable output. 
Recently, researchers have also shown interest on how to accurately benchmark firms' performance in view of CSR activities. Puggioni and Stefanou (2016) characterized CSR in a static by-production framework and assumed CSR to be an additional output of production. Static models fail to account for the adjustment costs associated with investments in capital assets and may confound inefficiency with adjustment costs (Oude Lansink et al, 2001; Silva et al, 2015; Silva \& Stefanou, 2003, 2007).. As a result, a static production framework will generate misleading estimates of performance (Nick \& Wetzel, 2016; Silva et al, 2015).

In light of the aforementioned, the objective of this study is to overcome the limitations with static measures and develop a dynamic by-production framework to evaluate input- and output-specific technical inefficiency in the presence of CSR. The contribution of this study to the existing literature is twofold. First, we develop dynamic input- and output-specific inefficiency in the presence of CSR. Second, we empirically demonstrate the applicability of the indicator using a data set of the European food and beverage industry. Bootstrapped, truncated regression model is applied to assess the association between firm-specific characteristics and the dynamic input-, output- specific inefficiency.

The next section describes a dynamic by-production model of corporate social responsibility and a bootstrap- truncated regression approach. This is followed by the description of the data on a sample of European Food and Beverage manufacturing firms. The section to follow presents the results of dynamic by production model of corporate social responsibility and the bootstrap- truncated regression approach. The final section offers concluding comments.

\subsection{Methods}

In this section, we first develop a dynamic by-production model to characterise a production technology that integrates CSR, and then estimate a bootstrap-truncated regression model to examine the factors that explain the variations in CSR-specific inefficiencies.

\subsubsection{Dynamic by-production model of corporate social responsibility}

Conventional production models cannot fully accommodate different types of inputs and outputs that are common in production. Specifically, each firm is assumed to jointly produce both desirable (conventional)and undesirable outputs, while it also engages in socially responsible activities to mitigate undesirable outputs. The variables that defined CSR include socially responsible output and undesirable outputs. Social responsible output consists of socially responsibleactivities that can be implemented to improve a dirty production process and support the use of sustainable inputs, analogous to the abatements implemented to clean up pollution. However, the implementation of CSR will generate an opportunity cost since firms are required to divert resources away from the production of conventional (marketable) outputs. 
It is critical to correctly account for this opportunity cost associated with CSR and the adjustment costs associated with quasi-fixed inputs in the production process. Therefore, our dynamic by-production framework incorporates socially responsible output as an additional output instead of an input of the underlying technology. The framework can better capture the trade-offs between these activities and helps provide a more accurate representation of the production process.

We start with a by-production model that is adapted from those used in Puggioni and Stefanou (2016), Dakpo (2016), Murty et al (2012), and Førsund (2008). Let $v(t), v \in \mathbb{R}_{+}^{J}$, denote a vector of variable inputs at time $t ; k(t), k \in \mathbb{R}_{+}^{L}$, a vector of quasi-fixed inputs; $i(t), i \in \mathbb{R}_{+}^{L}$, a vector of gross investments; $y d(t), y d \in \mathbb{R}_{+}^{Q}$, a vector of desirable outputs; $y r(t), y r \in \mathbb{R}_{+}^{E}$, a vector of socially responsible outputs; $b(t), b \in \mathbb{R}_{+}^{R}$, a vector of undesirable outputs; $N$, the number of decision-making units; and $t$, time.

Consider a by-production technology that consists of two sub-technologies: one describing the sub-production of desirable outputs and the other the sub-production of undesirable outputs. Specifically, this by-production technology uses $v(t)$ and invests $i(t)$ to produce three types of outputs given $k(t)$ : desirable outputs $y d(t)$, socially responsible outputs $y r(t)$, and undesirable outputs $b(t) \cdot y d(t)$ are the primary, marketable outputs by which the production process is motivated; $b(t)$ are the undesirable outputs that are unwanted but inevitably generated as by-products of the desirable outputs, and can be potentially detrimental to the firm or society; and $y r(t)$ consists of socially responsible activities implemented by firm managers to reduce the undesirable outputs $b(t)$. This dynamic by-production technology $\Psi(t)$ can be mathematically represented by the intersection of the desirable-outputs sub-technology $\Psi_{g}(t)$ and the undesirable-output sub-technology $\Psi_{b}(t)$ :

$$
\Psi(t)=\Psi_{g}(t) \cap \Psi_{b}(t)
$$

where

$$
\Psi_{g}(t)=[(v(t), i(t), y d(t), y r(t), b(t)):(v(t), i(t)) \text { can produce } y d(t) \text { and } y r(t) \text {, given } k(t)]
$$

and

$$
\Psi_{b}(t)=[(v(t), i(t), y d(t), y r(t), b(t)):(v(t), i(t), y r(t)) \text { can produce } b(t) \text {, given } k(t)]
$$

The set $\Psi_{g}(t)$ is a convex technology set, representing the desirable-output sub-technology that transforms inputs into desirable outputs and socially responsible output. Properties of 
$\Psi_{g}(t)$ is based on Dakpo \& Oude Lansink (2019); Silva et al (2015) and Silva \& Stefanou (2003)

g.1 No free lunch and inactivity

g.2 Input essentiality and attainability

g.3 Non-emptiness and closedness

g.4 Boundedness

g.5 Positive monotonicity in $v(t)$ : if $v(t) \in \Psi_{g}(t)$ and $v^{\prime}(t) \geq v(t)$ then $v^{\prime}(t) \in \Psi_{g}(t)$

g.6 Negative monotonicity in $i(t)$ : if $i(t) \in \Psi_{g}(t)$ and $i^{\prime}(t) \leq i(t)$ then $i^{\prime}(t) \in \Psi_{g}(t)$

g.7 Free disposability of desirable output: if $y d(t) \in \Psi_{g}(t)$ and $y d^{\prime}(t) \leq y d(t)$ then $y d^{\prime}(t) \in \Psi_{g}(t)$

g.8 Free disposability of socially responsible output: if $y r(t) \in \Psi_{g}(t)$ and $y r^{\prime}(t) \leq y r(t)$ then $y r^{\prime}(t) \in \Psi_{g}(t)$

g.9 Reverse nestedness in $k(t)$ : if $k(t) \in \Psi_{g}(t)$ and $k^{\prime}(t) \geq k(t)$ then $k^{\prime}(t) \in \Psi_{g}(t)$

g.10 Convexity in $(v(t), i(t), y d(t), y r(t))$

In particular, Property g.6 indicates the presence of adjustment costs. It states that $\Psi_{g}(t)$ is negatively monotonic in $i$, implying positive costs associated with investment in quasi-fixed inputs. Property g.8 indicates the opportunity cost of producing socially responsible output in terms of desirable outputs. Property g.9 establishes that outputs are increasing in quasi-fixed inputs, indicating that the marginal products of quasi-fixed inputs are positive. Properties g.6 and $\mathrm{g} .9$ together show the trade-off between current and future production. Current additions to quasi-fixed inputs reduce the current output level but improve the prospective level by improving future capital.

Given these properties and assuming a piecewise linear technology under variable returns to scale (VRS), ${ }^{3}$ the desirable-outputs sub-technology is defined as:

$$
\Psi_{g}(t)=[(v(t), i(t), k(t), y d(t), y r(t), b(t)):
$$

\footnotetext{
${ }^{3}$ We adopt the variable-returns-to-scale (VRS) assumption because it is more realistic and conceptually more flexible than the constant-returns-to-scale (CRS) assumption. The CRS technology is appropriate when firms operate in a perfectly competitive market, while the VRS technology is appropriate when firms face government regulations and imperfect competition (Huguenin, 2012). In addition, the VRS technology allows a firm to be compared to peers firms on the frontier having a similar size. This comparison can evaluate feasible efficiency improvements in the short-term and generate implications that are more practical. Therefore, we decide to adopt the VRS assumption for our analysis.
} 


$$
\begin{aligned}
& y d_{o}(t) \leq \sum_{n=1}^{N} \mu_{n}^{g} y d_{n}(t) \\
& y r_{o}(t) \leq \sum_{n=1}^{N} \mu_{n}^{g} y r_{n}(t) \\
& v_{o}(t) \geq \sum_{n=1}^{N} \mu_{n}^{g} v_{n}(t), \\
& i_{o}(t)-\delta k_{o}(t) \leq \sum_{n=1}^{N} \mu_{n}^{g}\left(i_{n}(t)-\delta k_{n}(t)\right) \\
& \sum_{n=1}^{N} \mu_{n}^{g}=1, \forall n \\
& \left.(v(t), i(t), k(t), y d(t), y r(t), b(t)) \in \mathbb{R}_{+}^{J+L+L+Q+E+R}\right]
\end{aligned}
$$

where $\delta$ is the depreciation rate vector associated with the quasi-fixed inputs $k$; in this way, $i_{o}(t)-\delta k_{o}(t)$ represents the net investments.

The undesirable-output sub-technology $\Psi_{b}(t)$ is convex and satisfies the following properties (Dakpo \& Oude Lansink, 2018). The properties are opposite to those of the desirable-output sub-technology

b.1 Positive monotonicity in $b(t)$ : if $b(t) \in \Psi_{b}(t)$ and $b^{\prime}(t) \geq b(t)$ then $b^{\prime}(t) \in \Psi_{b}(t)$

b.2 Positive monotonicity in $y r(t)$ : if $y r(t) \in \Psi_{b}(t)$ and $y r^{\prime}(t) \geq y r(t)$ then $y r^{\prime}(t) \in \Psi_{b}(t)$

b.3 Negative monotonicity in $v(t)$ : if $v(t) \in \Psi_{b}(t)$ and $v^{\prime}(t) \leq v(t)$ then $v^{\prime}(t) \in \Psi_{b}(t)$

b.4 Positive monotonicity in $i(t)$ : if $i(t) \in \Psi_{b}(t)$ and $i^{\prime}(t) \geq i(t)$ then $i^{\prime}(t) \in \Psi_{b}(t)$

b.5 Negative monotonicity in $k(t)$ : if $k(t) \in \Psi_{b}(t)$ and $k^{\prime}(t) \leq k(t)$ then $k^{\prime}(t) \in \Psi_{b}(t)$

b.6 Convexity in $(v(t), i(t), b(t), y r(t))$

The properties specific to the undesirable-output sub-technology are the costly disposability of undesirable and socially responsible outputs. Properties b.1 and b.2 suggest that undesirable outputs $b(t)$ are by-products of the production process and the disposability is costly. The property of positive monotonicity in socially responsible outputs (property b.2) implies that socially responsible activities can mitigate undesirable output (Puggioni \& Stefanou, 2016). In other words, this property indicates negative trade-offs between the undesirable outputs $b(t)$ and the socially responsible outputs $y r(t)$ since socially responsible activities can reduce undesirable outputs. The property of positive monotonicity in investments (property b.4) suggests that investments in quasi-fixed inputs can mitigate undesirable outputs. This 
assumption is reasonable when new investments lead to more cleaner technologies that produce less undesirable outputs.

Given these properties and assuming a piecewise linear technology with variable returns to scale (VRS), the undesirable-output sub-technology is defined as:

$$
\begin{aligned}
& \Psi_{b}(t)=[(v(t), i(t), k(t), f(t), y d(t), y r(t), b(t)): \\
& b_{o}(t) \geq \sum_{n=1}^{N} \mu_{n}^{b} b_{n}(t) \\
& y r_{o}(t) \geq \sum_{n=1}^{N} \mu_{n}^{b} y r_{n}(t) \\
& v_{o}(t) \leq \sum_{n=1}^{N} \mu_{n}^{b} v_{n}(t) \\
& i_{o}(t)-\delta k_{o}(t) \geq \sum_{n=1}^{N} \mu_{n}^{b}\left(i_{n}(t)-\delta k_{n}(t)\right), \ldots \text { (2.4) } \\
& \sum_{n=1}^{N} \mu_{n}^{b}=1, \forall n \\
& \left.(v(t), i(t), k(t), y d(t), y r(t), b(t)) \in \mathbb{R}_{+}^{J+L+L+Q+E+R}\right]
\end{aligned}
$$

Interdependence between the two sub-technologies is introduced through constraints 3.1 and 3.2 by setting equal values of the common variables (i.e. variable inputs, investments and socially responsible outputs) involved in the sub-technologies (Dakpo et al, 2016).

$$
\begin{aligned}
& \sum_{n=1}^{N} \mu_{n}^{g} v_{n}(t)=\sum_{n=1}^{N} \mu_{n}^{b} v_{n}(t), \ldots \ldots \ldots \ldots \ldots \ldots \ldots \ldots \ldots \ldots \ldots \ldots \ldots \ldots \ldots \ldots \ldots \ldots \ldots \\
& \sum_{n=1}^{N} \mu_{n}^{g}\left(i_{n}(t)-\delta k_{n}(t)\right)=\sum_{n=1}^{N} \mu_{n}^{b}\left(i_{n}(t)-\delta k_{n}(t)\right), \ldots \\
& \sum_{n=1}^{N} \mu_{n}^{g} y r_{n}(t)=\sum_{n=1}^{N} \mu_{n}^{b} y r_{n}(t), \ldots \ldots \ldots \ldots \ldots
\end{aligned}
$$

The dynamic by-production approach in this study uses the directional distance function proposed in Chambers et al. (1998). The directional distance function has previously been used to characterize production process and measure technical inefficiency (Berre et al., 2013; Chung et al., 1997; Hampf \& Krüger, 2014; Njuki \& Bravo-Ureta, 2015; Puggioni \& Stefanou, 2016). It is a generalization of Farrell's and Shephard's proportional approaches with the flexibility of several direction possibilities. However, the results are sensitive to the choice of the directional vector (Vardanyan \& Noh, 2006). In this study, we use a general formulation of the non-radial form of directional distance function (Zhang \& Choi, 2014), for which the dynamic version and the overall technology $\Psi(t)$ that combines $\Psi_{g}(t)$ and $\Psi_{b}(t)$ is represented by: 


$$
\begin{aligned}
& \vec{D}_{t}^{d y n}\left(v(t), i(t), k(t), y d(t), y r(t), b(t) ; \vec{g}_{y d}, \vec{g}_{y r}, \vec{g}_{b}, \vec{g}_{v}, \vec{g}_{i}\right) \\
& =\max _{\beta, \mu^{g}, \mu^{b}} \frac{1}{N_{\vec{g}}}\left[\beta_{y d}+\beta_{y r}+\beta_{b}+\beta_{v}+\beta_{i}\right] \\
& \text { s.t. } y d_{o}(t)+\beta_{y d} \vec{g}_{y d} \leq \sum_{n=1}^{N} \mu_{n}^{g} y d_{n}(t) \\
& y r_{o}(t)+\beta_{y r} \vec{g}_{y r} \leq \sum_{n=1}^{N} \mu_{n}^{g} y r_{n}(t) \\
& v_{o}(t)-\beta_{v} \vec{g}_{v} \geq \sum_{n=1}^{N} \mu_{n}^{g} v_{n}(t) \\
& i_{o}(t)-\delta k_{o}(t)+\beta_{i} \vec{g}_{i} \leq \sum_{n=1}^{N} \mu_{n}^{g}\left(i_{n}(t)-\delta k_{n}(t)\right) \\
& b_{o}(t)-\beta_{b} \vec{g}_{b} \geq \sum_{n=1}^{N} \mu_{n}^{b} b_{n}(t) \\
& y r_{o}(t)+\beta_{y r} \vec{g}_{y r} \geq \sum_{n=1}^{N} \mu_{n}^{b} y r_{n}(t) \\
& v_{o}(t)-\beta_{v} \vec{g}_{v} \leq \sum_{n=1}^{N} \mu_{n}^{b} v_{n}(t) \\
& i_{o}(t)-\delta k_{o}(t)+\beta_{i} \vec{g}_{i} \geq \sum_{n=1}^{N} \mu_{n}^{b}\left(i_{n}(t)-\delta k_{n}(t)\right) \\
& \sum_{n=1}^{N} \mu_{n}^{g} v_{n}(t)=\sum_{n=1}^{N} \mu_{n}^{b} v_{n}(t) \\
& \sum_{n=1}^{N} \mu_{n}^{g}\left(i_{n}(t)-\delta k_{n}(t)\right)=\sum_{n=1}^{N} \mu_{n}^{b}\left(i_{n}(t)-\delta k_{n}(t)\right) \\
& \sum_{n=1}^{N} \mu_{n}^{g} y r_{n}(t)=\sum_{n=1}^{N} \mu_{n}^{b} y r_{n}(t) \\
& \sum_{n=1}^{N} \mu_{n}^{g}=1 \\
& \sum_{n=1}^{N} \mu_{n}^{b}=1 \text {, }
\end{aligned}
$$

where $N_{\vec{g}}$ is the number of variables in the objective function. We assign the same weight to each inefficiency score to show an equal emphasis on both the contraction of inputs and expansion of outputs and investments. For the generalization of the non-radial approach, each of the $\beta$ technical inefficiency can be individualized with different corresponding variables of $\left(\beta_{y d q}, \beta_{y r e}, \beta_{b r}, \beta_{v j}, \beta_{i l}\right)$.

Solution to the problem in (4) yields estimates of dynamic technical inefficiency that quantify how much desirable outputs, socially responsible outputs, and investments can be expanded 
and how much undesirable outputs and inputs can be contracted within the feasibility constraint imposed by the technology $\Psi(t)$.

The dynamic inefficiency estimates can be compared to those of a static inefficiency model. In the static model $\left(\vec{D}_{t}^{\text {static }}\right)$, quasi-fixed inputs are assumed to adjust instantaneously like variable inputs. Hence, the objective function of the directional distance function also includes $\beta_{k}$, the inefficiency associated with the quasi-fixed inputs $k$. Furthermore, the static directional distance function has no constraints on investments. In other words, the static model has similar formulations as the dynamic version but excludes the constraints in (4.4), (4.8) and (4.10). The objective function and constraints associated with quasi-fixed inputs $k$ for the static version are represented as:

$$
\vec{D}_{t}^{\text {static }}\left(v(t), i(t), k(t), y d(t), y r(t), b(t) ; \vec{g}_{y d}, \vec{g}_{y r}, \vec{g}_{b}, \vec{g}_{v}, \vec{g}_{k}\right)=\max _{\beta, \mu^{g}, \mu^{b}} \frac{1}{N_{\vec{g}}}\left[\beta_{y d}+\beta_{y r}+\beta_{b}+\beta_{v}+\right.
$$

$\left.\beta_{k}\right]$

$$
\begin{aligned}
& k_{o}(t)-\beta_{k} \vec{g}_{k} \geq \sum_{n=1}^{N} \mu_{n}^{g} k_{n}(t) \\
& k_{o}(t)-\beta_{k} \vec{g}_{k} \leq \sum_{n=1}^{N} \mu_{n}^{b} k_{n}(t) \\
& \sum_{n=1}^{N} \mu_{n}^{g} k_{n}(t)=\sum_{n=1}^{N} \mu_{n}^{b} k_{n}(t) .
\end{aligned}
$$

\subsubsection{Bootstrap-truncated regression}

The DEA model described in the previous section characterizes the production process and can generate estimates of dynamic technical inefficiency specific to each type of output including social responsible outputs (i.e. CSR). For a companion question, researchers have searched for the sources of heterogeneity in firm performance, especially performance related to CSR, using observed traits of firms. Margolis et al. (2009) performed a meta-analysis and found that industry category, firm size, and risk have most frequently been associated to differences in performance, although other variables such as research and development (R\&D) intensity, leverage, liquidity, and profitability have also been reported to affect performance (Nelling and Webb (2009). Below we provide a brief review and discussion of how various factors may affect firms' performance. 


\section{Firm Size}

The firm size, which is often measured by the value of firms' assets, can improve firms' competitive advantage through economies of scale, economies of scope, or learning effects (Penrose, 1995). On the other hand, Robinson (1962) identified three scenarios for an inverse relation between efficiency and firm size to occur: (1) costs caused by boredom and diminished creativity outweighing the gains from labor division; (2) reduced speed and flexibility; and (3) increased costs of coordination. As a result, the empirical evidence has been mixed. For example, Khataza et al. (2018) and Majumdar (1997) found a negative relation between size and productivity, while Kapelko and Oude Lansink (2014) and Zelenyuk and Zheka (2006) found a positive relation. Regarding CSR performance, larger firms are more likely to show sustainable behavior since they are politically more accountable for the pressure from different stakeholders (Artiach et al, 2010; Surroca \& Tribó, 2008; Surroca et al., 2010).

\section{Leverage}

The ratio of total debt to total assets, i.e. leverage, measures the relative importance of financial stakeholders such as shareholders and debtholders. Debtholders, as suppliers of capital to firms, can exert substantial influences, and hence company managers are more likely respond to debtholders' interest than those of other stakeholders ( Vincent et al, 2007; Hossain et al, 2005; Ullmann, 1985; ). In contrast, firms with a higher level of engagement in CSR may have more incentive to mitigate the agency conflicts between shareholders and bondholders and lower agency costs of debt financing due to the improved shareholder-stakeholder relationships (Webb, 2005). The lower costs of debt financing may thus increase the leverage in the optimal capital structure.

\section{Free cash flow}

This variable reflects liquidity and firms' financial slack to continue their operations in the short term. When firms face low liquidity and profitability, financial stakeholders will have a higher priority compared to other stakeholders such as employees or the community (Artiach et al., 2010; Ullmann, 1985). On the other hand, a large free cash flow may allow firms to engage in social programs without compromising the demands of financial stakeholders.

\section{Profitability}

The level of profitability, measured by return on asset (ROA) in this study, influences investment decisions on CSR like free cash flows (Artiach et al., 2010). In periods of better economic performance, firms face low pressure from financial stakeholders. High levels of 
profitability may help meet shareholders' expectations and maintain the ability to attain social stakeholders' demands through investments in programs with social merits.

\section{Innovation and product differentiation}

R\&D investments can possibly lead to process and product innovations that may help address societal concerns (Alene, 2010). For instance, an organic, pesticide-free label clearly implies the use of organic methods, which constitutes a process innovation by farmers, and the creation of a new product category, which is a product innovation by natural foods retailers. We measure research and innovation by the ratio of $R \& D$ expenditure to total revenue.

\section{Corporate governance system}

Corporate governance influences corporate decisions and behavior (Aguilera et al., 2008; Sánchez-Ballesta \& García-Meca, 2007). Empirical results show that different corporate governance systems lead to different sustainable practices. According to Weimer and Pape (1999), the prevailing corporate governance systems in industrialized countries include the "market-oriented" system in Anglo-Saxon countries (e.g. USA and UK) and the "networkoriented" system (e.g. Germany and the Netherlands). The network-oriented system can be further divided into the Germanic model (e.g. Germany and the Netherlands), the Latin model (e.g. France and Italy), and the Japanese model. The chief feature of the market-oriented system is that the active external market may command and control managerial decisionmaking in an indirect mode (Fisher \& Lovell, 2009). In comparison, oligarchic groups in the network-oriented system significantly affect managerial decision-making in a more direct manner and can orient companies towards a more sustainable and socially responsible pathway (Fisher \& Lovell, 2009). A market-oriented system depends on the market while the network-oriented system relies on relationships among stakeholders.

For the first stage, we estimate inefficiencies using a dynamic by-production model. At the second stage, we use regression analysis to investigate the marginal effects of the above independent variables. The dependent variables, i.e. estimates of technical efficiencies, are serially correlated (Simar \& Wilson, 2007). Furthermore, the underlying data generating process of inefficiency are truncated. Simar and Wilson (2007) thus proposed a bootstraptruncated regression approach to solve both issues simultaneously. It is important to note that the bootstrap model at the second stage does not necessarily indicate causality but only association between variables. In addition, the two-stage analysis assumes the separability between efficiency estimates and the second stage variables. In other words, the separability assumption requires the second stage variables to be separable from the variables in the production technology ( Daraio \& Simar, 2016; Simar \& Wilson, 2007). 


\subsection{Data description}

Our empirical analysis is based on data obtained from ORBIS and Sustainalytics for a sample of European food and beverage companies.

Data on CSR were obtained from Sustainalytics, a company assesses management systems, practices, policies and other indicators reflecting the environmental, social and governance (ESG) performance of firms. The data set provided by Sustainalytics consists of detailed indicators on favorable/positive and controversial/negative aspects of ESG. This is particularly useful when identifying measures of mitigating CSR outputs (scores for the positive indicators) and measures of undesirable outputs (scores for the negative indicators). Composite measures for socially responsible ouputs $y r$ and undesirable outputs $b$ are constructed based on the favorable (positive) indicators and the controversial (negative) indicators using a method that combines principal component analysis (PCA) and data envelopment analysis (DEA), illustrated in Engida et al. (2018). The method first applies PCA to reduce the number of indicators and to construct a few uncorrelated synthesized components for each respective output. Next, DEA is used to construct composite measures for socially responsible and undesirable output using the synthesized components. Table 3.1 provides further details on the ESG indicators.

Data on desirable output, marketable output, and inputs are available from ORBIS. Sales (in US dollars) are used as a measure of the desirable output $(y d)$ and are deflated using the industrial price index for outputs. Two variable inputs and one quasi-fixed input are distinguished. The two variable inputs are material input, which is measured by costs of materials consumed, and labor input, which is measured by employment cost. Material input and labor input are deflated using the industrial price index for consumer non-durables and the labor cost index in manufacturing, respectively. The quasi-fixed input includes fixed assets and is deflated by the industrial price index for capital goods. To allow for adjustment costs, we obtain gross investments in fixed assets. We use cash flow from investing activities as a measure of gross investment. Table 3.1 provides further details on desirable (marketable) output, variable inputs and quasi-fixed inputs. 
Table 3.1. Input and output variables

\begin{tabular}{|c|c|c|c|}
\hline Variable & Description & Indicator & Source \\
\hline$y d$ & Desirable output & Sales & Orbis \\
\hline$y r$ & $\begin{array}{l}\text { Socially } \\
\text { responsible output }\end{array}$ & $\begin{array}{l}\text { Policy on Bribery and Corruption } \\
\text { Signatory to UN Global Compact } \\
\text { Board independence } \\
\text { Policy on Freedom of Association } \\
\text { Formal Policy on the Elimination of } \\
\text { Discrimination } \\
\text { Programs to Increase Workforce Diversity } \\
\text { Formal environmental policy } \\
\text { Environmental management system } \\
\text { Formal Policy or Program on Green } \\
\text { Procurement } \\
\text { Programs and Targets to Stimulate Sustainable } \\
\text { Agriculture } \\
\text { Programs \& Targets to Reduce Water Use } \\
\text { Scope of Social Supply Chain Standards }\end{array}$ & Sustainalytics \\
\hline$b$ & Undesirable output & $\begin{array}{l}\text { Business-Ethics-Related Controversies or } \\
\text { Incidents } \\
\text { Governance-Related Controversies or Incidents } \\
\text { Public-Policy-Related Controversies or } \\
\text { Incidents } \\
\text { Employee-Related Controversies or Incidents } \\
\text { Social supply chain incidents } \\
\text { Customer-Related Controversies or Incidents } \\
\text { Society-\&-Community-Related Controversies or } \\
\text { Incidents } \\
\text { Operations-Related Controversies or Incidents } \\
\text { Environmental supply chain incidents } \\
\text { Products-\&-Services-Related Controversies or } \\
\text { Incidents }\end{array}$ & Sustainalytics \\
\hline$v_{1}$ & Material & Material cost & Orbis \\
\hline$v_{2}$ & Labor & Employee cost & Orbis \\
\hline$k$ & Quasi fixed input & Fixed asset & Orbis \\
\hline$i$ & Investment & Cash flow from investing activities & Orbis \\
\hline
\end{tabular}

Our sample includes major players in the European food and beverage manufacturing industries. A focus on the food industry is warranted since it is linked to several societal concerns, such as food safety, labor rights, and animal welfare (Hartmann, 2011; Heyder \& Theuvsen, 2012). Given these concerns, there is high pressure and rising public scrutiny on the leading food companies regarding their CSR initiatives in environmental issues (e.g. Program on Green Procurement) as well as social issues (e.g. Policy on the Elimination of Discrimination). The EU food manufacturing sector has also been characterized by the implementation of the General Food Law (Regulation (EC) No 178/2002), the EU regulation 
regarding food safety (Commission, 2002). The dataset consists of 195 firm-year observations for the period 2013-2016, with an average of 49 observations per year. A pooled sample of the 195 observations is used in the empirical application, assuming there are no technological changes within such a short time span and all the changes in productivity are attributed to changes in technical efficiency.

Table 3.2 reports descriptive statistics of the variables used in the DEA models. Desirable outputs (sales) and inputs (capital, labor, and material inputs) are highly volatile, while undesirable and socially responsible outputs have a less disperse distribution. The investment variable is characterized by a large variance, which reflects the different behaviors of companies in capital acquisition.

The dynamic by-production technology in this study uses a directional distance functions with directional vectors, which were set as the observed values for variable inputs, and as unity for socially responsible output and undesirable output, i.e. $\vec{g}_{y d}=y d_{o}, \vec{g}_{y r}=1, \vec{g}_{b}=1, \vec{g}_{v}=v_{o}$. This is because the observed values for socially responsible output and undesirable output are scored 0 to 1 and thus there is low variation in the data set (Table 3.2). This helps to discriminate the inefficiency estimates specific these to socially responsible and undesirable output. The directional vector for the investment variable was set to $20 \%$ of the capital stock, i.e. $\vec{g}_{i}=0.2 \times k_{o}$, because the actual investments can be zero and using the actual value could then preclude a solution of the DEA models.

Table 3.2. Summary statistics of the pooled sample for the period 2013 to 2016

\begin{tabular}{clrrr}
\hline Variable & Description & \multicolumn{1}{c}{ Mean } & \multicolumn{1}{c}{ Median } & \multicolumn{1}{l}{ S.D. } \\
\hline$y d$ & Desirable output (Sales) & $9,812,946$ & $2,916,050$ & $17,200,000$ \\
$y r$ & Socially responsible output (Score) & 0.821 & 0.838 & 0.118 \\
$v_{1}$ & Material cost (USD) & 783,702 & 132,892 & $1,850,270$ \\
$v_{2}$ & Cost of employee (USD) & $1,252,192$ & 330,464 & $2,560,679$ \\
$k$ & Fixed assets (USD) & $11,400,000$ & $1,647,496$ & $26,000,000$ \\
$i$ & Investments (USD) & 870,360 & 132,794 & $4,492,006$ \\
$D_{2}$ & Depreciation (USD) & $1,139,463$ & 164,750 & $2,601,831$ \\
$b$ & Undesirable output (Score) & 0.015 & 0.001 & 0.028 \\
\hline
\end{tabular}

Once we characterize corporate social responsibility in the dynamic by-production framework developed in this study, we explain how various factors are associated with the technical inefficiency estimates. Data on the explanatory variables come from the Orbis database. In case of missing values, the data are supplemented with information from companies' annual 
reports that are retrieved from the company's website by the authors. Table 3.3 presents the descriptive statistics of explanatory variables.

Table 3.3. Descriptive statistics of determinants of technical inefficiency

\begin{tabular}{|c|c|c|c|c|c|}
\hline Variable & Description & Unit & Mean & Median & S.D. \\
\hline Size & $\begin{array}{l}\text { Natural log of total } \\
\text { assets }\end{array}$ & USD & 14.694 & 14.315 & 1.76 \\
\hline Leverage & $\begin{array}{l}\text { Ratio of total debt } \\
\text { divided to total } \\
\text { shareholder value }\end{array}$ & Ratio & 0.888 & 0.675 & 0.805 \\
\hline FCF & $\begin{array}{l}\text { Free cash flow divided } \\
\text { by total sales }\end{array}$ & Ratio & 0.112 & 0.108 & 0.105 \\
\hline ROA & $\begin{array}{l}\text { Earnings Before Interest } \\
\text { and Tax (EBIT) divided } \\
\text { by total assets }\end{array}$ & Ratio & 0.089 & 0.081 & 0.06 \\
\hline R\&D Intensity & $\begin{array}{l}\text { Ratio of total R\&D } \\
\text { expenditure to total sales }\end{array}$ & Ratio & 0.01 & 0.002 & 0.027 \\
\hline Market-oriented model & & Dummy & 0.328 & 0 & 0.471 \\
\hline Network-oriented model & & Dummy & 0.672 & 0 & 0.471 \\
\hline
\end{tabular}

Corporate governance systems are represented by a dummy variable indicating marketoriented (Anglo-Saxon) or network-oriented (Germanic and Latin). In the regression, the network-oriented category is set as the reference group. Table 3.3 also summarizes the corporate governance system and shows that $67.2 \%$ of the analyzed companies belong to the network-oriented system and $32.8 \%$ belong to the market-oriented system.

\subsection{Results and discussion}

In this section, we first present and compare the technical inefficiency estimates of dynamic and static by-production models that integrate CSR, and then discuss the results of bootstraptruncated regression analysis of the inefficiency associated factors.

\subsubsection{Inefficiency estimates}

Table 3.4 presents the average technical inefficiencies associated with each input and output assuming either a dynamic or a static technology. It shows that the average inefficiencies are lower under the dynamic framework than under the static framework. For example, material and labor inputs can be decreased by $13.5 \%$ and $16.3 \%$, respectively, under the dynamic technologies, while they can be reduced by $26.6 \%$ and $42.9 \%$ in the static context. Nick and 
Wetzel (2016) found a similar comparison between static and dynamic input technical inefficiencies. It is intuitive that the dynamic technical inefficiency is lower than the static estimates because the dynamic model accounts for adjustment costs of quasi-fixed inputs; these costs are mistakenly interpreted as inefficiency in the static context. The result also shows that the potential for increasing desirable output is lower with the dynamic approach than with the static approach. Regarding socially responsible and undesirable outputs, the improvement potential is also lower under dynamic technologies. There is high inefficiency associated with investments since companies vary greatly in terms of their investments. If we ignore adjustment costs and estimate inefficiencies using a static instead of dynamic technology, the average inefficiencies specific to material input, labor input, socially responsible output, and undesirable output would be overstated by $13.1,26.6,1.0$ and 0.6 percentage points, respectively.

Table 3.4 Inefficiency estimates: dynamic vs. static production technology

\begin{tabular}{lccc}
\hline & Dynamic & Static & $\begin{array}{c}\text { Adapted } \\
\text { Li-Test }\end{array}$ \\
\hline Desirable output & 0.771 & 0.243 & 7.043 \\
Socially responsible output & 0.041 & 0.051 & 0.113 \\
Material & 0.135 & 0.266 & $21.199^{\star \star \star}$ \\
Labor & 0.163 & 0.429 & $17.675^{\star \star *}$ \\
Capital & - & 0.217 & - \\
Investment & 29.225 & - & - \\
Undesirable output & 0.110 & 0.116 & 0.882 \\
\hline
\end{tabular}

We further estimate and compare the density distributions of technical efficiency estimates under the two technologies. The non-parametric Simar-Zeleyuk-adapted Li test, or Adapted Li test, (Li, 1996; Simar \& Zelenyuk, 2006) is used to draw statistical inferences. This test uses kernel densities to compare two unknown distributions (Epure et al., 2011; Li, 1996). The adapted $\mathrm{Li}$ test rejects the null hypothesis of equal distributions of inefficiency estimates specific to material input and labor input (Table 3.4). We do not find statistically significant difference between the dynamic and static approaches for the inefficiency specific to socially responsible output. Comparing the density plots of the dynamic and static inefficiency (Appendix 3A.1) also reveals the notable differences between static and dynamic technologies. The results confirm the necessity of accounting for adjustment costs and the advantages of our dynamic approach over existing static approaches. Therefore, the analysis and discussion in the subsequent sections are based on the inefficiency results from the dynamic production approach. Under the dynamic by-production approach, material input, labor input and undesirable output can be contacted by $13.5 \%, 16.3 \%$ and $11 \%$ respectively while desirable 
output can be expanded by $77.1 \%$, socially responsible output by $4.1 \%$ and the potential of doing investment by $585 \%\left(29.255^{\star} 0.2^{*} 100\right)$ of the capital stock. Under the static by-production approach, on the other hand, material input, labor input, capital input and undesirable output can be contacted by $26.6 \%, 21.7 \%, 42.9 \%$ and $11.6 \%$ respectively while desirable output and socially responsible output can be expanded by $24.3 \%$ and $5.1 \%$ respectively.

Table 3.5 shows the counts and percentages of inefficient and efficient firms in each input and output dimension under dynamic production technologies. It indicates that the largest source of technical inefficiency is labor input because $47 \%$ of the firms are inefficient in this dimension (Appendix 3A.2). The second and third largest sources of inefficiency are desirable outputs and undesirable outputs with $46 \%$ and $38 \%$ of the firms being inefficient, respectively. With regard to socially responsible outputs, $34 \%$ of the firms are inefficient. This result is comparable with the average inefficiency result in Table 3.4.

Table 3.5. Inefficient and efficient firms across input output dimensions

\begin{tabular}{lcccc}
\hline & \multicolumn{2}{c}{ Inefficient firms } & \multicolumn{2}{c}{ Efficient firms } \\
\hline & Count & $\%$ & Count & $\%$ \\
\cline { 2 - 5 } Desirable output only & 89 & 46 & 106 & 54 \\
Socially responsible output only & 66 & 34 & 129 & 66 \\
Material input only & 51 & 26 & 144 & 74 \\
Labour input only & 91 & 47 & 104 & 53 \\
Undesirable output only & 75 & 38 & 120 & 62 \\
All the inputs and outputs & 158 & 81 & 37 & 19 \\
At least in one input or output & 0 & 0 & 195 & 100 \\
\hline
\end{tabular}

The number of efficient firms is quite high in the sample of European food and beverages manufacturing firms analyzed here. The result shows that firms are technically efficient in at least one input or output dimension. This finding is consistent with that of Puggioni and Stefanou (2016) who reported a high level of efficiency for their sample of firms. Commenting on the observation of a large number of efficient firms, Puggioni and Stefanou (2016) noted that: "More freedom and more choices available to firms generate a very peculiar technology set that can accommodate for different production 'recipes' and make it easier for firms to be efficient". 


\subsubsection{Results of bootstrapped truncated regression}

Table 3.6 indicates that the coefficient for size is negative and statistically significant at the $5 \%$ level for inefficiencies specific to socially responsible output, material and labour inputs. This shows that a larger firm size is related to a lower level of inefficiency.

Regarding socially responsible output, the coefficient for size is -0.026 and it indicates that a one-percent increase in size is associated with a 0.0003 decrease in inefficiency specific to socially responsible output. This finding strongly supports the view that a large firm size is associated with high levels of performance in corporate social responsibility. A similar result has been found by Artiach et al. (2010) for a sample of U.S. firms. Firm size seems to be a crucial factor, and society's pressure for CSR initiatives and practices disproportionately affects large companies.

Table 3.6. Bootstrap-truncated regression estimates on factors associated with inefficiencies specific to outputs and inputs

\begin{tabular}{lccccc}
\hline & $\begin{array}{c}\text { Socially } \\
\text { responsible }\end{array}$ & Desirable & Undesirable & Material & Labour \\
\hline Size & $-0.026^{\star * *}$ & -1.464 & 0.409 & $-0.083^{* *}$ & $-.0 .141^{* * *}$ \\
Leverage & 0.009 & 1.294 & -0.39 & $0.292^{* *}$ & -0.062 \\
FCF & 0.211 & -3.331 & 8.761 & -0.338 & -0.901 \\
ROA & 0.196 & -1.737 & $-19.618^{\star * *}$ & -1.61 & -0.73 \\
R\&D Intensity & $-2.45^{\star * *}$ & -89.842 & $-50.274^{* * *}$ & $20.064^{* * *}$ & -0.44 \\
Market-oriented & $0.164^{* * *}$ & -7.977 & $2.179^{\star * *}$ & -0.217 & $-0.262^{\star * *}$ \\
dummy & & & & & \\
\hline
\end{tabular}

Note: Asterisks ${ }^{* \star *},{ }^{* *}$, and ${ }^{*}$ denote significance at the $1 \%, 5 \%$, and $10 \%$ levels, respectively.

$R \& D$ is positively associated with inefficiency specific to material input. A plausible explanation for the relation could be that $R \& D$ initiatives divert resources away from investment in rentable materials that could have increased desirable outputs. In comparison, R\&D helps reduce inefficiency specific to socially responsible and undesirable outputs. This is partly because CSR initiatives motivate R\&Ds. R\&D is an investment aiming at enhancing knowledge that leads to product and process innovations which can also be CSR related (McWilliams \& Siegel, 2001) . For example, R\&D activities might improve processes that reduce the amount of energy a firm consumes, with cost reductions and less pollution.

The estimated parameter of the dummy variable for a market-oriented (Anglo-Saxon) corporate governance system is positive and statistically significant at the $5 \%$ level in the inefficiency specific to socially responsible output. This supports the hypothesis that firms in network-oriented systems (Germanic and Latin) tend to be more socially responsible. In the 
network-oriented systems, networks of relationships between stakeholders influence managerial decision-making such that the firm incorporates sustainability and social responsibility principles into its strategy to satisfy the needs of multiple stakeholders. The dummy variable for a market oriented system have a statistically significant and negative association with inefficiency specific to labour input. This result suggests that firms in market oriented governance system devise better strategies on the use of labour compared to the network oriented counterpart.

Leverage reports a statistically significant and positive association with inefficiency specific to material input. It means that an increase in leverage is associated with an increase in inefficiency specific to material input. This could be because of firm's focus on debtholders' interest than shareholders' (Vincent et al, 2007; Hossain et al, 2005).

ROA is the ratio of earnings before interest and tax (EBIT) to total assets. The coefficient of $\mathrm{ROA}$ is negative and statistically significant for inefficiency specific to undesirable output; indicating that an increase in ROA is associated with a decrease in inefficiency specific to undesirable output. This result might be explained by the fact that firm will have the financial means to devise strategies that mitigate undesirable output when it enjoys high levels of profitability $(\mathrm{ROA})$.

\subsection{Conclusion}

This study integrates corporate social responsibility in a dynamic production framework. It measures inefficiency and examines the factors associated with CSR-specific inefficiencies. We adapt static by-production models and developed a dynamic by-production model that better represents the transformation process of multiple inputs into multiple outputs by accounting for adjustment costs associated with quasi-fixed inputs. The empirical analysis is applied to a sample of European food and beverage manufacturing firms. The results show the importance of accounting for the presence of adjustment costs associated with investments in quasi-fixed inputs. Ignoring adjustment costs may lead to an overestimation of the inefficiencies. This study also employs a bootstrap-truncated regression model to investigate firm-specific factors associated with inefficiency. The main findings are summarized as follows. First, higher levels of CSR performance is associated with a larger firm size. Second, more R\&D intensity is associated with higher CSR performance. Finally, network-oriented systems (Germanic or Latin) tend to be more socially responsible, in line with prior expectations that networks of relationships between stakeholders in the network-oriented systems influence a firm's decision to incorporate sustainability and social responsibility. 
Existing research has centered mainly on the financial implications of engaging in corporate social responsibility. In comparison, the present study takes a different prospective and investigates the process through which socially responsible output, namely CSR, is created by incorporating it into a dynamic by-production framework and examining the factors associated with CSR performance. Hence, this study provides a useful guide to benchmark performance in a way that accounts for resources allocated from the production of desirable outputs to the production of CSR and for mitigation effects of CSR as it reduces undesirable output. This in turn helps capture the correct trade-offs among inputs, desirable outputs, CSR, and undesirable output. This novel perspective allows a deeper examination of CSR performance and the factors that are associated with the variation in CSR. 


\section{References}

Aguilera, R. V., Filatotchev, I., Gospel, H., \& Jackson, G. (2008). An organizational approach to comparative corporate governance: Costs, contingencies, and complementarities. Organization science, 19(3), 475-492.

Alene, A. D. (2010). Productivity growth and the effects of R\&D in African agriculture. Agricultural economics, 41(3-4), 223-238.

Artiach, T., Lee, D., Nelson, D., \& Walker, J. (2010). The determinants of corporate sustainability performance. Accounting \& Finance, 50(1), 31-51.

Baron, D. P. (2001). Private politics, corporate social responsibility and integrated strategy. Journal of Economics and Management Strategy, 10: 7-45.

Berre, D., Boussemart, J.-P., Leleu, H., \& Tillard, E. (2013). Economic value of greenhouse gases and nitrogen surpluses: Society vs farmers' valuation. European Journal of Operational Research, 226(2), 325-331.

Chambers, R. G., Chung, Y., \& Färe, R. (1998). Profit, directional distance functions, and Nerlovian efficiency. Journal of optimization theory and applications, 98(2), 351-364.

Chung, Y. H., Färe, R., \& Grosskopf, S. (1997). Productivity and undesirable outputs: a directional distance function approach. Journal of environmental management, 51(3), 229-240.

Commission, E. (2002). Regulation (EC) No 178/2002 of the European Parliament and of the Council of 28 January 2002 laying down the general principles and requirements of food law, establishing the European Food Safety Authority and laying down procedures in matters of food safety. Official Journal of the European Communities, 31(01/02/2002), 1-24.

Dakpo, K. H. (2016). On modeling pollution-generating technologies: a new formulation of the by-production approach (No. 913-2016-72292).

Dakpo, K.H., Jeanneaux, P., Latruffe, L. (2016). Modelling pollution-generating technologies in performance benchmarking: Recent developments, limits and future prospects in the nonparametric framework. European Journal of Operational Research, 2502):347-359.

Dakpo, KH, \& Oude Lansink, AO (2019). Dynamic pollution-adjusted inefficiency under the byproduction or bad outputs. European Journal of Operational Research , 276 (1), 202211.

Daraio, C., Simar, L., (2016). Efficiency and benchmarking with directional distances. A data driven approach. Journal of the Operational Research Society , 67, 928-944.

Daraio, C., Simar, L., \& Wilson, P. W. (2018). Central limit theorems for conditional efficiency measures and tests of the 'separability'condition in non-parametric, two-stage models of production. The Econometrics Journal.

Dimson, E., Karakaş, O., \& Li, X. (2015). Active ownership. The Review of Financial Studies, 28(12), 3225-3268.

Eccles, R. G., \& Krzus, M. P. (2010). One report: Integrated reporting for a sustainable strategy: John Wiley \& Sons. 
Engida, T. G., Rao, X., Berentsen, P. B. M., \& Oude Lansink, A. G. J. M. (2018). Measuring corporate sustainability performance- the case of European food and beverage companies. Journal of Cleaner Production, 195, 734-743.

Epure, M., Kerstens, K., \& Prior, D. (2011). Bank productivity and performance groups: a decomposition approach based upon the Luenberger productivity indicator. European Journal of Operational Research, 211(3), 630-641.

Fisher, C., \& Lovell, A. (2009). Business ethics and values: Individual, corporate and international perspectives: Pearson education.

Førsund, F. R. (2008). Good modelling of bad outputs: pollution and multiple-output production (No. 2008, 30). Memorandum.

Galema, R., Plantinga, A., \& Scholtens, B. (2008). The stocks at stake: Return and risk in socially responsible investment. Journal of Banking \& Finance , 32 (12), 2646-2654.

Hampf, B., \& Krüger, J. J. (2014). Optimal directions for directional distance functions: An exploration of potential reductions of greenhouse gases. American Journal of Agricultural Economics, 97(3), 920-938.

Hartmann, M. (2011). Corporate social responsibility in the food sector. European Review of Agricultural Economics, 38(3), 297-324.

Heyder, M., \& Theuvsen, L. (2012). Determinants and effects of corporate social responsibility in German agribusiness: A PLS model. Agribusiness, 28(4), 400-420.

Hossain, F., Jain, R., \& Govindasamy, R. (2005). Financial structure, production, and productivity: evidence from the US food manufacturing industry. Agricultural economics, 33, 399-410.

Huguenin, J.-M. (2012). Data Envelopment Analysis (DEA): a pedagogical guide for decision makers in the public sector.

Kapelko, M., \& Oude Lansink, A. O. (2017). Dynamic multi-directional inefficiency analysis of European dairy manufacturing firms. European Journal of Operational Research, 257(1), 338-344.

Kapelko, M., \& Oude Lansink, A. (2014). Examining the relation between intangible assets and technical efficiency in the international textile and clothing industry. The Journal of the Textile Institute, 105(5), 491-501.

Khataza, RR, Hailu, A., Doole, GJ, Kragt, ME, \& Alene, AD (2019). Examining the relationship between farm size and productive efficiency: a Bayesian directional distance function approach. Agricultural Economics , 50 (2), 237-246.

$\mathrm{Li}, \mathrm{Q}$. (1996). Nonparametric testing of closeness between two unknown distribution functions. Econometric Reviews, 15(3), 261-274.

Majumdar, S. K. (1997). The impact of size and age on firm-level performance: some evidence from India. Review of industrial organization, 12(2), 231-241.

Margolis, J. D., Elfenbein, H., \& Walsh, J. (2009). Does it pay to be good... and does it matter? A meta-analysis and redirection of research on corporate social and financial performance. In Harvard University Working paper.

McWilliams, A., \& Siegel, D. (2001). Corporate social responsibility: A theory of the firm perspective. Academy of management review, 26(1), 117-127. 
Murty, S., Russell, R. R., \& Levkoff, S. B. (2012). On modeling pollution-generating technologies. Journal of environmental economics and management, 64(1), 117-135.

Nelling, E., \& Webb, E. (2009). Corporate social responsibility and financial performance: the "virtuous circle" revisited. Review of Quantitative Finance and Accounting, 32(2), 197209.

Nick, S., \& Wetzel, H. (2016). The hidden cost of investment: the impact of adjustment costs on firm performance measurement and regulation. Journal of Regulatory Economics, 49(1), 33-55.

Njuki, E., \& Bravo-Ureta, B. E. (2015). The economic costs of environmental regulation in US dairy farming: A directional distance function approach. American Journal of Agricultural Economics, 97(4), 1087-1106.

Oikonomou, I., Brooks, C., \& Pavelin, S. (2012). The impact of corporate social performance on financial risk and utility: A longitudinal analysis. Financial Management , 41 (2), 483515.

Oude Lansink, A. O., Verstegen, J., \& Van den Hengel, J. (2001). Investment decision making in Dutch greenhouse horticulture. NJAS-Wageningen Journal of Life Sciences, 49(4), 357-368.

Oude Lansink, A. O., Stefanou, S., \& Serra, T. (2015). Primal and dual dynamic Luenberger productivity indicators. European Journal of Operational Research, 241(2), 555-563.

Peloza, J., Loock, M., Cerruti, J., \& Muyot, M. (2012). Sustainability: How stakeholder perceptions differ from corporate reality. California Management Review, 55(1), 74-97. doi:10.1525/cmr.2012.55.1.74

Penrose, E. T. (1995). The theory of the growth of the firm. In. Retrieved from ebrary http://site.ebrary.com/id/10283659

Puggioni, D., \& Stefanou, S. (2016). The Value of Being Socially Responsible. A DEA Approach for Analyzing Efficiency and Recovering Shadow Prices of CSR Activities. Paper presented at the 2016 Annual Meeting, July 31-August 2, 2016, Boston, Massachusetts.

Robinson, E.A.G. (1962). The structure of competitive insustry. Chicago. The University of Chicago Press.

Rodger, J. A., \& George, J. A. (2017). Triple bottom line accounting for optimizing natural gas sustainability: A statistical linear programming fuzzy ILOWA optimized sustainment model approach to reducing supply chain global cybersecurity vulnerability through information and communications technology. Journal of cleaner production, 142, 1931 1949.

Sánchez-Ballesta, J. P., \& García-Meca, E. (2007). Ownership structure, discretionary accruals and the informativeness of earnings. Corporate Governance: An International Review, 15(4), 677-691.

Silva, E., Oude Lansink, A. O., \& Stefanou, S. E. (2015). The adjustment-cost model of the firm: Duality and productive efficiency. International Journal of Production Economics, $168,245-256$.

Silva, E., \& Stefanou, S. E. (2003). Nonparametric dynamic production analysis and the theory of cost. Journal of Productivity Analysis, 19(1), 5-32. 
Simar, L., \& Wilson, P. W. (2007). Estimation and inference in two-stage, semi-parametric models of production processes. Journal of econometrics, 136(1), 31-64.

Simar, L., Zelenyuk, V., (2007). Statistical inference for aggregates of Farrelltype efficiencies. Journal of Applied Econometrics 22 (7), 1367-1394.

Simar, L., \& Zelenyuk, V. (2006). On testing equality of distributions of technical efficiency scores. Econometric Reviews, 25(4), 497-522.

Surroca, J., \& Tribó, J. A. (2008). Managerial entrenchment and corporate social performance. Journal of Business Finance \& Accounting, 35(5-6), 748-789.

Surroca, J., Tribó, J. A., \& Waddock, S. (2010). Corporate responsibility and financial performance: The role of intangible resources. Strategic management journal, 31(5), 463-490.

Ullmann, A. A. (1985). Data in search of a theory: A critical examination of the relationships among social performance, social disclosure, and economic performance of US firms. Academy of management review, 10(3), 540-557.

Vardanyan, M., \& Noh, D.-W. (2006). Approximating pollution abatement costs via alternative specifications of a multi-output production technology: a case of the US electric utility industry. Journal of environmental management, 80(2), 177-190.

Vincent Mok, Godfrey Yeung , Zhaozhou Han \& Zongzhang Li (2007) Leverage, Technical Efficiency and Profitability: an application of DEA to foreign-invested toy manufacturing firms in China, Journal of Contemporary China, 16:51, 259-274

Webb, E. (2005). Agency costs, leverage, and corporate social responsibility: A test of causality. Financial Decisions, 3(1), 1-19.

Weimer, J., \& Pape, J. (1999). A taxonomy of systems of corporate governance. Corporate Governance: An International Review, 7(2), 152-166.

Zelenyuk, V., \& Zheka, V. (2006). Corporate governance and firm's efficiency: the case of a transitional country, Ukraine. Journal of Productivity Analysis, 25(1-2), 143-157.

Zhang, N., \& Choi, Y. (2014). A note on the evolution of directional distance function and its development in energy and environmental studies 1997-2013. Renewable and Sustainable Energy Reviews, 33, 50-59. 


\section{Appendix 3A Supplementary material}

Appendix 3A.1 The density distributions of dynamic and static inefficiency estimates

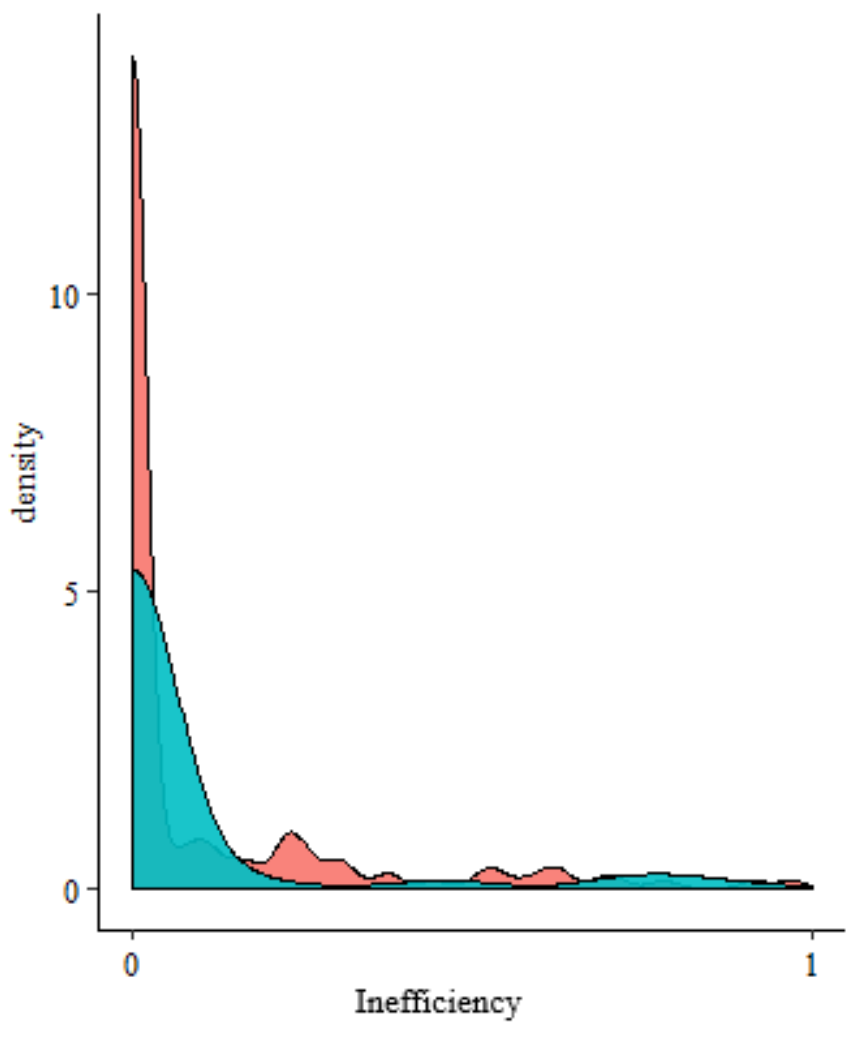

Desirable output

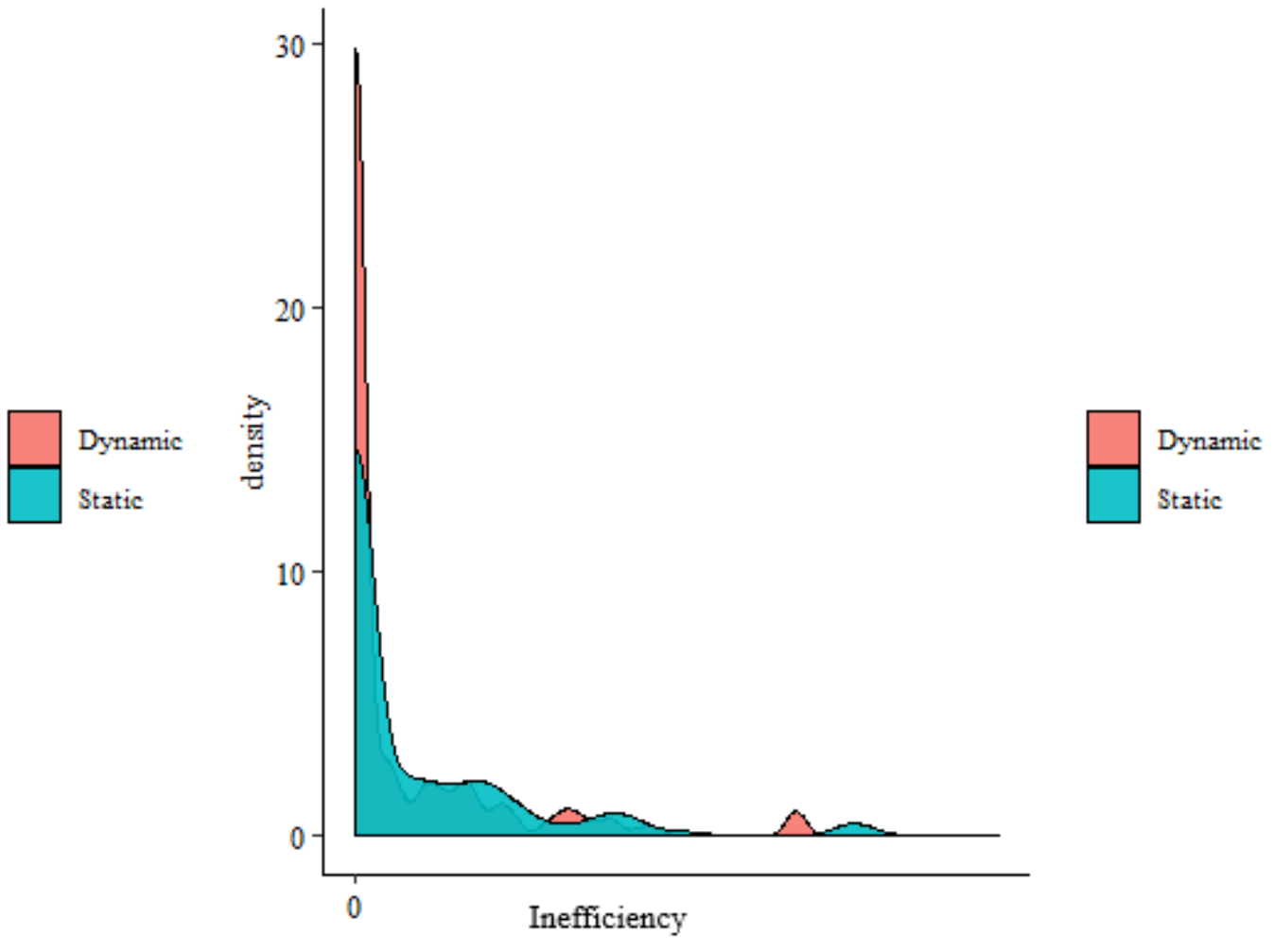

Socially responsible output 


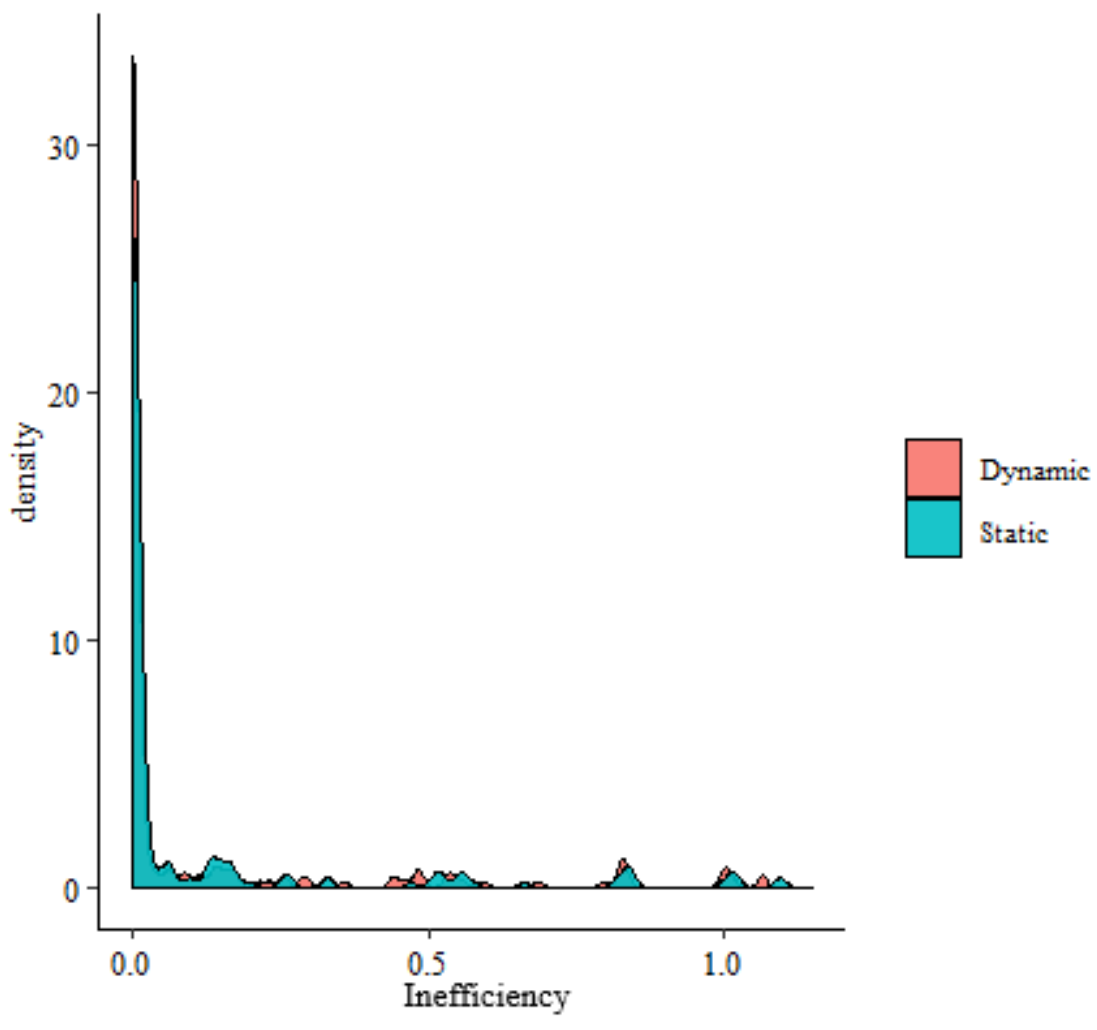

Undesirable output 


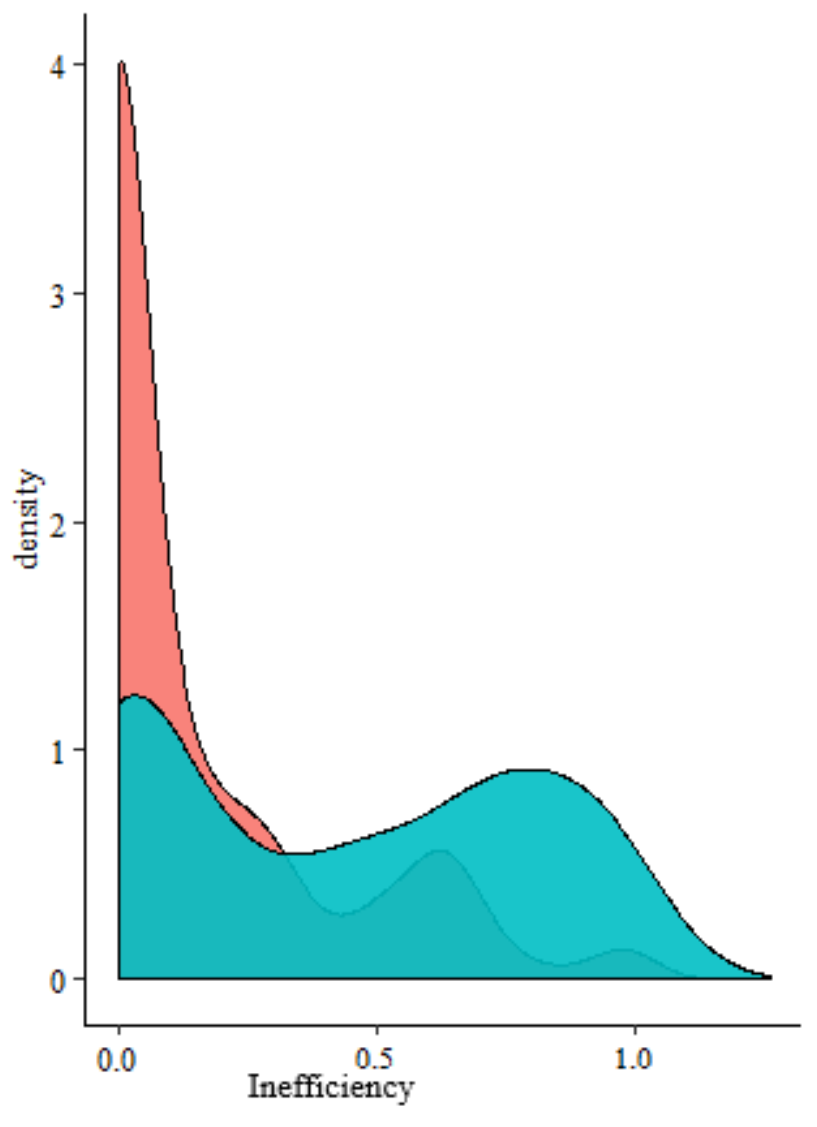

Material input

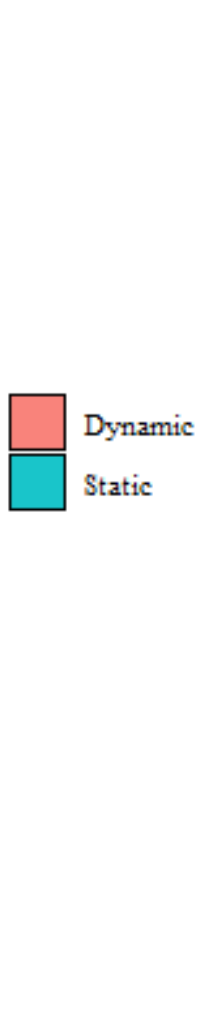

0.

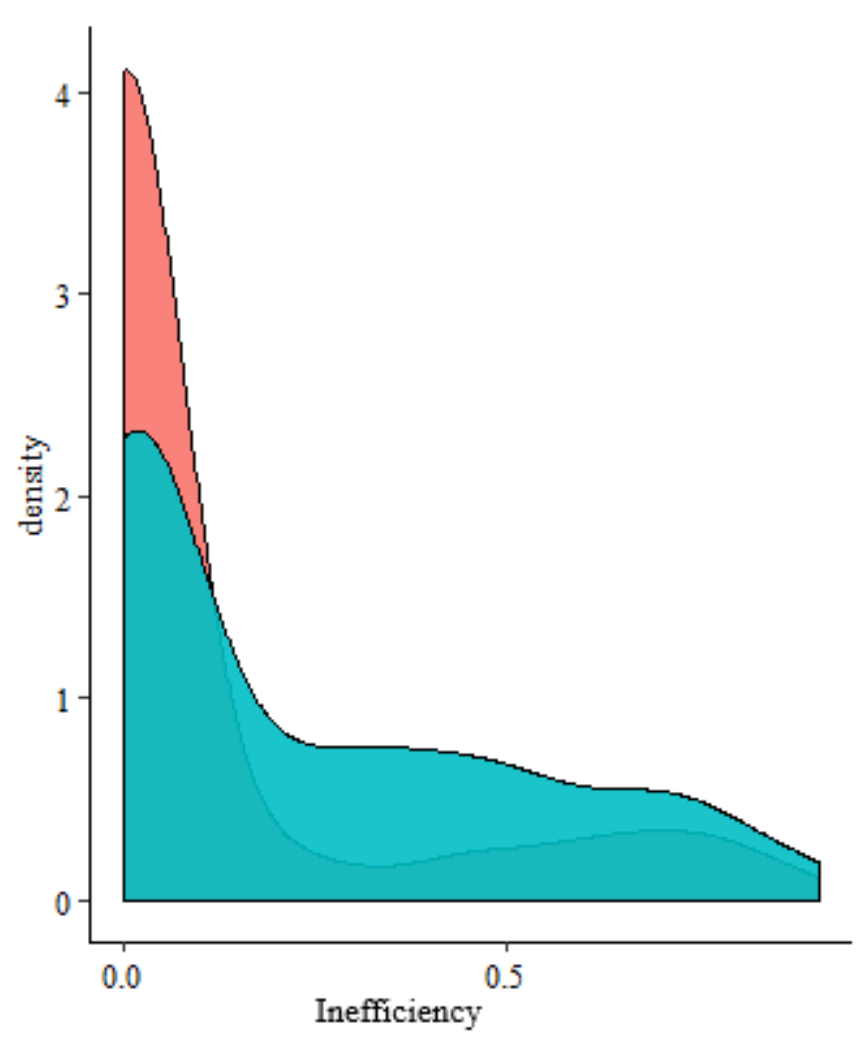

Labour input 
Appendix 3A.2 Box plot of input-output-specific inefficiencies under dynamic production technologies

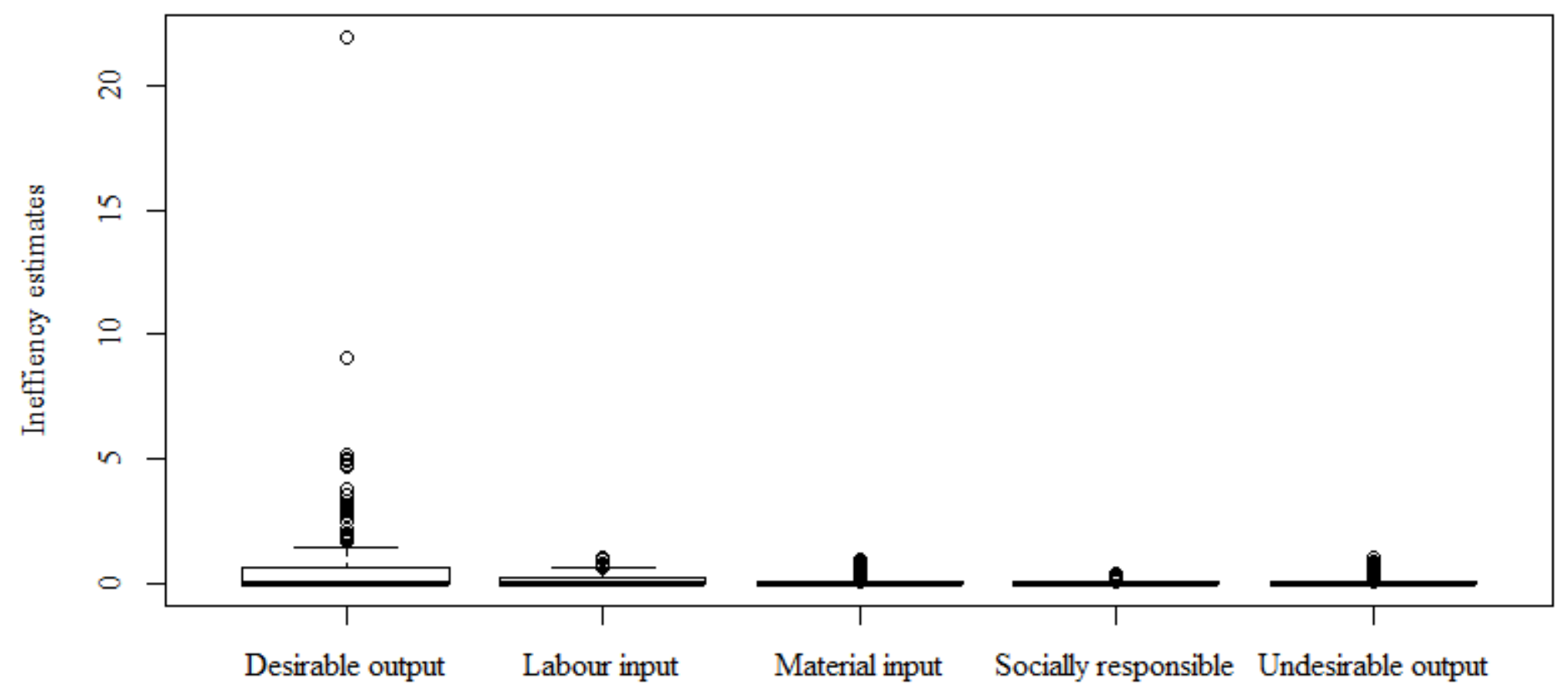




\section{Chapter 4}

\section{Measuring dynamic input- and output-specific productivity change in the presence of socially responsible and undesirable outputs}

${ }^{a}$ Wageningen University \& Research, Business Economics Group, Hollandseweg 1, $6706 \mathrm{KN}$, Wageningen, The Netherlands 


\section{Abstract}

This study contributes to the efficiency and productivity literature by evaluating productivity change in the presence of corporate social responsibility in the production process. The production model integrates corporate social responsibility in the production framework and it represents the transformation of multiple inputs into desirable (marketed), socially responsible and undesirable outputs, in a dynamic context where we account for adjustment costs in quasi-fixed inputs. The study illustrates the method using a sample of European food and beverage manufacturing firms. The results of the empirical application show a decline in dynamic Luenberger indicators which is mainly due to technical inefficiency change. Hence, firms should devise strategies to enhance utilizations of resources and reduce technical inefficiency. This study also provides insights into the associations between firm-specific factors and dynamic Luenberger indicators.

Keywords: Corporate Social Responsibility, dynamic input-and output-specific productivity change, data envelopment analysis, dynamic Luenberger indicator, food and beverage manufacturing industry 


\subsection{Introduction}

Corporate social responsibility (CSR) defines a set of corporate practices that improve the social and environmental standards of the markets in which companies operate. CSR shifts corporate goals from value maximisation for shareholders towards a broader, multi-stakeholder satisfaction (Paul \& Siegel, 2006). There is an increasing societal demand for firms integrating CSR and sustainability in their business practices in all sectors of the economy. Given the characteristics of the industry, there is also high pressure on the food and beverage industry to take up CSR since it is subject to more scrutiny from both financial regulators and social stakeholders. Recent decades have seen a shift in customer preferences towards socially responsible consumption globally and in Europe in particular (European Commission 2016).

CSR initiatives of food companies have evolved around environmental issues (e.g. Program on Green Procurement) as well as social issues (e.g. Policy on the Elimination of Discrimination). The EU food-manufacturing sector has implemented the General Food Law (Regulation (EC) No 178/2002). One of the objectives of food and feed law, which relates to CSR, is the requirement for companies to guarantee fair practices in food trade and to take responsibility for their environmental impact. In addition, CSR engagement is also driven by investors' preferences for CSR stocks, and firms are required to divert resources from the production of desirable outputs to the production of CSR (Shiu \& Yang, 2017). CSR activities imply a shift of productive resources from the production of marketable outputs to socially desirable outputs and to a reduction of undesirable outputs. Socially responsible activities such as environmental programs and community programs appear to mitigate undesirable outputs while diverting resources that could have been employed in the production of marketable output. Therefore, it is important to incorporate CSR into a production framework that captures the trade-offs among inputs, desirable output, CSR, and undesirable output. Recently, Puggioni and Stefanou (2016) integrated CSR in a production framework that aimed to investigate the economic and technical efficiency with which firms operate.

Research exploring the relation of CSR with productivity change and/or efficiency is still limited (Guillamon-Saorin et al.,2018; Puggioni and Stefanou, 2016; Sun and Stuebs, 2013; Wang et al., 2014). These articles aim at analyzing the productivity change for all inputs simultaneously, ignoring differences in productivity change between inputs. In addition, these studies on the relation between CSR and productivity change are generally performed in the static context. Static models fail to account for the adjustment costs associated with investments in capital assets and may confound inefficiency with adjustment costs (Oude Lansink et al, 2001; Silva \& Stefanou, 2003, 2007). 
Measuring productivity change provides valuable insights into the evolution of a firm and its degree of competitiveness. It is a useful technique to devise strategies towards improvement of performance over time. Analysing input- and output-specific productivity change helps in disaggregating the sources of productivity change and in exploring the contribution of inputs and outputs to the overall productivity change. However, the literature on evaluating productivity change to date does not account for the role of CSR in the production process.

In light of the aforementioned, the objective of this study is to evaluate input- and output-specific productivity change in the presence of socially responsible and undesirable outputs. The study uses a dynamic by-production model to characterize the transformation of multiple inputs into desirable, socially responsible and undesirable outputs. In order to measure the input-and output-specific productivity change, we employ a dynamic Luenberger indicator developed as in (Oude Lansink et al, 2015) and decompose it into dynamic technical inefficiency change, dynamic scale inefficiency change, dynamic technical change and scale change of dynamic technology. The contribution of this study to the existing literature is twofold. First, we develop dynamic input- and output-specific productivity change in the presence of socially responsible and undesirable output. Second, we empirically demonstrate the applicability of the indicator using a data set of the European food and beverage industry.

Ordinary least square (OLS) bootstrap regression will be employed to assess the association between firm-specific factors and the dynamic input-, output- and investment-specific productivity change. The next section develops the methodology of dynamic productivity change and shows its empirical implementation using data envelopment analysis (DEA). The subsequent section presents the description of the data in a sample of European food and beverage manufacturing firms. This is followed by the results of the estimation of the dynamic productivity change and the OLS bootstrap regression. The final section offers concluding comments.

\subsection{Methods}

\subsubsection{The Luenberger Indicator of Dynamic Productivity change}

This study extends the dynamic by-production model developed in Dakpo (2016) and Dakpo \& Oude Lansink (2019) by integrating CSR in the production process. The implementation of CSR will generate an opportunity cost since firms are required to divert resources away from the production of marketable outputs to socially desirable activities (Puggioni \& Stefanou, 2016). It is critical to correctly account for the opportunity cost associated with CSR and the adjustment costs associated 
with quasi-fixed inputs in the production process. Therefore, our model incorporates CSR as an additional output instead of an input of the underlying technology in a dynamic by production framework.

Let us consider a data series $\left(y d_{\mathrm{t}}, y r_{\mathrm{t}}, b_{\mathrm{t}}, k_{\mathrm{t}}, v_{\mathrm{t}}, i_{\mathrm{t}}\right.$ ) that represents the observed behaviour of $j=$ $1, \ldots, J$ firms at time t. Consider a by-production technology that consists of two sub-technologies: one describing the sub-production of desirable outputs and the other the sub-production of undesirable outputs. Specifically, this by-production technology uses $v(t)$ and invests $i(t)$ to produce three types of outputs given $k(t)$ : desirable outputs $y d(t)$, socially responsible outputs $y r(t)$, and undesirable outputs $b(t) . y d(t)$ are the primary, marketable outputs by which the production process is motivated; $b(t)$ are the undesirable outputs that are unwanted but inevitably generated as by-products of the desirable outputs, and can be potentially detrimental to the firm or society; and $y r(t)$ consists of socially responsible activities implemented by firm managers to reduce the undesirable outputs $b(t)$. This dynamic by-production technology $\Psi(t)$ is mathematically represented by the intersection of the desirable-output sub-technology $\Psi_{g}(t)$ and the undesirableoutput sub-technology $\Psi_{b}(t)$ :

$$
\Psi(t)=\Psi_{g}(t) \cap \Psi_{b}(t)
$$

Where

$\Psi_{g}(t)=[(v(t), i(t), y d(t), y r(t), b(t)):(v(t), i(t))$ can produce $y d(t)$ and $y r(t)$, given $k(t)]$

$\Psi_{b}(t)=[(v(t), i(t), y d(t), y r(t), b(t)):(v(t), i(t), y r(t))$ can produce $b(t)$, , given $k(t)$

$\Psi_{g}(t)$ is the conventional convex technology set representing the good outputs sub-technology that transforms inputs into desirable outputs and socially responsible output. $\Psi_{b}(t)$ is the undesirableoutput-generating technology set representing the transformation of inputs into undesirable outputs. The dynamic by-production technology in this study uses the directional distance function (DDF) proposed by Chambers et al., (1998). A general representation of the non-radial form of the DDF with directional vectors for social responsible output $\left(\vec{g}_{y d}\right)$, undesirable output $\left(\vec{g}_{b}\right)$, variable inputs $\left(\vec{g}_{v}\right)$ and investments $\left(\vec{g}_{i}\right), \vec{D}_{t}^{i}\left(y r_{\mathrm{t}}, b_{\mathrm{t}}, k_{\mathrm{t}}, v_{\mathrm{t}}, i_{\mathrm{t}}:, \vec{g}_{y r}, \vec{g}_{b}, \vec{g}_{v}, \vec{g}_{i}\right)$, measuring dynamic technical inefficiency for each firm at time $t$, is defined as follows: 


$$
\begin{gathered}
\vec{D}_{t}^{i}\left(y d_{t}, y r_{t}, b_{t}, k_{t}, v_{t}, i_{t}: \vec{g}_{y r}, \vec{g}_{b}, \vec{g}_{v}, \vec{g}_{i}\right)=\max _{\beta} \frac{1}{N_{\vec{g}}}\left[\beta_{b}+\beta_{v}+\beta_{i}\right. \\
\in \mathbb{R}:\left(b_{t}-\beta_{b} \vec{g}_{b}, v_{t}-\beta_{v} \vec{g}_{v}, i_{t}+\beta_{i} \vec{g}_{i}\right) \in \Psi(t), \\
\vec{g}_{b} \in \mathbb{R}_{+}^{R}, \vec{g}_{v} \in \mathbb{R}_{+}^{J}, \vec{g}_{i} \in \mathbb{R}_{+}^{L},\left(\vec{g}_{y r}, \vec{g}_{b}, \vec{g}_{v}, \vec{g}_{i}\right) \neq\left(0^{E}, 0^{R}, 0^{J}, 0^{L}\right)
\end{gathered}
$$

where $\beta_{b}, \beta_{v}, \beta_{i}$ are measures of dynamic technical inefficiency specific to the socially undesirable output, variable inputs and investments.

A dynamic Luenberger productivity indicator (Kapelko et al, 2017) is employed to measure input, output and investment specific productivity changes. Investment in quasi-fixed inputs (e.g. building and machinery) involves an intertemporal decision that decreases current production while increasing future capital stock for increasing future production. The dynamic Luenberger indicator of input-, output- and investment-specific productivity change was estimated using DEA by solving four linear programming (LP) models for two consecutive years: two single period models (for time $t$ and $t+1$ ) and two mixed period models (for a firm in $t$ in relation to the technology in time $t+1$, and the other for a firm in $t+1$ in relation to the technology in time $t$ ) for firm $\mathrm{i}$. 
A single period model for evaluating a firm in $\mathrm{t}$ in relation to the technology in time $\mathrm{t}$ is computed as:

$$
\begin{aligned}
& \vec{D}_{t}^{i}\left(v(t), i(t), k(t), y d(t), y r(t), b(t) ; \vec{g}_{b}, \vec{g}_{v}, \vec{g}_{i}\right)=\max _{\beta, \mu}, \mu^{b} \frac{1}{N_{\vec{g}}}\left[\beta_{b}^{1}+\beta_{v}^{1}+\beta_{i}^{1}\right] \\
& \text { s.t. } y d_{o}(t) \leq \sum_{n=1}^{N} \mu_{n}^{g} y d_{n}(t) \\
& y r_{o}(t) \leq \sum_{n=1}^{N} \mu_{n}^{g} y r_{n}(t) \\
& v_{o}(t)-\beta_{v} \vec{g}_{v} \geq \sum_{n=1}^{N} \mu_{n}^{g} v_{n}(t) \\
& i_{o}(t)-\delta k_{o}(t)+\beta_{i} \vec{g}_{i} \leq \sum_{n=1}^{N} \mu_{n}^{g}\left(i_{n}(t)-\delta k_{n}(t)\right) \\
& b_{o}(t)-\beta_{b} \vec{g}_{b} \geq \sum_{n=1}^{N} \mu_{n}^{b} b_{n}(t) \\
& y r_{o}(t) \geq \sum_{n=1}^{N} \mu_{n}^{b} y r_{n}(t) \\
& v_{o}(t)-\beta_{v} \vec{g}_{v} \leq \sum_{n=1}^{N} \mu_{n}^{b} v_{n}(t) \\
& i_{o}(t)-\delta k_{o}(t)+\beta_{i} \vec{g}_{i} \geq \sum_{n=1}^{N} \mu_{n}^{b}\left(i_{n}(t)-\delta k_{n}(t)\right) \\
& \sum_{n=1}^{N} \mu_{n}^{g} v_{n}(t)=\sum_{n=1}^{N} \mu_{n}^{b} v_{n}(t) \\
& \sum_{n=1}^{N} \mu_{n}^{g}\left(i_{n}(t)-\delta k_{n}(t)\right)=\sum_{n=1}^{N} \mu_{n}^{b}\left(i_{n}(t)-\delta k_{n}(t)\right)
\end{aligned}
$$


where $N_{\vec{g}}$ is the number of variables in the objective function. We assign the same weight to each inefficiency score to equally emphasize both the contraction of inputs and the expansion of outputs and investments. For the generalization of the non-radial approach, each of the $\beta$ inefficiency can be individualized with different corresponding variables $\left(\beta_{b r}, \beta_{v j}, \beta_{i l}\right)$.

The directional vector enters the constraints additively, and the inefficiency score $\beta$ has a lower bound at 0 while it does not have an upper bound. Therefore, $\beta=0$ indicates full efficiency, while $\beta>0$ indicates technical inefficiency. $\mu_{n}^{g}, \mu_{n}^{b}$ are the two intensity variables associated with each sub-technology: good outputs sub-technology and undesirable-output-generating technology.

$\sum_{n=1}^{N} \mu_{n}^{g} v_{n}(t)=\sum_{n=1}^{N} \mu_{n}^{b} v_{n}(t) \quad$ and $\quad \sum_{n=1}^{N} \mu_{n}^{g}\left(i_{n}(t)-\delta k_{n}(t)\right)=\sum_{n=1}^{N} \mu_{n}^{b}\left(i_{n}(t)-\delta k_{n}(t)\right) \quad$ are interdependence constraints that ensure equality of the optimal values of the variables (i.e. the variable inputs and investments) involved in both sub-systems. 
A mixed period model for evaluating a firm in $t$ in relation to the technology in time $t+1$ is represented as:

$$
\begin{aligned}
& \vec{D}_{t+1}^{i}\left(v(t), i(t), k(t), y d(t), y r(t), b(t) ; \vec{g}_{b}, \vec{g}_{v}, \vec{g}_{i}\right)=\max _{\beta, \mu^{g}, \mu^{b}} \frac{1}{N_{\vec{g}}}\left[+\beta_{b}^{2}+\beta_{v}^{2}+\beta_{i}^{2}\right] \\
& \text { s.t. } y d_{o}(t) \leq \sum_{n=1}^{N} \mu_{n}^{g} y d_{n}(t+1) \\
& y r_{o}(t) \leq \sum_{n=1}^{N} \mu_{n}^{g} y r_{n}(t+1) \\
& v_{o}(t)-\beta_{v} \vec{g}_{v} \geq \sum_{n=1}^{N} \mu_{n}^{g} v_{n}(t+1) \\
& i_{o}(t)-\delta k_{o}(t)+\beta_{i} \vec{g}_{i} \leq \sum_{n=1}^{N} \mu_{n}^{g}\left(i_{n}(t+1)-\delta k_{n}(t+1)\right) \\
& b_{o}(t)-\beta_{b} \vec{g}_{b} \geq \sum_{n=1}^{N} \mu_{n}^{b} b_{n}(t+1) \\
& y r_{o}(t) \geq \sum_{n=1}^{N} \mu_{n}^{b} y r_{n}(t+1) \\
& v_{o}(t)-\beta_{v} \vec{g}_{v} \leq \sum_{n=1}^{N} \mu_{n}^{b} v_{n}(t+1) \\
& i_{o}(t)-\delta k_{o}(t)+\beta_{i} \vec{g}_{i} \geq \sum_{n=1}^{N} \mu_{n}^{b}\left(i_{n}(t)-\delta k_{n}(t+1)\right) \\
& \sum_{n=1}^{N} \mu_{n}^{g} v_{n}(t+1)=\sum_{n=1}^{N} \mu_{n}^{b} v_{n}(t+1) \\
& \sum_{n=1}^{N} \mu_{n}^{g}\left(i_{n}(t+1)-\delta k_{n}(t+1)\right)=\sum_{n=1}^{N} \mu_{n}^{b}\left(i_{n}(t+1)-\delta k_{n}(t+1)\right)
\end{aligned}
$$

A mixed period model for evaluating a firm in $t+1$ in relation to the technology in time $t$ is estimated analogously to (4):

$\left.\vec{D}_{t+1}^{i}\left(y d_{t+1}, y r_{t+1}, b_{t+1}, k_{t+1}, v_{t+1}, i_{t+1}: \vec{g}_{y r}, \vec{g}_{b}, \vec{g}_{v}, \vec{g}_{i} \vec{g}_{i}\right)=\max _{\beta, \mu} \mu^{b} \frac{1}{N_{\vec{g}}}\left[\beta_{y r}^{3}+\beta_{b}^{3}+\beta_{v}^{3}+\beta_{i}^{3}\right]\right)$

A single period model for evaluating a firm in $t+1$ in relation to the technology in time $t+1$ is estimated analogously to (3): 
$\left.\vec{D}_{t+1}^{i}\left(y d_{t+1}, y r_{t+1}, b_{t+1}, k_{t+1}, v_{t+1}, i_{t+1}: \vec{g}_{b}, \vec{g}_{v}, \vec{g}_{i} \vec{g}_{i}\right)=\max _{\beta, \mu} \frac{1}{\mu^{b}} \frac{1}{N_{\vec{g}}}\left[\beta_{b}^{4}+\beta_{v}^{4}+\beta_{i}^{4}\right]\right)$

The measures of dynamic technical inefficiency specific to the outputs, inputs and investments are denoted by $\beta_{m}$, where $m=y r, b, v, i . \beta_{m}$ comprises measures of dynamic technical inefficiency specific to the outputs, inputs and investments. The Luenberger indicator of input-, output- and investment-specific dynamic inefficiency changes $\left(L_{m}\right)$ is computed as:

$L_{m}=\frac{1}{2}\left(\beta_{m}^{2}-\beta_{m}^{4}+\beta_{m}^{1}-\beta_{m}^{3}\right)$

The measure $L_{m}$ can be decomposed into dynamic inefficiency change $\left(T E I_{i}^{C R S}\right)$ and dynamic technical change $\left(T C_{i}\right)$ :

$T E I_{m}^{C R S}=\beta_{m}^{1}-\beta_{m}^{4}$

$T C_{m}=\frac{1}{2}\left(\beta_{m}^{4}-\beta_{m}^{3}+\beta_{m}^{2}-\beta_{m}^{1}\right)$

Input-, output- and investment-specific dynamic technical inefficiency change evaluates the position of a firm relative to the dynamic production frontier between two time periods, while dynamic technical change measures the shift of the frontier between two time periods. Input-, output- and investment-specific dynamic technical change measure the shift of best practice in the dynamic byproduction technology defined by the expansion of desirable outputs, socially responsible outputs and investments, and the reduction of undesirable outputs and inputs, between two periods of time.

The dynamic technical inefficiency change $\left(T E I_{i}^{C R S}\right)$ can be further decomposed into dynamic technical inefficiency changes under variable returns to scale (VRS), and dynamic scale inefficiency changes. The measures are computed by estimating the two single-period LP models for time $t$ and $\mathrm{t}+1$, with the addition of restriction: $\sum_{n=1}^{N} \mu_{n}^{g}=1$ and $\sum_{n=1}^{N} \mu_{n}^{b}=1$. This produces two estimates that are denoted as $\beta_{i}^{1 V R S}$ and $\beta_{i}^{4 V R S}$. The dynamic technical inefficiency changes under VRS $\left(T E I_{i}^{V R S}\right)$ are then computed as:

$T E I_{m}^{V R S}=\beta_{m}^{1 V R S}-\beta_{m}^{4 V R S}$

The dynamic scale inefficiency changes $\left(S E I_{i}\right)$ can be given by:

$S E I_{m}=\left(\beta_{m}^{1}-\beta_{m}^{4}\right)-\left(\beta_{m}^{1 V R S}-\beta_{m}^{4 V R S}\right)$ 
Dynamic scale inefficiency change $\left(S E I_{m}\right)$ evaluates the movement of firms towards or away from the optimal scale.

The input-, output- and investment-specific dynamic productivity change is decomposed into dynamic technical change $T C_{i}$, dynamic technical inefficiency change under variable returns to scale $T E I_{i}^{V R S}$, and dynamic scale inefficiency change $S E I_{i}$ :

$L_{m}=T C_{m}+T E I_{m}^{V R S}+S E I_{m}$

\subsubsection{OLS bootstrap regression}

This study investigates the association between firm-specific factors and dynamic Luenberger indicators of input-, output- and investment-specific productivity change. This is achieved by running an OLS bootstrap regression separately for each input-, output- and investment-specific Luenberger indicator. The regression equation is written as:

$$
L_{j}=f_{j} \beta+\varepsilon_{j}
$$

where $L_{j}$ is the input-, output- or investment-specific Luenberger indicator, $f_{j}$ is the vector of explanatory variables, and $\varepsilon_{j}$ is the error term that is independently and identically distributed: $\varepsilon_{j} \sim N\left(0, \delta^{2}\right)$.

Several explanatory variables affecting CSR practices and firm performance have been examined in previous studies. Margolis et al. (2009) performed a meta-analysis and found that industry, firm size and risk have been used most frequently to explain differences in performance; other variables such as research and development (R\&D) intensity, leverage, liquidity and profitability have also been reported to affect performance (Nelling and Webb, 2009). Below we provide a brief review and discussion of how various factors are related to firm performance.

\section{Size}

Firm size can improve a firm's competitive advantage through economies of scale, economies of scope or learning effects (Penrose \& Penrose, 2009). On the other hand, Robinson (1962) identified three scenarios for an inverse relation between efficiency and firm size: (1) costs caused by boredom and diminished creativity outweighing the gains from labor division; (2) reduced speed and flexibility; and (3) increased costs of coordination. As a result, the empirical evidence has been 
mixed. For example, Majumdar (1997) found a negative relation between firm size and productivity, while Kapelko and Oude Lansink (2014) and Zelenyuk and Zheka (2006) found a positive relation.

\section{Leverage}

Leverage measures the relative importance of the firm's financial stakeholders. Debtholders, as suppliers of capital to firms, can be an influential stakeholder, and hence company managers are more likely to focus on debtholders' interest than those of other stakeholders (Ullmann, 1985). On the other hand, firms with a high level of engagement in CSR may have more incentive to address the agency conflicts between shareholders and bondholders and may have lower agency costs of debt financing (Webb, 2005).

\section{Free cash flow}

Free cash flow, often measured as a cash flow to sales ratio, reflects a firm's liquidity to continue its operations and meet immediate cash demands. A high level of free cash flow indicates that a firm has sufficient financial capacity to invest and engage in sustainable initiatives without compromising the demands of economic claimants (Artiach et al., 2010; Ullmann, 1985).

\section{Profitability}

The level of profitability, measured by return on asset (ROA) in this study, influences investment decisions like increasing free cash flows (Artiach et al., 2010). When firms face low profitability, financial stakeholders will have a higher priority than other stakeholders, such as employees or the community, and hence, there will be low engagement in social programs. On the other hand, a high level of profitability may allow firms to engage in social programs without compromising the demands of financial stakeholders.

\section{Innovation and product differentiation}

Research and innovation is captured by $R \& D$ intensity, which is the ratio of $R \& D$ expenditure to total revenue. Firms address the pressure from stakeholder groups on the social and environmental consequences of their operations through their engagement to produce in a socially responsible manner (process innovation) and by producing goods that have certain socially responsible attributes (product innovation) (Martínez-Ferrero \& Frías-Aceituno, 2015; McWilliams \& Siegel, 2001). This highlights the fact that innovation may be employed to address societal concerns. 


\section{Corporate Governance System}

Corporate governance mechanisms influence corporate decisions and behavior (Aguilera \& Cuervo-Cazurra, 2004; Aguilera et al., 2008; Sánchez-Ballesta \& García-Meca, 2007). The prevailing corporate governance systems in industrialized countries include the "market-oriented" system in Anglo-Saxon countries (e.g. the USA and the UK) and the "network-oriented" system (e.g. Germany and the Netherlands) (Weimer \& Pape, 1999). A market-oriented system depends on the market, while a network-oriented system relies on networks of relationships among stakeholders. The network-oriented systems can further be differentiated into the Germanic model (e.g. Germany and the Netherlands), the Latin model (e.g. France and Italy), and the Japanese model. The different corporate governance systems lead to different sustainable practices. Network-oriented systems (Germanic or Latin ones) tend to be more socially responsible since networks of relationships between stakeholders influence the firm's decision to incorporate sustainability and social responsibility (Weimer \& Pape, 1999).

\subsection{Data description}

Data on CSR were obtained from Sustainalytics, a company assesses management systems, practices, policies and other indicators reflecting the environmental, social and governance (ESG) performance of firms. The data set provided by Sustainalytics consists of detailed indicators on favorable/positive and controversial/negative aspects of ESG. This is particularly useful when identifying measures of mitigating CSR outputs (scores for the positive indicators) and measures of undesirable outputs (scores for the negative indicators). Composite measures for socially responsible outputs $y r$ and undesirable outputs $b$ are constructed based on the favorable (positive) indicators and the controversial (negative) indicators using a method that combines principal component analysis (PCA) and data envelopment analysis (DEA), illustrated in Engida et al. (2018). The method first applies PCA to reduce the number of indicators and to construct a few uncorrelated synthesized components for each respective output. Next, DEA is used to construct composite measures for socially responsible and undesirable output using the synthesized components. Table 4.1 provides further details on the ESG indicators. 
Table 4.1. Input and output variables: description, measure, and data source

\begin{tabular}{|c|c|c|c|}
\hline Variable & Description & Indicator & Source \\
\hline$y d$ & Desirable output & Sales & Orbis \\
\hline$y r$ & $\begin{array}{l}\text { Socially } \\
\text { responsible } \\
\text { output }\end{array}$ & $\begin{array}{l}\text { Policy on Bribery and Corruption } \\
\text { Signatory to UN Global Compact } \\
\text { Board Independence } \\
\text { Policy on Freedom of Association } \\
\text { Formal Policy on the Elimination of } \\
\text { Discrimination } \\
\text { Programs to Increase Workforce Diversity } \\
\text { Formal Environmental Policy } \\
\text { Environmental Management System } \\
\text { Formal Policy or Program on Green } \\
\text { Procurement } \\
\text { Programs and Targets to Stimulate } \\
\text { Sustainable Agriculture } \\
\text { Programs \& Targets to Reduce Water Use } \\
\text { Scope of Social Supply Chain Standards }\end{array}$ & Sustainalytics \\
\hline$b$ & $\begin{array}{l}\text { Undesirable } \\
\text { output }\end{array}$ & $\begin{array}{l}\text { Business-Ethics-Related Controversies or } \\
\text { Incidents } \\
\text { Governance-Related Controversies or } \\
\text { Incidents } \\
\text { Public-Policy-Related Controversies or } \\
\text { Incidents } \\
\text { Employee-Related Controversies or } \\
\text { Incidents } \\
\text { Social Supply Chain Incidents } \\
\text { Customer-Related Controversies or } \\
\text { Incidents } \\
\text { Society-\&-Community-Related } \\
\text { Controversies or Incidents } \\
\text { Operations-Related Controversies or } \\
\text { Incidents } \\
\text { Environmental Supply Chain Incidents } \\
\text { Products-\&-Services-Related } \\
\text { Controversies or Incidents }\end{array}$ & Sustainalytics \\
\hline$v_{1}$ & Material & Material cost & Orbis \\
\hline$v_{2}$ & Labor & Employee cost & Orbis \\
\hline$k$ & Quasi fixed input & Fixed asset & Orbis \\
\hline$i$ & Investment & Cash flow from investing activities & Orbis \\
\hline
\end{tabular}

Data on desirable output, marketable output, and inputs are available from ORBIS. Sales (in US dollars) are used as a measure of the desirable output $(y d)$ and are deflated using the industrial price index for outputs. Two variable inputs and one quasi-fixed input are distinguished. The two variable inputs are material input, which is measured by costs of materials consumed, and labor input, which is measured by employment cost. Material input and labor input are deflated using the 80 
industrial price index for consumer non-durables and the labor cost index in manufacturing, respectively. The quasi-fixed input includes fixed assets and is deflated by the industrial price index for capital goods. To allow for adjustment costs, we obtain gross investments in fixed assets. We use cash flow from investing activities as a measure of gross investment. Table 4.1 provides further details on desirable (marketable) output, variable inputs and quasi-fixed inputs.

The sample includes European food-and-beverage-manufacturing companies. The data set consists of 185 observations for the period 2013 to 2016, with an average of 46 observations per year. Table 4.2 reports descriptive statistics of the variables used to estimate dynamic input-, outputand investment-specific productivity change. Desirable output (sales) and inputs (material, labor and quasi-fixed inputs) have very high variability, while undesirable and socially responsible outputs demonstrate less variability. The investment variable is characterized by large variance, which reflects the variation across years and between companies in investment activities.

Table 4.2. Descriptive statistics of pooled sample for the period 2013-201

\begin{tabular}{lcccc}
\hline & Mean & Std. Dev. & Min & Max \\
\hline Turnover & $10,300,000$ & $18,100,000$ & 106,678 & $104,000,000$ \\
Socially responsible output & 0.790 & 0.111 & 0.461 & 0.950 \\
(score) & & & & \\
Raw Material & 791,318 & $1,912,028$ & 5,388 & $14,200,000$ \\
Labor & $1,336,804$ & $2,728,742$ & 397 & $17,400,000$ \\
Fixed asset & $13,000,000$ & $28,100,000$ & 80,145 & $211,000,000$ \\
Investment & $1,038,718$ & $4,894,346$ & 6 & $60,100,000$ \\
Depreciation & 296,770 & 579,806 & 7,664 & $3,477,000$ \\
Undesirable output (score) & 0.013 & 0.044 & 0.000 & 0.393
\end{tabular}

The dynamic by-production technology in this study uses a directional distance functions with directional vectors, which were set as the observed values for variable inputs, and as unity for socially undesirable output, i.e. $\vec{g}_{b}=1, \vec{g}_{v}=v_{o}$. We set the directional vector as unity because the observed values for socially responsible output and undesirable output are scored 0 to 1 and have low variation in the data set (Table 4.2). This helps to discriminate the productivity estimates specific to socially responsible output and undesirable output. The directional vector for the investment variable was set to $20 \%$ of the capital stock, i.e. $\vec{g}_{i}=0.2 \times k_{o}$, because the actual investments can be zero and using the actual value could then preclude a solution of the DEA models. 
Once we estimate the input-, output- and investment-specific productivity change, we investigate the factors that are associated with productivity change. Several factors are identified and discussed in the previous section. Data on these factors come from the ORBIS database. In case companies had missing values in the ORBIS dataset, the data were supplemented with information from the annual reports that were recovered from the company's website. The descriptive statistics for these factors are presented in Table 4.3.

Table 4.3. Descriptive statistics of factors associated with productivity change

\begin{tabular}{llccccc}
\hline Variable & \multicolumn{1}{c}{ Description } & Units & Mean & Std. Dev. & Min & Max \\
\hline Size & $\begin{array}{l}\text { Natural log of total assets } \\
\text { Leverage }\end{array}$ & $\begin{array}{l}2013 \\
\text { USD }\end{array}$ & 15.585 & 1.588 & 12.831 & 18.775 \\
Fatio of total debt divided & $\begin{array}{l}\text { Ratio } \\
\text { to total shareholder value }\end{array}$ & 0.942 & 0.725 & 0.109 & 3.909 \\
& $\begin{array}{l}\text { Free cash flow divided by } \\
\text { net sales }\end{array}$ & Ratio & 0.119 & 0.131 & -0.747 & 0.392 \\
ROA & $\begin{array}{l}\text { Earnings Before Interest } \\
\text { and Tax (EBIT) divided by } \\
\text { total assets }\end{array}$ & Ratio & 0.090 & 0.053 & -0.051 & 0.249 \\
R\&D & $\begin{array}{l}\text { Ratio of total R\&D } \\
\text { Intensity }\end{array}$ & Ratio & 0.062 & 0.198 & 0.000 & 1.466 \\
$\begin{array}{l}\text { Market-oriented model } \\
\text { Network-oriented model }\end{array}$ & Dummy & 0.329 & 0.473 & 0.000 & 1.000 \\
\hline
\end{tabular}

Corporate governance systems are represented by a set of dummy variables indicating market-oriented (Anglo-Saxon) and network-oriented (Germanic and Latin) categories. In the regression, the network-oriented category is used as the reference group. Table 4.3 also summarizes the corporate governance system and it shows that $32.9 \%$ of the analyzed companies belong to a market-oriented system while $67.1 \%$ belongs to network-oriented system.

\subsection{Results and discussion}

\subsubsection{Estimates of dynamic input-, output- and investment-specific productivity change}

Dynamic input-, output- and investment-specific productivity change indicators and their respective decomposition are generated for each period separately (from 2013/2014 until 2015/16) for a sample of European food and beverage companies. Table 4.4 reports the decomposition of the Luenberger indicator (L) into technological change (TC), technical inefficiency change under VRS (TEIVRS), and scale inefficiency change (SEI) with regard to variable input, investment and undesirable output for the period 2013 to 2016 (arithmetic averages). 
Table 4.4. Decomposition of input-, output- and investment-specific Luenberger indicators for selected European Food and Beverage Companies, 2013-2016

\begin{tabular}{ccccc}
\hline & 2013 & 2014 & 2015 & Overall \\
\hline Variable input & & & & \\
L & -0.035 & 0.065 & -0.029 & -0.003 \\
TC & -0.009 & 0.036 & 0.033 & 0.023 \\
TEIVRS & 0.007 & 0.015 & -0.022 & -0.003 \\
SEI & -0.033 & 0.014 & -0.040 & -0.022 \\
Investment & & & & \\
L & 0.424 & -0.192 & 0.182 & 0.135 \\
TC & -0.550 & -0.070 & 2.112 & 0.772 \\
TEIVRS & -0.001 & -0.072 & -1.385 & -0.636 \\
SEI & 0.975 & -0.050 & -0.545 & -0.001 \\
Undesirable output & & & & \\
L & -0.055 & -0.011 & -0.020 & -0.027 \\
TC & -0.004 & -0.004 & -0.013 & -0.008 \\
TEIVRS & -0.075 & 0.033 & -0.041 & -0.028 \\
SEI & 0.024 & -0.041 & 0.034 & 0.009 \\
\hline
\end{tabular}

The average annual dynamic productivity growth associated with variable input during the sample period was negative and 0.003 . This implies that the use of variable input has increased by $0.03 \%$ per year during the sample period while still producing the same level of the two outputs (socially desirable and marketable). A similar pattern of dynamic productivity change and its components for variable input is observed in Kapelko et al. (2017), who investigate input-specific dynamic productivity change in European dairy manufacturing. The key factor driving the process of productivity decline is dynamic scale inefficiency change. The negative average scale inefficiency change associated with variable input $(2.2 \%)$ implies productivity has decreased because of an unfavourable change in the scale of operation. The positive technical change in variable input suggests that productivity increases by $2.3 \%$ as the technology of variable input used in the sample improves in the period under investigation. In other words, either firms change from technical regress to technical progress, or the technical progress of their variable input becomes larger in the period under investigation. The negative contribution of technical inefficiency change to productivity growth of variable input indicates that productivity on average decreased by $0.03 \%$ due to higher technical inefficiency in using variable input during the sample period. The positive contribution of 
technical change is not large enough to offset the negative scale inefficiency and technical inefficiency change on productivity growth of labour.

The average annual dynamic productivity growth associated with investment in capital during the sample period was positive and 0.135 . This implies that the potential for doing investment in capital has increased by $2.7 \%{ }^{4}\left(=0.135^{\star} 0.2^{*} 100\right)$ of the capital stock per year during the sample period while producing the same level of the two outputs. This was mainly due to scale inefficiency change. The potential for investing in capital has increased by $15.44 \%\left(=0.645^{\star} 0.2^{\star} 100\right)$ as a result of technical progress. Over the sample period, the potential for doing investment in capital has decreased by $12.72 \%\left(=0.636^{*} 0.2^{*} 100\right)$ as a result of a decline in the optimal use of available capital. Over the sample period, the potential for doing investment has decreased by $0.002 \%(=0$. $0.001^{*} 0.2{ }^{*} 100$ ) of the capital stock per year due to a decline in scale of operation.

The average annual dynamic productivity growth associated with undesirable output during the sample period was negative and 0.027 . This implies that production of undesirable output has increased by $0.0027^{5}(0.027 / 10)$ per year during the sample period while producing the same level of the two outputs. The drivers of the negative growth were technical change and technical inefficiency change. The negative average technical change implies that productivity decreased by $0.0008(=0.008 / 10)$ as the result of technological regress in undesirable output. The negative technical inefficiency change implies that productivity decreased by $0.0028(=0.028 / 10)$ because the gap between efficient and inefficient firms with regard to undesirable output increased on average. The positive average scale inefficiency change implies that productivity increased by $0.0009(0.009 / 10)$ as a result of improvement in scale of operation associated with undesirable output (i.e. following production technology movement from VRS towards CRS).

\subsubsection{OLS bootstrap regression}

The econometric equation (11) is estimated by applying the bootstrap OLS regression, described in section 2, to the pooled data. The results from the regression analyses are reported in Table 4.5, which shows the relationship between the explanatory variables and the dynamic Luenberger indicators.

\footnotetext{
${ }^{4}$ as the directional vector for investment is $20 \%$ of capital stock ${ }^{5}$ Note: Undesirable output was multiplied with a factor 10 to ease the computation process and the directional vector for socially undesirable output equals one. 
Table 4.5 Results of the OLS Bootstrap Regression on factors explaining dynamic Luenberger indicators specific to each output, to input and to investment

\begin{tabular}{lccc}
\hline & $\begin{array}{c}\text { Variable } \\
\text { input }\end{array}$ & Investment & $\begin{array}{c}\text { Undesirable } \\
\text { output }\end{array}$ \\
\hline Size & -0.004 & 0.064 & -0.012 \\
Leverage & -0.002 & -0.146 & $-0.056^{*}$ \\
FCF & 0.526 & -4.504 & -0.14 \\
ROA & $-0.738^{* *}$ & $7.952^{* *}$ & -0.091 \\
R\&D Intensity & $0.142^{*}$ & -0.485 & 0.015 \\
Market-oriented model & 0.028 & $-0.404^{*}$ & -0.016 \\
\hline
\end{tabular}

Note: Asterisks denote significance at the $10 \%\left({ }^{*}\right), 5 \%\left({ }^{* *}\right)$ and $1 \%\left({ }^{* * *}\right)$ level

A higher debt-to-equity ratio is associated with a lower productivity growth of undesirable output. Firms with high leverage have less opportunity to reduce socially undesirable output. A possible explanation for this relation could be that high-debt firms are more concerned about the obligation to pay interest and the possibility of default, and that this in turn limits investments in social programs to mitigate undesirable outputs ( Sheikh, 2018; Ullmann, 1985; Umutlu, 2010). In other words, the increase in leverage is associated with a decrease in productivity growth specific to undesirable output because a firm focuses on its short-term obligation to pay debtholders' interest rather than on dealing with undesirable output such as environmental risks.

The coefficient of ROA is negative and statistically significant for dynamic Luenberger indicator specific to variable input; indicating that an increase in ROA is associated with a decrease in productivity growth specific to variable input. This indicates that when a firm has high levels of profitability, it will have more financial means and may invest in non-rentable inputs. On the other hand, ROA has a positive and statistically significant association with the dynamic Luenberger indicator specific to investment. This indicates that the potential for doing investment in quasi fixed inputs increases with an increase in level of profitability.

The coefficient of R\&D intensity is positive and statistically significant for the dynamic Luenberger indicator specific to variable input; indicating that an increase in R\&D intensity is associated with an increase in productivity growth specific to variable input. A possible explanation for this relation could be that $R \& D$ help companies in developing new resources and capabilities that would lead to 
more efficient use of resources. In other words, $R \& D$ initiatives contribute to business value through cost control (Roberts and Dowling, 2002).

The estimated parameter of the dummy variable for a market-oriented (Anglo-Saxon) corporate governance system is negative and statistically significant for the dynamic Luenberger indicator specific to investment. This implies that firms in a market-oriented governance system have a lower potential to make investments than those in network-oriented systems.

\subsection{Conclusion}

This study contributes to the efficiency and productivity literature by evaluating productivity change that accounts for corporate social responsibility (CSR) activities. The production model integrates CSR in the production framework and it represents the transformation of multiple inputs in to desirable (marketed), socially responsible and undesirable outputs, in a dynamic context where we account for adjustment costs in quasi-fixed inputs. It further extends the decomposition of each Luenberger indicator into technical change, technical efficiency change and scale efficiency change to obtain more detailed information regarding the source of productivity change. This study illustrates the method using data of a sample of European food and beverage manufacturing firms. The results show that the average annual dynamic productivity growth associated with variable input, undesirable output and investment were $-0.003,-0.027$ and +0.135 , respectively while keeping marketable and socially desirable outputs constant. These results imply that, in order to produce the same quantity of marketable and socially desirable outputs, the use of variable input increased by $0.03 \%$, the production of undesirable output increased by 0.027 and the potential for doing investment in capital increased by $2.7 \%^{6}\left(=0.135^{*} 0.2^{*} 100\right)$ of the capital stock per year during the sample period. Hence, the results suggest a productivity decline in variable inputs and undesirable outputs and a productivity increase in investment. The negative productivity growth was mainly due to technical inefficiency change. The implication of this finding is that incentives aimed at improving productivity growth should focus on improving and promoting strategies that can help to reduce technical inefficiency.

This study also employed a bootstrap OLS regression model to investigate the association between firm-specific factors and productivity growth. The firm-level econometric estimates show a positive association between leverage and the Luenberger indicator specific to undesirable output. This finding is in line with the claim that debt limits investments on socially responsible activities and investments to deal with undesirable output due to the obligation to pay interest. ROA has a

\footnotetext{
${ }^{6}$ as the directional vector for investment is $20 \%$ of capital stock 86
} 
negative and statistically significant association with the dynamic Luenberger indicator specific to variable input, implying that firms may tend invest on non-rentable inputs during times of high profitability. On the other hand, ROA has a positive and statistically significant association with the dynamic Luenberger indicator specific to investment, implying that $t$ the potential for doing investment in quasi fixed inputs increases with an increase in level of profitability. R\&D intensity has a positive and statistically significant association with the dynamic Luenberger indicator specific to variable input. This indicates that higher $R \& D$ is associated with a higher productivity growth in variable input. This is in line with the claim that R\&D helps to develop new resources and capabilities that would lead to more efficient use of inputs. Lastly, the coefficient of a market-oriented (AngloSaxon) corporate governance system is negative and statistically significant for the dynamic Luenberger indicator specific to investment. This implies that the potential to invest is lower for firms with market-oriented systems compared to those in network-oriented systems. 


\section{References}

Aguilera, R. V., \& Cuervo-Cazurra, A. (2004). Codes of good governance worldwide: what is the trigger? Organization studies, 25(3), 415-443.

Aguilera, R. V., Filatotchev, I., Gospel, H., \& Jackson, G. (2008). An organizational approach to comparative corporate governance: Costs, contingencies, and complementarities. Organization science, 19(3), 475-492.

Artiach, T., Lee, D., Nelson, D., \& Walker, J. (2010). The determinants of corporate sustainability performance. Accounting \& Finance, 50(1), 31-51.

Chambers, R. G., Chung, Y., \& Färe, R. (1998). Profit, directional distance functions, and Nerlovian efficiency. Journal of optimization theory and applications, 98(2), 351-364.

Dakpo, K. H. (2016). On modeling pollution-generating technologies: a new formulation of the byproduction approach (No. 913-2016-72292).

Dakpo, KH, \& Lansink, AO (2019). Dynamic pollution-adjusted inefficiency under the by-production or bad outputs. European Journal of Operational Research , 276 (1), 202-211.

Engida, T. G., Rao, X., Berentsen, P. B. M., \& Oude Lansink, A. G. J. M. (2018). Measuring corporate sustainability performance- the case of European food and beverage companies. Journal of Cleaner Production, 195, 734-743.

European Commission. (2016). The competitive position of the European food and drink industry. Luxembourg: Publication Office of the European Union. [http://ec.europa.eu/DocsRoom/documents/15496/attachments/1/translations]. Accessed 2 February 2018.

Guillamon-Saorin, E., Kapelko, M., and Stefanou, S. (2018). Corporate social responsibility and operational inefficiency: A dynamic approach. Sustainability, 10(7):2277.

Kapelko, M., \& Oude Lansink, A. (2014). Examining the relation between intangible assets and technical efficiency in the international textile and clothing industry. The Journal of the Textile Institute, 105(5), 491-501.

Kapelko, M., Oude Lansink, A., \& Stefanou, S. E. (2017). Input-Specific Dynamic Productivity Change: Measurement and Application to European Dairy Manufacturing Firms. Journal of agricultural economics, 68(2), 579-599.

Majumdar, S. K. (1997). The impact of size and age on firm-level performance: some evidence from India. Review of industrial organization, 12(2), 231-241.

Margolis, J. D., Elfenbein, H., \& Walsh, J. (2009). Does it pay to be good... and does it matter? A meta-analysis and redirection of research on corporate social and financial performance. In Harvard University Working paper.

Martínez-Ferrero, J., \& Frías-Aceituno, J. V. (2015). Relationship between sustainable development and financial performance: international empirical research. Business Strategy and the Environment, 24(1), 20-39.

McWilliams, A., \& Siegel, D. (2001). Corporate social responsibility: A theory of the firm perspective. Academy of management review, 26(1), 117-127. 
Nelling, E., \& Webb, E. (2009). Corporate social responsibility and financial performance: the "virtuous circle" revisited. Review of Quantitative Finance and Accounting, 32(2), 197-209.

Oude Lansink, A. O., Stefanou, S., \& Serra, T. (2015). Primal and dual dynamic Luenberger productivity indicators. European Journal of Operational Research, $241(2), 555$.

Oude Lansink, A. O., Verstegen, J., \& Van den Hengel, J. (2001). Investment decision making in Dutch greenhouse horticulture. NJAS-Wageningen Journal of Life Sciences, 49(4), 357-368.

Paul, C. J., \& Siegel, D. S. (2006). Corporate social responsibility and economic performance. Journal of Productivity Analysis, 26(3), 207-211.

Penrose, E., \& Penrose, E. T. (2009). The Theory of the Growth of the Firm: Oxford university press.

Puggioni, D., \& Stefanou, S. (2016). The Value of Being Socially Responsible. A DEA Approach for Analyzing Efficiency and Recovering Shadow Prices of CSR Activities. Paper presented at the 2016 Annual Meeting, July 31-August 2, 2016, Boston, Massachusetts.

Roberts, P. W., \& Dowling, G. R. (2002). Corporate reputation and sustained superior financial performance. Strategic Management Journal, 23(12), 1077-1093.

Robinson, E.A.G. (1962). The structure of competitive insustry. Chicago. The University of Chicago Press.

Sánchez-Ballesta, J. P., \& García-Meca, E. (2007). Ownership structure, discretionary accruals and the informativeness of earnings. Corporate Governance: An International Review, 15(4), 677-691.

Sheikh, S. (2019). Corporate social responsibility and firm leverage: The impact of market competition. Research in International Business and Finance, 48, 496-510.

Shiu, Y. M., \& Yang, S. L. (2017). Does engagement in corporate social responsibility provide strategic insurance-like effects? Strategic Management Journal, 38(2), 455-470.

Silva, E., \& Stefanou, S. E. (2007). Dynamic efficiency measurement: theory and application. American Journal of Agricultural Economics, 89(2), 398-419.

Silva, E., \& Stefanou, S. E. (2003). Nonparametric dynamic production analysis and the theory of cost. Journal of Productivity Analysis, 19(1), 5-32.

Sun, L. and Stuebs, M. (2013). Corporate social responsibility and firm productivity: Evidence from the chemical industry in the united states. Journal of Business Ethics, 118(2)

Surroca, J., \& Tribó, J. A. (2008). Managerial entrenchment and corporate social performance. Journal of Business Finance \& Accounting, 35(5-6), 748-789.

Surroca, J., Tribó, J. A., \& Waddock, S. (2010). Corporate responsibility and financial performance: The role of intangible resources. Strategic Management Journal, 31(5), 463-490.

Ullmann, A. A. (1985). Data in search of a theory: A critical examination of the relationships among social performance, social disclosure, and economic performance of US firms. Academy of management review, 10(3), 540-557. 
Umutlu, M. (2010). Firm leverage and investment decisions in an emerging market. Quality \& Quantity, 44(5), 1005-1013.

Wang, W.-K., Lu, W.-M., Kweh, Q. L., and Lai, H.-W. (2014). Does corporate social responsibility influence the corporate performance of the us telecommunications industry? Telecommunications Policy, 38(7):580- 591.

Webb, E. (2005). Agency costs, leverage, and corporate social responsibility: A test of causality. Financial Decisions, 3(1), 1-19.

Weimer, J., \& Pape, J. (1999). A taxonomy of systems of corporate governance. Corporate Governance: An International Review, 7(2), 152-166.

Zelenyuk, V., \& Zheka, V. (2006). Corporate governance and firm's efficiency: the case of a transitional country, Ukraine. Journal of Productivity Analysis, 25(1-2), 143-157. 


\section{Chapter 5}

\section{Investment Inefficiency and Corporate Social Responsibility}

Tadesse Getacher Engida ${ }^{\text {a,. }}$ Christopher F. Parmeter ${ }^{\mathrm{c}}$, Xudong Rao ${ }^{\text {a }}$, Alfons G.J.M. Oude Lansink $^{a}$

${ }^{a}$ Wageningen University \& Research, Business economics group, Hollandseweg 1, 6706 KN, Wageningen, The Netherlands

${ }^{c}$ Department of Economics, University of Miami, Miami, FL, USA

Submitted to a journal 


\begin{abstract}
In this study, we propose the use of the stochastic frontier methodology to model the impact that corporate social responsibility (CSR) has on investment efficiency. The stochastic frontier approach aptly characterizes CSR as having a downward pull on firm level investment efficiency. We apply the approach to a sample of European listed companies, providing robust evidence that high CSR performance reduces investment inefficiency. This result is consistent with the claim that high CSR firms are characterized by low information asymmetry and high stakeholder solidarity, which may represent a source of competitive advantage and helps to reduce investment inefficiency. This study contributes to the understanding on the economic effects of CSR and provides arguments for regulatory bodies to promote CSR activities.
\end{abstract}

Keywords: Corporate social responsibility, Stochastic frontier model, Partly linear 


\subsection{Introduction}

In a world without frictions, firms can reach optimal investment levels, carrying out all positive net present value projects and forgoing all negative net present value projects (Modigliani and Miller, 1958). However, both the theoretical and empirical literature shows that there exist frictions that lead firms to deviate from their optimal levels of investment, commonly known as investment inefficiency. The prior literature suggests that one of the main sources of friction that leads to investment inefficiency is information asymmetry (Myers and Majluf, 1984). Information asymmetry between managers and shareholders can affect the cost of raising funds and project selection when they have private information. In the presence of high information asymmetry, the cost of capital firms to raise external funds will increase, which in turn induce under-investment. Hence, information asymmetry can increase investment inefficiency.

Understanding the determinants of information asymmetries is thus of great importance to firm managers. One key determinant that has received a great deal of attention is corporate social responsibility (CSR), which defines a set of corporate practices that improve the social and environmental standards of the markets in which companies operate. CSR shifts corporate goals from value maximization for shareholders towards broader satisfaction for multiple stakeholders (Paul and Siegel, 2006). The rise in firms' interest of adopting CSR is a result of the growing pressure from various stakeholder groups on firms to consider the social and environmental consequences of their operations and to provide more transparency and openness with respect to their actions (Molina-Azorín et al., 2009). Several researchers have investigated the benefits of CSR and have found evidence that CSR contributes to business value through revenue generation (McWilliams and Siegel, 2001), cost control (Roberts and Dowling, 2002), risk management (Choi and Wang, 2009), improved information quality (Cho et al., 2013, Lopatta et al., 2016) and investment efficiency (Benlemlih and Bitar, 2018). This last stream is especially salient to our work here.

It is common in the investigation of the impact of CSR on investment inefficiency to use a set of firm characteristics to estimate the parameters of the investment inefficiency distribution in a two step fashion. This two step approach begins by constructing estimates of firm level investment inefficiency, usually through a first stage regression which models firm level investment based on past sales growth, and then regresses the residual (investment inefficiency) on firm level characteristics. Recent studies that use the two step approach to investigate CSR and the distribution of investment inefficiency include Benlemlih and Bitar (2018), Zhong and Gao (2017) and Samet and Jarboui (2017). However, this approach attributes all deviations from optimal 
investment levels as investment inefficiency, and does not allow for noise, omitted variables which determine the optimal level of investment, nor misspecification of the relationship between past sales and current investment levels. These omissions most likely produce biased parameter estimates in the second stage regression. Moreover, this two-stage approach treats both positive and negative residuals in the same fashion. However, investment inefficiency is likely to work in a purely one-sided fashion, lowering optimal investment levels as financial frictions prevent firms from borrowing to invest in future project streams. Since there is no accounting for noise, it is likely this will lead to biased estimates of the impact of determinants of investment inefficiency (Wang, 2003). These biased, potentially including CSR.

As we will detail later, investment inefficiency acts as a strictly one-sided force on optimum investment levels, with additional variation in firm level investment being driven by stochastic shocks. These two disturbances then appear together and lead to overall variation in investment levels. It is important to adequately separate these effects to rigorously decipher the impact that CSR (or any other potential determinant) has on investment efficiency. This two-stage approach has been shown to be illogical and inconsistent in Wang and Schmidt (2002), Schmidt (2011), Parmeter and Kumbhakar (2014) and Parmeter et al. (2017) when applied to a composed error term.

Given this coupling of stochastic noise and pure investment inefficiency, the preferred approach is to explicitly account for the presence of investment inefficiency in the first stage investment model and to directly recover the influences of firm level characteristics. This can readily be accomplished in the stochastic frontier setting via maximum likelihood (Kumbhakar et al., 1991, Caudill and Ford, 1993, Caudill et al., 1995). Such an approach, however, typically requires specifying stringent distributional assumptions on the makeup of the composed error, which may not pass empirical scrutiny. Here we elect to go in another direction and use recently developed partly linear methods (Tran and Tsionas, 2009, Parmeter et al., 2017) to estimate both the optimum level of investment and the determinants of investment inefficiency including CSR .

In this study, we provide new evidence that enriches the debate on the value of high CSR involvement. The results of the empirical application shows that the estimated coefficient of CSR is negative and statistically significant, and it is consistent across all models including the parametric(SFA) model or the recently developed partly linear models. We estimate the two stage model for comparison, where we first estimate inefficiency from the investment model and run regression of the inefficiency on determinant variables. The two-stage model ignores the composed error structure of the investment model. Our findings here show that two stage model results in 
under-estimating (downward) the effects of the explanatory variables on investment inefficiency. Specifically, ignoring investment inefficiency from the outset leads the two stage method to understate the importance of CSR when explaining the association between CSR and investment inefficiency. This finding is consistent with the argument in Parmeter and Kumbhakar (2014) that ignoring the dependency of inefficiency and the determinants in the first stage would lead to under dispersed inefficiency estimates and the coefficients of the second stage would likely to be biased downward.

This study makes an important contribution to the debate on whether involvement in CSR is valueincreasing by demonstrating that higher CSR performance improves investment efficiency. The remainder of this chapter is organized as follows. Section 5.2 reviews the literature on investment inefficiency and CSR. Section 5.3 presents the stochastic frontier method and the empirical issues that are likely to arise with the two-stage approaches which currently dominate the literature. Section 5.4 describes our data while Section 5.5 reports the empirical results. Section 5.6 concludes the chapter.

\subsection{Investment Inefficiency and CSR Performance}

\subsubsection{Investment Inefficiency}

The literature on investment has been dominated by the $Q$ theory and accelerator theory. The $Q$ theory of investment proposes that investment opportunities could be summarized by the ratio of the market value of capital stock to its replacement cost (Tobin, 1969, Fazzari et al., 1987, Hayashi, 1985, Gertler and Gilchrist, 1994). Hayashi (1982) extends the $Q$ theory to models of investment claiming that average $Q$ can sufficiently capture investment opportunities and explain investment demand under the assumption of perfect competition, constant returns and convex costs of adjusting the capital stock with capital as the only quasi-fixed factor.

According to accelerator theory, fluctuations in sales or output motivate changes in investment. In other words, the accelerator model links the demand for capital goods to the level or change in a firm's output or sales (Fazzari et al., 1987, Abel and Blanchard, 1986). Although the $Q$ investment demand model has many attractive features, other approaches such as accelerator models have a better empirical performance (Abel and Blanchard, 1986).

In the absence of capital market imperfections and financial constraints, Tobin's $Q$ and current and past sales are sufficient to characterize optimal investment decisions of the firm. However, both 
theoretical and empirical evidence indicates that there exists frictions that lead to observed investment levels being less than the efficient (optimal) investment level (Wang, 2003, Bhaumik et al., 2012, Parmeter et al., 2017). These frictions are commonly attributed to investment inefficiency.

\subsubsection{CSR and investment Inefficiency}

CSR reflects the commitment of firms to behave responsibly by honoring ethical values and respect people, communities, and the natural environment (White, 2006). Understanding the effect of CSR involvement on investment efficiency is important because investment efficiency is critical to a firm's growth. CSR may be associated with investment inefficiency through the following channels. High CSR firms may be associated with high investment inefficiency due to low information asymmetry and better management practices due to stakeholders' consideration (stakeholders' theory). A number of studies shows that high CSR firms are associated with low information asymmetry (Cho et al., 2013, Dhaliwal et al., 2011). According to Cho et al. (2013) and Dhaliwal et al. (2011) high CSR firms consider the social and environmental consequences of their operations and disclose more information with respect to their action compared to low CSR firms. Consequently, high CSR firms are likely to be associated with more investment inefficiency due to the less information asymmetry. Firms investment is less constrained if it addresses its information problem.

Another way looking at this relationship is through stakeholder theory. The stakeholders theory considers CSR engagement as a mechanism to develop and maintain firm reputation (Cornell and Shapiro, 1987, Freeman, 2010, Cui et al., 2012, Dhaliwal et al., 2011, 2012). Meeting stakeholders' expectations helps to improve firm reputation, which in turn increases its financial performance; which is more likely because of good investment inefficiency. More formally, our main hypothesis of interest is formulated as follows:

HO: Corporate social responsibility performance is not associated with investment inefficiency

H1: Corporate social responsibility performance decreases investment inefficiency.

\subsection{Methods}

The common strategy for estimating investment inefficiency and incorporating determinants variables into the analysis is first to estimate deviations from the expected optimal investment, which is reflected in the residuals of the investment model, and then to run a regression of these 
residuals on the determinant variables. Benlemlih and Bitar (2018), Zhong and Gao (2017), Cook et al. (2019), Li and Liao (2014), Chen et al. (2011) and Biddle et al. (2009) all implement this two stage approach.

The first step suffers from omitted variable bias unless the investment frontier is correctly specified and all deviations around optimal investment represent investment inefficiency. Ignoring the dependence of investment inefficiency on determinants will lead to the estimated first-step efficiency index to be under-dispersed, and the results of the second-step regression are likely to be biased downward even when the determinants of investment and firm level characteristics are uncorrelated (Parmeter and Kumbhakar, 2014,Wang and Schmidt, 2002). To see this more explicitly, consider the simple setting of predicting optimal investment with lagged sales growth, as in Biddle et al. (2009) and Chen et al. (2011):

$$
\operatorname{Inv}_{i}=\beta_{0}+\beta_{1} \Delta \text { Sales }_{i}+\varepsilon_{i}
$$

where $\operatorname{In} v_{i}$ is firm $i$ 's investment, $\Delta$ Sales $_{i}$ is lagged sales growth for firm $i$ and $\varepsilon_{i}$ captures all other deviations from optimal investment. Estimation of equation (1) captures the investment frontier and $\varepsilon_{i}$ is variation around optimal investment. It is this metric which is termed investment inefficiency and further regressed on a set of determinants, including CSR:

$$
\hat{\varepsilon}_{i}=\alpha_{0}+\alpha_{1} C S R_{i}+\text { OtherFactors }
$$

The two main issues with this approach, as highlighted earlier, are that if any of the determinants of investment inefficiency influence actual investment levels directly, then (1) is mis-specified and this will lead to omitted variable bias. Secondly, even if we were to assume that (1) was correctly specified, treating $\hat{\varepsilon}_{i}$ as investment inefficiency ignores stochastic noise and measurement error, which implies that the true level of variation in investment inefficiency is not adequately captured in (2), leading to further biases in the estimates of $\alpha$.

The approach which we propose is to treat shocks to optimal investment as two separate components, $\varepsilon_{i}=v_{i}-u_{i}$ and to model the influence of determinants of inefficiency $(z)$ directly. This can easily be accomplished using the stochastic frontier framework. To our knowledge, this marks the first attempt to use the stochastic frontier methodology to determine CSR impact on investment inefficiency. 
The procedure estimates parameters of the relationship between inefficiency $\left(u_{i}\right)$ and determinants of inefficiency $z_{i}$ together with other parameters of the model using either a parametric stochastic frontier approach (DFA) (Kumbhakar et al., 1991, Caudill and Ford, 1993, Caudill et al., 1995) or stochastic frontier approach under semiparametric settings(Tran and Tsionas, 2009, Parmeter et al., 2017, Simar et al., 2017).

\subsubsection{Parametric Stochastic Frontier model}

Let $\left\{Y_{i t}, X_{i t}, Z_{i t}\right\}_{i}^{n}=1$ denote independently and identically distributed sample pairs of response, inputs and exogenous determinants of inefficiency where $Y_{i t}$ is a scaler, $X_{i t}$ is a $p$ dimensional vector of variables that define investment frontier, $Z_{i t}$ is of $q$ dimension and $n$ denotes the sample size. The stochastic investment frontier is represented as:

$$
Y_{i t}=X_{i t}^{\prime} \beta+V_{i t}-U\left(Z_{i t}\right)
$$

Where $u_{i t}$ is the classical idiosyncratic error term, with $E[V \mid X, Z]=E[V]=0$ and $\operatorname{Var}[V \mid X, Z]=\sigma_{V}^{2}$ and $U\left(Z_{i t}\right) \geq 0$ is the one-sided inefficiency term with $E\left(U \mid Z_{i t}\right)=g\left(Z_{i t}\right) \geq 0$.

The generic stochastic investment frontier model ignores the presence of determinants of inefficiency, and it is based on distributional assumptions for the noise and inefficiency

$$
\begin{aligned}
& V_{i} \sim N\left(0, \sigma_{V}^{2}\right) \\
& U\left(Z_{i}\right)=U_{i} \sim \mathrm{N}^{+}\left(\mu, \sigma_{V}^{2}\right)
\end{aligned}
$$

Where $\mathrm{N}^{+}($.$) is a positive truncation of the underlying normal distribution. In the presence of$ determinants of inefficiency, a normal-truncated normal model is estimated with the determinants entering the pre-truncation mean $\mu$ in an exponential fashion

$$
U\left(Z_{i}\right)=U_{i} \sim \mathrm{N}^{+}\left(\exp \left(Z_{i}, \gamma\right), \sigma_{V}^{2}\right)
$$

\subsubsection{Semi parametric stochastic frontier estimation}

A key concern with application of the stochastic investment frontier model is the reliance on the distributional assumptions for $v_{i t}$ and $u_{i t}$. If either of these assumptions were to fail there is concern that the subsequent estimates may be invalid. It is instructive to note here that if the scaling approach specification is imposed in (7) the distribution of inefficiency can be multiplicatively 
decomposed into a function of the determinants of inefficiency and a random variable whose distribution has no dependence on these characteristics.

$$
U\left(Z_{i t}\right)=U_{i t} \sim \exp \left(Z^{\prime}{ }_{i} \gamma\right) \cdot \mathrm{N}^{+}\left(\mu, \sigma^{2}\right) .
$$

With this framework, it is possible to relax the distributional assumptions and estimate expected inefficiency without requiring distributional assumptions. All model parameters can be recovered via nonlinear least square(NLS). This in turn leads to the potential for more robust conclusions regarding observation specific inefficiency. However, there is still the issue of exactly how the determinants impact investment inefficiency, i.e. the exponential specification with a linear index may not be appropriate.

Recent advances in efficiency estimation have focused on relaxing the stringent distributional assumptions on noise and inefficiency. Tran and Tsionas (2009) proposed a semiparametric stochastic frontier model with an assumption that the expected inefficiency depends on a set of covariates through an unknown but smooth function and this approach is applied in Parmeter et al. (2017). The model does not makes assumptions regarding the scaling property or the distributions of $v_{i t}$ and $u_{i t}$ if separability assumption holds and determinants of inefficiency(inefficiency function) are separable from the frontier function holds (Parmeter et al., 2017, Robinson, 1988, Tran and Tsionas, 2009). The stochastic frontier model with separable determinants of inefficiency is exactly the partly linear regression model (PLM) of Robinson (1988).

The key assumption in the PLM method is $E[U \mid X, Z]=E[U \mid Z]=g(Z)$, which forms the separability assumption. If the distribution of inefficiency depends on any of the traditional inputs of production then it is not possible to nonparametrically identify which part of the model corresponds to the production technology and which corresponds to inefficiency without imposing further restrictions (Parmeter et al., 2017, Tran and Tsionas, 2009).

The identification and estimation of the conditional mean of inefficiency is described as follows. Let $u_{i t}^{*}=u_{i t}-E\left(u_{i t} \mid z_{i t}\right)=u_{i t}-g\left(z_{i t}\right), \varepsilon_{i t}=v_{i t}-u_{i t}^{*}$. Thus, Eq.(1) can be rewritten as:

$$
Y_{i t}=Y_{i t}^{\prime} \beta-g\left(Y_{i t}\right)+\varepsilon_{i t}
$$

and by assumption $E\left(\varepsilon_{i t} \mid x_{i t}, \varepsilon_{i t}\right)=0$.

The principal interest is to consistently estimate the technical inefficiency function $g\left(Z_{i t}\right)$ and its derivative function, $\nabla g\left(Z_{i t}\right)$, which is a measure of the marginal effects of covariates on the 
technical inefficiency. The focus here is on the estimation of $g\left(Z_{i t}\right)$ without imposing distributional assumptions on $U\left(Z_{i t}\right) \mathrm{m}$, such as half normal or truncated normal.

The identification of $g\left(Z_{i t}\right)_{0}$ proceeds by noting that the model in (8) is a PLM in the model of Robinson (1988) and Fan et al.(1992). Once $\beta$ is estimated, $g\left(Z_{i t}\right)$ could then be identified. $\beta$ can be estimated as follows.

Taking conditional expectations in Eq.(8) we obtain

$$
E\left(Y_{i t} \mid z_{i t}=E\left(Y_{i t}^{\prime} \mid z_{i t}\right) \beta-g\left(Z_{i t}\right)\right. \text {. }
$$

Subtracting Eq.(9) from Eq.(8), yields

$$
\begin{aligned}
& Y_{i t}-E\left(Y_{i t} \mid z_{i t}=\left(X_{i t}-E\left[X_{i t} \mid z_{i t}\right)^{\prime} \beta+\varepsilon_{i t}\right.\right. \\
& y_{i t}=\left(x_{i t} \mid z_{i t}\right)^{\prime} \beta+\varepsilon_{i t}
\end{aligned}
$$

where $y_{i t}=Y_{i t}-E\left(Y_{i t} \mid z_{i t}\right)$ and $x_{i t}=X_{i t}-E\left(X_{i t} \mid z_{i t}\right)$.

The conditional expectations $E\left(Y_{i t} \mid z_{i t}\right)$ and $E\left(X_{i t} \mid z_{i t}\right)$ can consistently estimated by using nonparametric approaches such as kernel method and $\beta$ could be estimated by least squares.

Let $\varepsilon_{i t}=Y_{i t}-X_{i t}{ }^{\prime} \beta^{*}$ where $\beta^{*}$ is our estimator from the LS method. We then estimate the conditional mean of inefficiency $g\left(Z_{i t}\right)$ as the conditional mean of $\varepsilon_{i t}$ given $Z_{i t}$ via local-linear leastsquares. The use of a local-linear estimator allows us to estimate gradients of the conditional mean inefficiency and helps to determine the effect of each $Z$ variables on the conditional mean inefficiency.

The PLM method can be applicable especially in estimating investment efficiency and its determinants since investment literature distinguishes real decision variables (that define the frontier) from financial friction variables (of the inefficiency function). This method estimates unobserved maximum investment and determine the shortfall of actual investment from the maximum level. The shortfall indicates the presence of investment inefficiency which could be attributed to financial constraints. 


\subsubsection{Model specification}

\subsubsection{Investment frontier}

Capital markets are imperfect due to informational problems, and capital investment is no longer determined only by fundamentals such as Tobin's $Q$ and current and past sales (Fazzari and Petersen, 1993). All things equal, financing constraints limit investment below the neoclassical level. Therefore, the effect of capital market imperfections is one-sided and pushes investment to go below, but never above, the frictionless level. It is with this justification that financing constraints could be investigated using the SFA approach. With a neoclassical model describing the investment frontier, the level of financing constrained investment is evaluated as a deviation from the frontier, with the option of modelling the one sided deviation as a function of firm characteristics (Wang, 2003). The degree of investment inefficiency is estimated using the difference between the frontier and the actual level of investment. This difference is attributed to investment inefficiency and it can be represented by a non- negative term $u_{i t}$. In keeping with this, Wang (2003) a firm's investment decision can be defined as follows:

$$
Y_{i t}=X_{i t}^{\prime} \beta+V_{i t}-U_{i t}
$$

Where $Y_{i t}$ is defined as $\ln \left(I_{i t} / K_{i t}\right) ; X_{i t}: \ln \left(Q_{i t}\right), \ln \left(\frac{\text { sales }_{i t}}{K_{i t}}\right), \ln \left(\right.$ Sales $\left._{i t-1} / K_{i t-1}\right)$ and $I_{i t}$ is the capital expenditure from the cash flow statement, $Q_{i t}$ is Tobin's $Q$ for investment opportunities. Sales $_{i t}$ is the net sales from firm $i$. Note that each variable is divided by the firm's capital in order to control for size effects (Wang, 2003, Fazzari et al., 1987, Bhaumik et al., 2012).

Model in Eqs. (12) define the stochastic frontier formulation of the investment function, and can be estimated using semi parametric without imposing distributional assumptions or using parametric with underlying the distributional assumptions on $V_{i t}$ and $U_{i t}$ that were discussed earlier.

The components of vector $X_{i t}$ in Eq. (12) is based on the the discussion that a firm's investment decisions depend on its future prospect, which is captured by Tobin's q, and possibly also by its current and past sales in accord with the accelerator hypothesis of investment as sales captures the output effect (i.e., current sales promote current investment and predict future sales). 


\subsubsection{Firm characteristics ( $Z$ variables)}

The $Z$ variables are firm characteristics that affect financial constraint of firms. Cash flow and total asset variables are emphasized in the literature as significant factors affecting firm's investment inefficiency (Wang, 2003, Parmeter et al., 2017). Regarding cash flow, firm's investment would be higher if it has higher level of internal funds. Firms with larger assets are capable of providing collateral that in turn mitigates information asymmetry and ease financial constraints. On the contrary, firms with increased size might have lower investment opportunities. Including CSR variable as Z variable allow us to determine the effect of CSR on the conditional mean of investment inefficiency.

We accommodate these $Z$ variables into the model via the inefficiency term $U\left(Z_{i t}\right)$ and our empirical model is specified as:

$$
Y_{i t}=X_{i t}^{\prime} \beta+V_{i t}-U_{i t}
$$

where $Y_{i t}$ is defined as $\ln \left(I_{i t} / K_{i t}\right) ; X_{i t}: \ln \left(Q_{i t}\right), \ln \left(\frac{\text { sales }_{i t}}{K_{i t}}\right), \ln \left(\right.$ Sales $\left._{i t-1} / K_{i t-1}\right), r G D P_{i t}, r G D P_{i t-1}$, $\tau_{i t}$ and $Z_{i t}: C S R_{i t},\left(C F_{i t} / K_{i t}\right), \ln \left(\right.$ Assets $\left._{i t}\right), I_{i t}$ is the capital expenditure from the cash the cash flow statement, $Q_{i t}$ is Tobin's $Q$ for investment opportunities, Sales $i t$ is the net sales from firm $i, r G D P_{i t}$ is the growth rate of real GDP, $\tau_{i t}$ is a time trend, $C S R_{i t}$ is corporate social responsibility score of firm $i, C F_{i t}$ is the cash flow of firm $i$, and Assets $s_{i t}$ is the firm's fixed assets. In order to control for size effects, all variables, except for Assets $s_{i t}$ are divided by the firm's capital $K_{i t}$. The $X_{i t}$ vector include Tobin's $Q$ and sales variable. The $Z_{i t}$ vector contains corporate social responsibility $(\mathrm{CSR})$, the cash flow ratio variable(CF) and the total assets variable(Assets).

We used the scaling specification in Eqs. (7) and the partly linear method to determine investment inefficiency and investigate the effect of corporate social responsibility on investment inefficiency. We also estimate alternative models which make distributional assumptions for comparison. The empirical application uses data from a sample of European listed companies. The data is obtained from ORBIS and Sustainalytics for the time period of 2009 to 2016, and the data is treated as pooled cross sections.

\subsection{Data description}

We obtain financial data from the ORBIS database. The data consist of the following variables. These include investment defined as capital expenditures from the cash flow statement (I), Tobin's 104 
$Q$, sales, the cash flow $(\mathrm{CF})$, and fixed assets. In order to control for size effects, all these variables, except for fixed assets are divided by the firm's capital(K). Data on the growth of real GDP(rGDP) is obtained from the world bank database. The growth in real GDP helps to capture the economic environment the firm operates.

Data on corporate social responsibility (CSR) were obtained from Sustainalytics ${ }^{7}$. According to Sustainalytics, CSR broadly addresses companies' management systems, practices, policies, and other indicators reflecting environmental, social, and governance (ESG) performance of firms. CSR reflects a balanced view of performance on the environmental, the social and the corporate governance dimensions. The environmental dimension looks at how well a firm uses best management practices to deal with environmental risks. It covers categories including: operations, contractors supply chain, and products and services. The social dimension is a reflection of how a company manages relationships with its employees, suppliers, customers and the communities where it operates. It covers categories including employees, contracts supply chain, consumers, society community and philanthropy. The governance dimension deals with a company's leadership, audits and internal controls, and shareholder rights. It covers three categories including business ethics, corporate governance and public policy. The dataset provided by Sustainalytics consists of detailed scores for the different indicators across Environment, Social and Governance dimensions of CSR performance. Sustainalytics groups firms into different peer industry groups and weights of indicators are uniquely defined for every peer group that reflects the relative importance given to the indicators. Every peer group is assessed for a fixed number of core indicators. In addition to the core indicators, sector-specific indicators are assigned to each peer group. For the core and sectorspecific indicators, firms are assigned with a raw score between 0 and 100 where 0 denotes a very poor performance and 100 denotes an excellent performance. To construct CSR, Governance, Social and environmental index, we select relevant indicators and aggregate them into a weighted score using the system of weights form Sustainalytics dataset.

We winsorize the data at the 1st and 99th percentile levels to reduce effects of possibly spurious outliers. In Table 1, we report the summary statistics of the variables we use in our analysis, including the first quartile, median, third quartile, mean and standard deviation. CSR has a mean

\footnotetext{
$7 \mathrm{http}: / /$ www.sustainalytics.com/ "Sustainalytics is an award winning global responsible investment research firm specialized in environmental, social and governance (ESG) research and analysis. The firm offers global perspectives and solutions that are underpinned by local expertise, serving both values-based and mainstream investors that integrate ESG information and assessments into their investment decisions."
} 
value of 55.28 and standard deviation of 19.726 , indicating significant variation concerning the CSR involvement.

Table 5.2. Descriptive statistics of variables

\begin{tabular}{|c|c|c|c|}
\hline & Description & Mean & SD \\
\hline \multicolumn{4}{|l|}{$X$ variables } \\
\hline $\ln (\mathrm{l} / \mathrm{K})$ & Investment to capital ratio & -1.250 & 1.135 \\
\hline $\ln ($ TobinQ) & $\begin{array}{l}\text { Total market value divided } \\
\text { by total asset value of a firm }\end{array}$ & -0.111 & 0.796 \\
\hline $\ln ($ Sales/K) & Ratio of sales to capital & 1.558 & 1.047 \\
\hline $\ln ($ Sales-1/K-1) & $\begin{array}{l}\text { Ratio of sales divided by } \\
\text { lagged capital }\end{array}$ & 1.561 & 1.018 \\
\hline Rgdp & $\begin{array}{l}\text { Real GDP growth(annual } \\
\text { percentage change) }\end{array}$ & 1.568 & 2.960 \\
\hline rGDP-1 & $\begin{array}{ll}\text { Lagged Real } & \text { GDP } \\
\text { growth(annual } & \text { percent- } \\
\text { age change) } & \end{array}$ & 1.398 & 3.095 \\
\hline \multicolumn{4}{|l|}{$Z$ variables } \\
\hline$(\mathrm{CF} / \mathrm{K})$ & $\begin{array}{l}\text { Free cash flow divided by } \\
\text { Capital }\end{array}$ & 0.845 & 1.863 \\
\hline $\ln$ (Assets) & $\begin{array}{l}\text { Natural log of total assets } \\
\text { Ratio }\end{array}$ & 15.458 & 1.589 \\
\hline CSR & Score $[0,100]$ & 55.280 & 19.726 \\
\hline Governance & Score $[0,100]$ & 15.250 & 5.938 \\
\hline Social & Score $[0,100]$ & 20.663 & 7.442 \\
\hline Environment & Score $[0,100]$ & 18.650 & 7.991 \\
\hline
\end{tabular}

\subsection{Results and discussion}

The results of estimated models with the aim of assessing the relation between CSR and investment are presented in Table 5.2. The key findings indicate that Tobin's $Q$ has a statistically significant coefficient at the $1 \%$ level indicating Tobin's $Q$ is significant in explaining investment behavior with an elasticity of around 0.04-0.23. This implies that one percent increase in Tobin's $Q$ is associated with $0.04-0.23 \%$ increase in investment to capital ratio. The NLS estimates consistent with (7) indicate that cumulative sales is positively associated with firm investment. Looking at the partly linear estimates as described in Eqs. (8-11), the cumulative effect of sales also has a positive effect on firm investment. The lagged sales is positively related with firm investment whereas current sales 106 
is negatively associated with investment. This finding is consistent with a relationship found in Abel and Blanchard (1986), Bhaumik et al. (2012) and Parmeter et al. (2017). The lagged sales have elasticity of around $0.13-0.80$. This indicate that one percent increase in lagged sales to capital ratio is related with a $0.13-0.80 \%$ increase in investment to capital ratio. The accelerator effect of sales on investment appears to have effect with a time lag. The current and lagged economic environment appears to have an economically negligible effect on investment.

We now turn to the factors that alleviate or aggravate the friction from optimal investment, i.e. investment inefficiency. The coefficients of these variables are robust and consistent across estimation methodologies and specifications and,hence, are meaningful. Cash flow and asset size are shown to have an economically meaningful and positive association with the degree of investment inefficiency. This indicates that most financially successful and least constrained firms in our sample do not rely on internal cash flow. Financially least constrained firms tend to utilize cheaper external funds and would in turn have high level of cash flow. Regarding size, large firms are more likely to have lower growth opportunities and tend to reduce investment activities (Benlemlih and Bitar, 2018). The lower growth opportunities with large size firms could explain why firm's size is associated with high investment inefficiency.

The estimates across models which were used to analyse whether CSR performance is associated with investment inefficiency are shown in Table 5.2 under determinants of investment inefficiency. The estimated coefficient of CSR is negative and statistically significant, and it is consistent across all models including PLM. The negative coefficient indicates that a higher CSR performance is associated with lower investment inefficiency. A plausible explanation for this is that firms with higher CSR enjoy lower information asymmetry and higher stockholder's solidarity improving management quality and helping to address financial constraints (investment inefficiency). This explanation is consistent with the findings of Cho et al. (2013) and Cui et al. (2018) that high CSR firms provide extra financial information that helps to reduce information asymmetry and provide a more accurate image regarding their performance.

There is also an emergence of numerous voluntary reporting standards that provide relevant information about companies' CSR practices and standardise their disclosure. In addition, third party disclosure on CSR performance provides new information beyond that reported by firms' voluntary CSR disclosures. Such disclosures increase firms' transparency that in turn, help to reduce information asymmetry (Cho et al., 2013, Cai et al., 2016). A number of empirical studies has indicated the beneficial influence of information disclosure on improving investment efficiency 
(Biddle and Hilary, 2006, Biddle et al., 2009, Gomariz and Ballesta, 2014). The role of CSR can also be explained in light of the stakeholder theory. Freeman (2010) and Cornell and Shapiro (1987) argue that failing to meet stakeholders' expectations is more likely to generate market fears, which in turn will result in the loss of profit opportunities for the firm. CSR related multi stakeholder welfare targets, may help to meet implicit claims of stakeholders and reduce information asymmetry, thereby decreasing investment inefficiency. Therefore, the implementation of CSR strategy does not only improve firms' sustainability but it also enhances competitive position (Whitehouse, 2006, Samet and Jarboui, 2017).

The results of the two stage approach is included in the appendix for comparison. In the two stage procedure, we first estimate investment inefficiency and run regression of the inefficiency on determinant variables. Looking at the results in the appendix, the two stage approach procedure results in under-estimating (downward) the effect of the explanatory variables. It understates the importance of CSR when explaining the association between CSR and investment inefficiency. This is consistent with the claim that ignoring the dependency of inefficiency and the determinants in the first stage would lead to under dispersed inefficiency estimates and the coefficients of the second stage are likely to be biased downward as indicated in Parmeter and Kumbhakar (2014) and Wang (2002). 
Table 5.2. Estimation results

\begin{tabular}{|c|c|c|c|c|c|c|c|}
\hline & SFA(No Z) & SFA(a) & $\mathrm{SFA}(\mathrm{b})$ & NLS(a) & NLS(b) & PLM (a) & PLM (b) \\
\hline & \multicolumn{7}{|c|}{ Investment frontier parameters } \\
\hline $\ln ($ TobinQ) & $\begin{array}{l}0.23^{* * * *} \\
(0.031)\end{array}$ & $\begin{array}{l}0.125^{* * * *} \\
(0.036)\end{array}$ & $\begin{array}{l}0.124^{* * *} \\
(0.037)\end{array}$ & $\begin{array}{l}0.194^{* * * *} \\
(0.032)\end{array}$ & $\begin{array}{l}0.194^{* * * *} \\
(0.032)\end{array}$ & $\begin{array}{l}0.078 \\
(0.061)\end{array}$ & $\begin{array}{l}0.042 \\
(0.099)\end{array}$ \\
\hline $\ln ($ Sales $/ K)$ & $\begin{array}{l}0.217^{* * *} \\
(0.094)\end{array}$ & $\begin{array}{l}0.115 \\
(0.077)\end{array}$ & $\begin{array}{l}0.112 \\
(0.088)\end{array}$ & $\begin{array}{l}0.115 \\
(0.09)\end{array}$ & $\begin{array}{l}0.114 \\
(0.09)\end{array}$ & $\begin{array}{l}-0.435^{* *} \\
(0.124)\end{array}$ & $\begin{array}{l}-0.348^{*} \\
(0.206)\end{array}$ \\
\hline $\ln ($ Sales- $1 / \mathrm{K}-1)$ & $\begin{array}{l}0.277^{* * * *} \\
(0.094)\end{array}$ & $\begin{array}{l}0.131 \\
(0.082)\end{array}$ & $\begin{array}{l}0.13 \\
(0.092)\end{array}$ & $\begin{array}{l}0.205^{* *} \\
(0.09)\end{array}$ & $\begin{array}{l}0.204^{* * *} \\
(0.091)\end{array}$ & $\begin{array}{l}0.575^{* * * *} \\
(0.12)\end{array}$ & $\begin{array}{l}0.799^{* * * *} \\
(0.221)\end{array}$ \\
\hline rGDP & $\begin{array}{l}0.009 \\
(0.017)\end{array}$ & $\begin{array}{l}0.009 \\
(0.015)\end{array}$ & $\begin{array}{l}0.009 \\
(0.016)\end{array}$ & $\begin{array}{l}0.007 \\
(0.015)\end{array}$ & $\begin{array}{l}0.006 \\
(0.016)\end{array}$ & $\begin{array}{l}-0.013 \\
(0.015)\end{array}$ & $\begin{array}{l}0.012 \\
(0.023)\end{array}$ \\
\hline rGDP-1 & $\begin{array}{c}-0.0003 \\
(0.012)\end{array}$ & $\begin{array}{l}-0.01 \\
(0.011)\end{array}$ & $\begin{array}{l}-0.01 \\
(0.012)\end{array}$ & $\begin{array}{l}-0.008 \\
(0.011)\end{array}$ & $\begin{array}{l}-0.009 \\
(0.011)\end{array}$ & $\begin{array}{l}0.005 \\
(0.009)\end{array}$ & $\begin{array}{l}0.002 \\
(0.01)\end{array}$ \\
\hline & \multicolumn{7}{|c|}{ Determinants of investment inefficiency } \\
\hline $\mathrm{CF} / \mathrm{K}$ & & $\begin{array}{l}0.372^{\text {**** }} \\
(0.034)\end{array}$ & $\begin{array}{l}0.373^{* * * *} \\
(0.035)\end{array}$ & $\begin{array}{l}0.124^{* * * *} \\
(0.011)\end{array}$ & $\begin{array}{l}0.126^{* * * *} \\
(0.011)\end{array}$ & & \\
\hline $\ln$ (Assets) & & $\begin{array}{l}0.038^{* * *} \\
(0.018)\end{array}$ & $\begin{array}{l}0.036^{*} \\
(0.019)\end{array}$ & $\begin{array}{l}0.044^{* * * *} \\
(0.007)\end{array}$ & $\begin{array}{l}0.044^{* * * *} \\
(0.007)\end{array}$ & & \\
\hline CSR & & $\begin{array}{l}-0.846 \\
0.147)\end{array}$ & & $\begin{array}{l}-0.612^{* * * *} \\
(0.096)\end{array}$ & & & \\
\hline GOV & & & $\begin{array}{l}-0.562 \\
(0.597)\end{array}$ & & $\begin{array}{l}-0.48 \\
(0.355)\end{array}$ & & \\
\hline SOC & & & $\begin{array}{l}-1.347^{* * * *} \\
(0.532)\end{array}$ & & $\begin{array}{l}-0.891^{* *} \\
(0.371)\end{array}$ & & \\
\hline ENV & & & $\begin{array}{l}-0.569 \\
(0.4598)\end{array}$ & & $\begin{array}{l}-0.47 \\
(0.296)\end{array}$ & & \\
\hline
\end{tabular}

Significance *** $1 \%$ level, $* * 5 \%$ level; * $10 \%$ level

In order to better understand the dimensions that have consistent effect on investment inefficiency, we disaggregate CSR performance into its dimensions and estimate separate models. The results are reported in Table 5.2 as SFA(b), NLS(b). We find social dimension has a negative and significant effect on investment inefficiency. However, governance and environmental dimensions exhibits an insignificant effect. Thus, the empirical result shows that the key role of CSR in reducing investment inefficiency is mainly driven by social dimension.

We investigate the gradients of the conditional mean inefficiency in order to properly compare the insights of the two specifications (NLS and PLM). Because the models have gradients which vary with the level of the covariates, Table 5.3 presents the median, upper and lower quartile estimates across NLS and PLM models. 
Table 5.3. shows the following insights. The impact of assets and cash flow on investment inefficiency is consistent across the models and is relatively constant. CSR has a negative impact on the investment inefficiency, and thus firms with larger CSR performance have lower levels of investment inefficiency. Moreover, both the NLS and PLM models suggest a negative effect of governance, social and environmental dimension on investment inefficiency, and thus firms with higher performance in the CSR dimensions have lower levels of investment inefficiency.

Table 5.3. Median estimated gradients of conditional inefficiency for NLS and PLM models

\begin{tabular}{llllc}
\hline & NLS $(\mathrm{a})$ & $\mathrm{NLS}(\mathrm{b})$ & $\mathrm{PLM}(\mathrm{a})$ & $\mathrm{PLM}(\mathrm{b})$ \\
\hline CF/K & 0.189 & 0.189 & 0.731 & 0.283 \\
& $(0.17,0.207)$ & $(0.170,0.207)$ & $(0.515,0.960)$ & $(-0.05,0.593)$ \\
In(Assets) & 0.067 & 0.066 & 0.013 & 0.034 \\
& $(0.060,0.073)$ & $(0.059,0.072)$ & $(-0.050,0.124)$ & $(-0.086,0.137)$ \\
CSR & -0.929 & & -0.715 & \\
& $(-1.019,-0.838)$ & & $(-1.350,-0.060)$ & \\
GOV & & -0.722 & -0.667 \\
& & $(-0.792,-0.651)$ & & $-(-3.666,2.899)$ \\
SOC & -1.340 & -0.169 \\
& & $(-1.470,-1.207)$ & & $-1.930,2.451)$ \\
ENV & -0.707 & $(-3.718,0.853)$ \\
\hline
\end{tabular}

Upper and lower quartiles appear in parentheses beneath each median

Fig 5.1. present a $45^{\circ}$ plot of the gradients of the conditional mean of investment inefficiency for assets, cash flow and CSR. $45^{\circ}$ plots are useful tool to visualize results in nonlinear regression models. "These plots will easily allow the user to distinguish where a bulk of the effects lie, which effects are significant and which effects are insignificant." (Henderson et al., 2012). The plot consist of the gradient estimates plotted against themselves (the $45^{\circ}$ line) represented with circles together with their upper and lower confidence bounds (in this case the $95 \%$ confidence bound) represented with triangles. The majority of the significant effects for asset and cash flow are positive while the majority of the significant effects for CSR being negative. Twenty one of our 1461 observations produced estimated gradients for firm assets which were negative and statistically significant. Sixteen out of 1461 observation have estimated gradients for cash flow were negative and statistically significant. Only two observations have estimated positive gradients for CSR. 

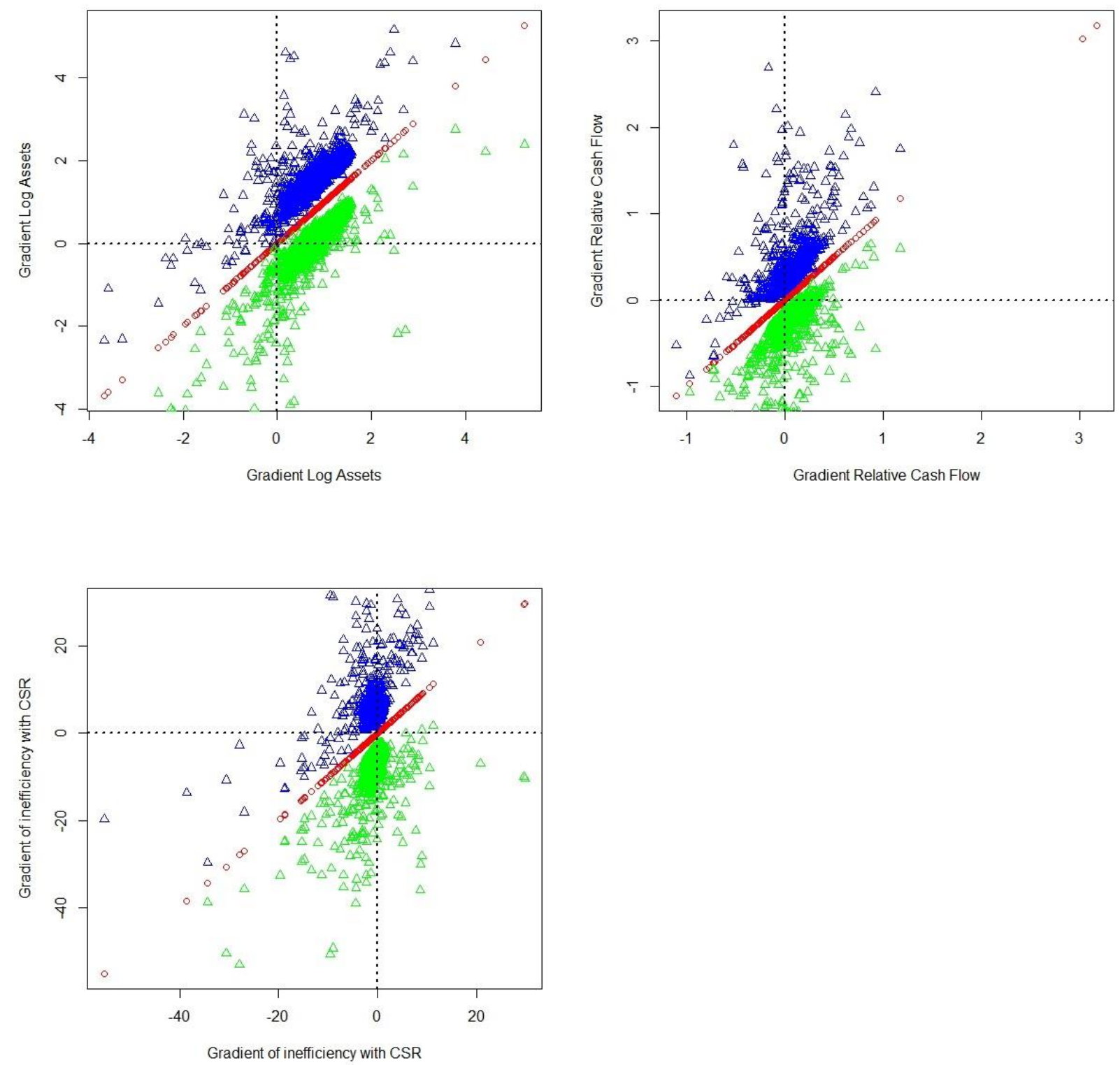

Fig 5.1. $45^{\circ}$ plot of significant gradient effects for asset, cash flows and CSR. Significance is at the 95\% level. Circles represent the gradient estimates while the triangles are the upper and lower bootstrap confidence interval.

Fig. 5.2. present the $45^{\circ}$ plot of the gradients of the conditional mean of investment inefficiency for the three dimensions of CSR: governance(GOV), social(SOC) and environmental(ENV) dimensions. The plots consist of the gradient estimates plotted against themselves (the $45^{\circ}$ line) represented with circles, together with their lower and upper confidence interval (95\% confidence interval) represented with green and blue triangles, respectively. All plots reveal substantial heterogeneity in the effects of these three covariates on investment inefficiency, with a majority of the significant effects being negative. 

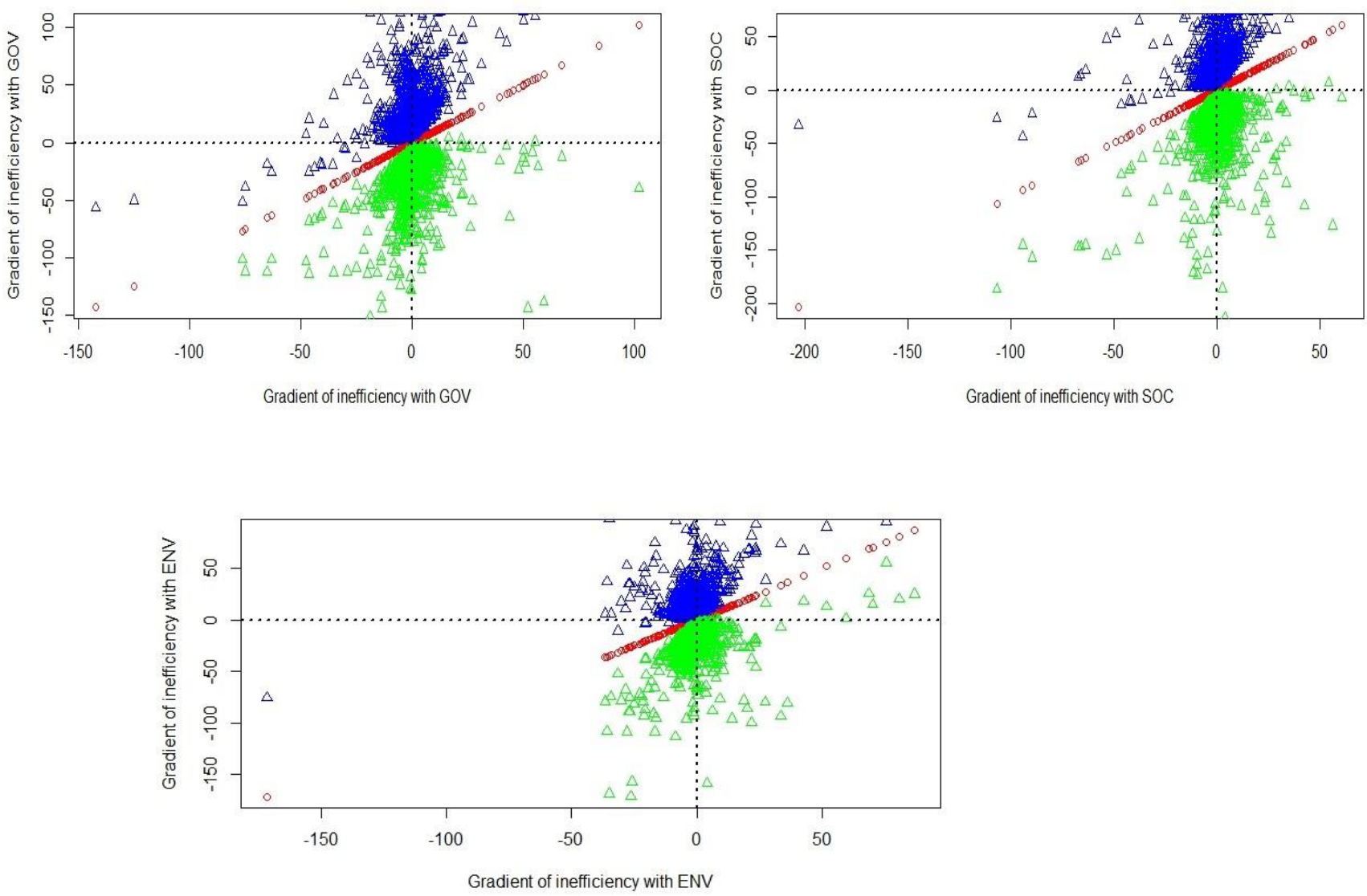

Fig. 5.2. $45^{\circ}$ plot of significant gradient effects for components of CSR. Significance is at the 95\% level. Circles represent the gradient estimates while the triangles are the upper and lower bootstrap confidence bound. 


\subsection{Conclusion}

We employ a semiparametric method to investigate the effect of CSR on firms' investment inefficiency. The model that we used stems from recent advances in semiparametric stochastic frontier analysis that do not require distributional assumptions on the composed errors. In other words, the stochastic frontier and the conditional mean of inefficiency are estimated without imposing any distributional assumptions. The main advantage of the semi parametric approach is that we are not only able to determine whether or not the average firm is financially constrained without imposing distributional assumptions, but we are also able to estimate a measure of the degree of the constraint for each firm and determine the marginal effect of corporate social responsibility on this measure.

The empirical analysis applies a sample of European listed companies, for the time period of 2009 to 2016, and the data is treated as pooled cross sections. This study provides strong and robust evidence that higher CSR performance is associated with lower reduces investment inefficiency. This result strengthens the idea that high CSR firms enjoy low information asymmetry and high stakeholder solidarity, which may represent a source of competitive advantage and helps to reduce investment inefficiency. This study contributes to our understanding on the economic effects of CSR and provides arguments for relevant stakeholders to promote CSR initiatives.

The semiparametric stochastic frontier provides us with a powerful approach to investigate financial constraint and analyse the effect of CSR. This approach requires less assumptions and involves much easier, faster and numerically more robust computations. A wider adoption of this approach is important to improve the investigation of financial constraints (investment inefficiency) that has grown interest since the financial crisis of 2008-2009. An important practical implications can also be derived from results of this study that the development and implementation of CSR strategies is crucial to improve firm growth and safeguard interests of different stakeholders. Therefore, firms' need to integrate social and environmental issues in their strategies as they helps to move towards decisions that are better for the business and the society. 


\section{References}

Abel, A. B. and Blanchard, O. J. (1986). Investment and sales: Some empirical evidence. In Barnett, W., Berndt, E., and White, H., editors, Dynamic Econometric Modeling: Proceedings of the Third International Symposium in Economic Theory and Econometrics (International Symposia in Economic Theory and Econometrics, pages 269-296.

Benlemlih, M. and Bitar, M. (2018). Corporate social responsibility and investment efficiency. Journal of Business Ethics, 148(3):647-671.

Bhaumik, S. K., Das, P. K., and Kumbhakar, S. C. (2012). A stochastic frontier approach to modelling financial constraints in firms: An application to india. Journal of Banking \& Finance, 36(5):1311-1319.

Biddle, G. C. and Hilary, G. (2006). Accounting quality and firm-level capital investment. The Accounting Review, 81(5):963-982.

Biddle, G. C., Hilary, G., and Verdi, R. S. (2009). How does financial reporting quality relate to investment efficiency? Journal of Accounting and Economics, 48(2-3):112-131.

Cai, L., Cui, J., and Jo, H. (2016). Corporate environmental responsibility and firm risk. Journal of Business Ethics, 139(3):563-594.

Caudill, S. B. and Ford, J. M. (1993). Biases in frontier estimation due to heteroscedasticity. Economics Letters, 41(1):17-20.

Caudill, S. B., Ford, J. M., and Gropper, D. M. (1995). Frontier estimation and firm-specific inefficiency measures in the presence of heteroscedasticity. Journal of Business \& Economic Statistics, 13(1):105-111.

Chen, F., Hope, O.-K., Li, Q., and Wang, X. (2011). Financial reporting quality and investment efficiency of private firms in emerging markets. The Accounting Review, 86(4):12551288.

Cho, S. Y., Lee, C., and Pfeiffer Jr, R. J. (2013). Corporate social responsibility performance and information asymmetry. Journal of Accounting and Public Policy, 32(1):71-83.

Choi, J. and Wang, H. (2009). Stakeholder relations and the persistence of corporate financial performance. Strategic Management Journal, 30(8):895-907.

Cook, KA, Romi, AM, Sanchez, D., \& Sanchez, JM (2019). The influence of corporate social responsibility on investment efficiency and innovation. Journal of Business Finance \& Accounting , 46 (3-4), 494-537.

Cornell, B., \& Shapiro, A. C. (1987). Corporate stakeholders and corporate finance. Financial management, 5-14.

Cui, J., Jo, H., \& Na, H. (2012). Does corporate social responsibility reduce information asymmetry. Journal of Banking and Finance, 1-43.

Cui, J., Jo, H., and Na, H. (2018). Does corporate social responsibility affect information asymmetry? Journal of Business Ethics, 148(3):549-572.

Dhaliwal, D. S., Li, O. Z., Tsang, A., and Yang, Y. G. (2011). Voluntary nonfinancial disclosure and the cost of equity capital: The initiation of corporate social responsibility reporting. The Accounting Review, 86(1):59-100. 
Dhaliwal, D. S., Radhakrishnan, S., Tsang, A., and Yang, Y. G. (2012). Nonfinancial disclosure and analyst forecast accuracy: International evidence on corporate social responsibility disclosure. The Accounting Review, 87(3):723-759.

Fazzari, S., Hubbard, R. G., and Petersen, B. C. (1987). Financing constraints and corporate investment.

Fazzari, SM, \& Petersen, BC (1993). Working capital and fixed investment: new evidence on financing constraints. The RAND Journal of Economics , 328-342.

Freeman, R. E. (2010). Strategic management: A stakeholder approach. Cambridge University Press.

Gertler, M. and Gilchrist, S. (1994). Monetary policy, business cycles, and the behavior of small manufacturing firms. The Quarterly Journal of Economics, 109(2):309-340.

Gomariz, M. F. C. and Ballesta, J. P. S. (2014). Financial reporting quality, debt maturity and investment efficiency. Journal of Banking \& Finance, 40:494-506.

Hayashi, F. (1982). Tobin's marginal $q$ and average $q$ : A neoclassical interpretation. Econometrica: Journal of the Econometric Society , 213-224.

Hayashi, F. (1985). Corporate finance side of the q theory of investment. Journal of Public Economics, 27(3):261-280.

Henderson, D. J., Kumbhakar, S. C., and Parmeter, C. F. (2012). A simple method to visualize results in nonlinear regression models. Economics Letters, 117(3):578-581.

Kumbhakar, S. C., Ghosh, S., and McGuckin, J. T. (1991). A generalized production frontier approach for estimating determinants of inefficiency in us dairy farms. Journal of Business \& Economic Statistics, 9(3):279-286.

Li, K.-F. and Liao, Y.-P. (2014). Directors' and officers' liability insurance and investment efficiency: Evidence from taiwan. Pacific-Basin Finance Journal, 29:18-34.

Lopatta, K., Buchholz, F., and Kaspereit, T. (2016). Asymmetric information and corporate social responsibility. Business \& Society, 55(3):458-488.

McWilliams, A. and Siegel, D. (2001). Corporate social responsibility: A theory of the firm perspective. Academy of Management Review, 26(1):117-127.

Modigliani, F. and Miller, M. H. (1958). The cost of capital, corporation finance and the theory of investment. The American Economic Review, 48(3):261-297.

Molina-Azorín, J. F., Claver-Cortés, E., López-Gamero, M. D., and Tarí, J. J. (2009). Green management and financial performance: a literature review. Management Decision, 47(7):1080-1100.

Myers, S. C. and Majluf, N. S. (1984). Corporate financing and investment decisions when firms have information that investors do not have. Journal of Financial Economics, 13(2):187-221.

Parmeter, C. F. and Kumbhakar, S. C. (2014). Efficiency analysis: a primer on recent advances. Foundations and Trends $R$ in Econometrics, 7(3-4):191-385.

Parmeter, C. F., Wang, H.-J., and Kumbhakar, S. C. (2017). Nonparametric estimation of the determinants of inefficiency. Journal of Productivity Analysis, 47(3):205-221. 
Paul, C. J. and Siegel, D. S. (2006). Corporate social responsibility and economic performance. Journal of Productivity Analysis, 26(3):207-211.

Roberts, P. W. and Dowling, G. R. (2002). Corporate reputation and sustained superior financial performance. Strategic Management Journal, 23(12):1077-1093.

Robinson, P. M. (1988). Root-n-consistent semiparametric regression. Econometrica, pages 931-954. Samet, M. and Jarboui, A. (2017). How does corporate social responsibility contribute to investment efficiency? Journal of Multinational Financial Management, 40:33-46.

Schmidt, P. (2011). One-step and two-step estimation in sfa models. Journal of Productivity Analysis, 36(2):201-203.

Simar, L., Van Keilegom, I., and Zelenyuk, V. (2017). Nonparametric least squares methods for stochastic frontier models. Journal of Productivity Analysis, 47(3):189-204.

Tobin, J. (1969). A general equilibrium approach to monetary theory. Journal of Money, Credit and Banking, 1(1):15-29.

Tran, K. C. and Tsionas, E. G. (2009). Estimation of nonparametric inefficiency effects stochastic frontier models with an application to british manufacturing. Economic Modelling, 26(5):904-909.

Wang, H.-J. (2002). Heteroscedasticity and non-monotonic efficiency effects of a stochastic frontier model. Journal of Productivity Analysis, 18(3):241-253.

Wang, H.-J. (2003). A stochastic frontier analysis of financing constraints on investment: the case of financial liberalization in taiwan. Journal of Business \& Economic Statistics, 21(3):406-419.

Wang, H.-J. and Schmidt, P. (2002). One-step and two-step estimation of the effects of exogenous variables on technical efficiency levels. Journal of Productivity Analysis, 18(2):129-144.

White, A. L. (2006). Business brief: Intangibles and CSR. Business for social responsibility, 6, $1-10$.

Whitehouse, L. (2006). Corporate social responsibility: Views from the frontline. Journal of Business Ethics, 63(3):279-296.

Zhong, M. and Gao, L. (2017). Does corporate social responsibility disclosure improve firm investment efficiency? evidence from china. Review of Accounting and Finance, 16(3):348-365. 


\section{Appendix 5A}

Appendix 5A.1 Estimation results based on two stage approach

\begin{tabular}{llll}
\hline & Model $(1)$ & Model $(2)$ & Model $(3)$ \\
\hline $\ln ($ Tobin $)$ & $0.23^{* * * *}$ & $0.027^{* * *}$ & \\
& $(0.031)$ & $(0.032)$ & \\
$\ln \left(\right.$ Sales $\left._{t} / K_{t}\right)$ & $0.217^{* * *}$ & $0.216^{* *}$ & \\
& $(0.094)$ & $(0.097)$ & \\
$\ln \left(\right.$ Sales $_{t-1} / K_{t-1}$ & $0.277^{* * *}$ & $0.279^{* * *}$ & $0.527^{* * *}$ \\
& $(0.094)$ & $(0.098)$ & $(0.025)$ \\
$r G D P_{t}$ & 0.009 & 0.009 & \\
$r G D P_{t-1}$ & $(0.017)$ & $(0.017)$ & \\
& -0.0003 & -0.001 & \\
Determinants of investment inefficiency & $(0.012)$ & $(0.012)$ & \\
CF $/ \mathrm{K}$ & & & \\
& & & \\
$\ln ($ Assets $)$ & $0.0001109^{* * *}$ & $0.143^{* * *}$ & 0.0009 \\
& $(0.0000117)$ & $(0.0146)$ & $(0.016)$ \\
CSR & $0.000064 * * *$ & $0.078^{* * *}$ & 0.006 \\
& $(.0000128$ & $(0.016)$ & $(0.017)$ \\
& $-8.12 \mathrm{e}-06^{* * *}$ & $-0.0102^{* * *}$ & $-0.006^{* * *}$ \\
& $(1.04 \mathrm{e}-06)$ & $(0.001)$ & $(0.001)$ \\
\hline
\end{tabular}

Significance $* * * 1 \%$ level, $* * 5 \%$ level; * $10 \%$ level

In Model 1, the first stage uses SFA to obtain investment inefficiency and we ran a regression to see the association between CSR and the inefficiency. Model 2 and Model 3 follow the two stage approach of Biddle, Hilary and Verdi (2009). We extracted residuals from OLS estimates of the investment model then ran second regression on CF, CSR and IAssets. Model 3 estimates investment level in the following year as a function of growth opportunities in the current year as measured by sales. 


\section{Chapter 6}

General discussion 


\subsection{Introduction}

The overall objective of this thesis was to assess the relationship between CSR and firm performance with a focus on the European food and beverage industry. As described in Chapter 1 , the overall objective was split into four sub-objectives that were addressed in Chapters 2-5.

Chapter 2 developed a method to derive a single composite measure of corporate sustainability that comprises a large number of highly correlated indicators. The method combined Principal Component Analysis (PCA) and Data Envelopment Analysis (DEA). The subsequent chapters (Chapters 3 and 4 ) aimed to model corporate social responsibility (CSR) within a formal by-production framework and examine the factors associated with the CSR performance. This was done by developing a framework of production of desirable and undesirable outputs, attempting to capture the trade-offs at the point of allocating resources to CSR. Going back to production theory fundamentals, the approach in Chapters 3 and 4 accounted for adjustment costs and quasi-fixed inputs. Chapter 5 assessed the association between corporate social responsibility and investment inefficiency.

The remainder of this Chapter is structured as follows. First, it presents the synthesis of the main results. Next, methodological approaches and data limitations are discussed. This is followed by the presentation of policy and business implications of the results. Then, potential avenues for future research are discussed. Finally, the main conclusions are listed.

\subsection{Synthesis of results}

This thesis developed tools and generated insights that help accurately benchmark firms' performance in the presence of CSR. First, the proposed aggregation technique to construct a composite measure of CSR was described. Second, a dynamic by-production framework was developed with the aim of specifying a technology set that best captures the link between production of desirable outputs(conventional and socially responsible outputs) and by-products (socially undesirable outputs). This approach addressed measurement problems in inefficiency and productivity. Lastly, the relationship between CSR and investment inefficiency was examined using a semiparametric stochastic frontier approach. In what follows, the results of this thesis will be synthesized along the following themes: 'Aggregation Method', 'byproduction model of corporate social responsibility', 'dynamic efficiency and productivity growth', 'determinants of productivity and efficiency', and 'Investment inefficiency and CSR performance'). 


\section{Aggregation Method}

Assessments of corporate sustainability or corporate social responsibility usually embrace a large number of correlated variables capturing different dimensions. A composite measure that integrates all indicators is important as it helps summarize multi-dimensional issues and provides synthesized information.

The method proposed in Chapter 2 builds on a combination of Principal Component Analysis and Data Envelopment Analysis. PCA was used to reduce the large number of highly correlated indicators to a small number of uncorrelated principal components (Jolliffe, 2002). The composite measure was then obtained from a set of selected principal components by using DEA. The basic DEA method for estimating efficiency distinguishes between inputs and outputs while the DEA method for constructing composite measure focuses on outputs (achievements) without explicitly considering the inputs used (Lovell et al. 1995; Cherchye et al., 2004). The DEA approach has been widely used in aggregating individual measures into a composite measure of performance. Applications of the DEA approach include human development levels of nations, and environmental performance of firms and farm sustainability (e.g., Zhou et al., 2010; Hatefi and Torabi, 2010; Dong et al., 2015). This method decides weights endogenously and assigns weights according to the relative performance of a firm in any particular indicator. The method developed in Chapter 2 uses a combined PCA-DEA approach to address the limitations of aggregating multidimensional constructs that use expert opinions to determine weights of indicators. The use of PCA addresses limitations of DEA when a large number of correlated indicators exist in the assessment. An application of DEA with a large number of variables will have a frontier defined by a larger number of DMUs and an increasing number of DMUs are ranked as efficient thereby decreasing the ability to differentiate among DMUs (Adler and Yazhemsky, 2010). The use of PCA made it possible to reduce the number of variables and helped to address the problems related to the dimensionality of the DEA formulation.

Chapter 2 demonstrated that combined PCA-DEA approach is suitable to construct a composite measure for the multi- dimensional construct of corporate sustainability that comprises a large number of highly correlated indicators.

\section{By-production model of corporate social responsibility}

The performance benchmarking literature (Dakpo and Oude Lansink, 2018; Puggioni and Stefanou, 2016; Murty et al, 2012, and Førsund , 2008) has shown interest on how to include the generation of undesirable outputs as by products in the production technology. They developed non-parametric frontier estimation models to incorporate undesirable outputs in the 
technology and capture the trade-off between the undesirable outputs (residuals) \& good outputs. The interest on modelling undesirable(pollution) generating technologies is a result of the widespread societal environmental concerns and firms' adoption of sustainable production behaviors by considering social and environmental factors in their business decisions.

The by-production model developed in this thesis follows the work of Puggioni and Stefanou(2016) that features different types of inputs and outputs that are common in production but cannot be fully accommodated by conventional production models. Each firm is assumed to produce both desirable (conventional) and undesirable outputs, while it also participates in socially responsible activities and produces socially responsible outputs. CSR is defined in terms of socially responsible outputs and socially undesirable outputs. These two types of CSR variables were treated separately in a by-production framework. The byproduction model distinguishes two sub-technologies. The first sub-technology describes the production of desirable outputs such as conventional desirable outputs and socially responsible outputs. The second describes production of undesirable outputs. However, the estimation of two independent sub-technologies are with the assumption that the production of the undesirable output does not have any direct effect on the production of the desirable output'(Puggioni and Stefanou, 2016). Dakpo et al. (2016) criticized the independence between the two sub-technologies and introduced dependence constraints for modeling interconnected sub-processes. The production framework developed in this thesis considers this development and ensures the interdependence of the two sub-technologies. Most importantly, it accounts for adjustment costs of investment in quasi-fixed inputs, hence, it is a dynamic by-production model in the presence of CSR. It accounts for resources allocated from the production of desirable outputs (conventional) to the production of socially responsible outputs. The socially responsible output is linked to undesirable output in the undesirable sub technology and it has a property of positive monotonicity with socially responsible outputs. This implies that socially responsible activities (i.e. socially responsible outputs) can mitigate or help reduce undesirable output. In other words, we treated socially responsible output as 'purification possibility' (pollution control) and accounted for it.

Hence, the dynamic by-production framework specifies a technology set that captures corporate social responsibility in the production process. This helps to understand the way CSR is integrated in the production process and capture the effect of CSR on various outputs(conventional desirable output and undesirable outputs). This helps to accurately benchmark firms' performance in presence of CSR activities. 
Data on CSR of firms comprised indicators that assess management systems, practices, policies and other indicators reflecting the environmental, social and governance (ESG) performance of firms. This is important to identify and categorize indicators of mitigating CSR outputs (socially responsible outputs) and socially undesirable outputs. Composite measures for socially responsible outputs and undesirable outputs are constructed using a method that combines principal component analysis (PCA) and data envelopment analysis (DEA) as illustrated in Chapter 2.

We contributed to the wider application of the recently proposed by-production approach of Murty et al. (2012) and Dakpo (2016) by proposing some possible extensions. In our work, we discuss the importance and implications of considering corporate social responsibility in the production processes under the dynamic context that accounts for adjustment costs. More specifically, additional constraints were introduced in the by-production model and socially responsible outputs are treated as additional desirable output. This accounts for resources diverted from the production of desirable outputs to CSR activities. A constraint on socially responsible outputs in the undesirable output technology was introduced to capture the mitigation effect of socially responsible output on undesirable output as socially responsible activities helps to reduce the undesirable output. These additional constraints offer the opportunities to understand the way CSR integrated is integrated in the production process.

\section{Dynamic efficiency and productivity growth}

Several representations of the production technology are defined and characterized in the static theory of production (Shephard, 1970; Färe and Primont, 1995; Chambers, 2008; Ball et al., 2002; Färe et al., 2005). The static theory of production is criticized as it does not account for adjustment costs associated with changes in the level of the quasi-fixed factors. In contrast, dynamic theory of production accounts for adjustment cost associated with changes in levels of quasi-fixed factors, which are the source of the time interdependence of the firm's production decisions. Including investment (change in the level of the quasi-fixed factors) in the production technology implies maximum output levels depend not only on variable and quasi-fixed factors but also depends on the magnitude of the change in the dynamic factors (investment). Recently, representations of the adjustment-cost production technology have emerged in the literature. Silva et al (2015) built on earlier work of Silva and Stefanou (2003) to define a directional input distance function and characterize it to represent an adjustmentcost production technology. Kapelko et al (2017) addresses adjustment costs and developed a measurement of input-specific dynamic productivity change. Dakpo and Oude Lansink (2019) show that an adjustment-cost production technology can be represented when modeling pollution-adjusted inefficiency under the by-production or bad outputs. The dynamic by- 
production model in this thesis made use of directional distance functions that would allow integrating multiple outputs, including socially responsible outputs and socially undesirable outputs and inputs. The directional distance function is defined and characterized to represent an adjustment-cost production technology.

The empirical results Chapter 3, which estimates dynamic inefficiency in the presence of socially responsible and undesirable outputs, showed the importance of accounting for the presence of adjustment costs associated with investments in quasi-fixed inputs. Ignoring adjustment costs in the by-production model leads to an overestimation of technical inefficiencies (Chapter 3). The overestimation of technical inefficiency in the static production technology varies from $40 \%$ for undesirable output to $26.6 \%$ for labor input. (Chapter 3 ). This finding is consistent with Dakpo, \& Oude Lansink (2019) who estimated input and outputspecific technical inefficiency scores in the dynamic context and compares them with efficiency measures from the conventional static context. Under the dynamic by-production approach, material input, labor input and undesirable output can be contacted by $13.5 \%, 16.3 \%$ and $11 \%$ respectively while desirable output can be expanded by $77.1 \%$, socially responsible output by $4.1 \%$ and the potential of doing investment by $585 \%$ of the capital stock. Under the static by-production approach, on the other hand, material input, labor input, capital input and undesirable output can be contacted by $26.6 \%, 21.7 \%, 42.9 \%$ and $11.6 \%$ respectively while desirable output and socially responsible output can be expanded by $24.3 \%$ and $5.1 \%$ respectively. The number of efficient firms is quite high in the sample and firms are found to be technically efficient in at least one input or output dimension. This finding is similar to Puggioni and Stefanou (2016) who also reported a high level of efficiency for their sample. The observation of large number of efficient firms is sensible as the analysis is based on three outputs, two variable inputs and one quasi fixed input that have specific role in the production. This gives the firm more choices available to generate a 'very peculiar technology set that can accommodate different production 'recipes' and make it easier for firms to be efficient'(Puggioni and Stefanou, 2016).

Chapter 4 estimated dynamic productivity changes in the presence of socially responsible and undesirable outputs within the dynamic by-production framework. It further extends the decomposition of productivity change into the contributions of technical change, technical efficiency change and scale efficiency change to provide insights in to the source of productivity changes. The average annual dynamic productivity growth (the dynamic Luenberger indicators) associated with variable input, undesirable output and investment were $-0.003,-0.027$ and +0.135 respectively. These results imply that, while producing the same quantity of marketable and socially desirable outputs, the use of variable input increased by $0.03 \%$, the production of undesirable output has increased by 0.027 and the potential for doing investment in capital 
increased by $2.7 \%^{8}\left(=0.135^{\star} 0.2^{*} 100\right)$ of the capital stock per year during the sample period. . The results of the empirical application show that there is a decline in dynamic productivity change mainly due to technical inefficiency change. Comparing with existing literature such as Kapelko et al (2017), who investigated input specific dynamic productivity change, we found similar result on drivers of negative dynamic productivity growth for labor. It is mainly due to the negative dynamic technical inefficiency change. This shows firms are using the existing production potential of labor less efficiently over time.

We contributed to the literature on dynamic productivity and efficiency analysis by illustrating the role of adjustment costs in quasi fixed inputs in the production process. We evaluate the input-output specific dynamic productivity and efficiency estimates in the presence of CSR. There exist adjustment costs associated with investments in quasi fixed inputs, such as search costs of new capital, costs of installing new equipment, costs of learning to use new equipment. We provide evidence that supports the view in Oude Lansink et al (2001), Silva \& Stefanou (2003), Silva et al (2015) and Oude Lansink et al (2015) that failing to account for the adjustment costs associated with investments in quasi fixed assets confound inefficiency with adjustment costs. We confirm the importance of accounting for adjustment costs in quasi-fixed inputs.

\section{Determinants of technical inefficiency and productivity}

Besides modelling corporate social responsibility (CSR) within a formal by-production framework, the factors associated with CSR performance were also examined. This was done once the efficiency and productivity specific to the inputs and outputs were determined. The findings on firm specific factors associated with dynamic technical inefficiency and productivity growth specific to CSR variables and other inputs \& outputs are shown in Table 6.1.

The results on the relationship between factors associated with dynamic inefficiencies and productivity growth specific to CSR variables are summarized as follows. First, lower levels of technical inefficiency specific to socially responsible output are associated with a larger firm size. This finding is consistent with that of Artiach et al. (2010) who reported firm size is a crucial factor as society's pressure for CSR initiatives is disproportionately higher for large companies. However, size does not have any effect on productivity change. Second, ROA was negatively related with technical inefficiency specific to undesirable output, in line with prior expectations that at times of high levels of profitability (ROA), firms will have the financial means to devise strategies that mitigate undesirable output. Third, high levels of R\&D intensity are associated with better CSR performance (i.e. lower levels of technical inefficiency specific

\footnotetext{
${ }^{8}$ as the directional vector for investment is $20 \%$ of capital stock
} 
to socially responsible output). Fourth, network-oriented systems (e.g., Germanic or Latin) ceteris paribus tend to be more socially responsible, in line with prior expectations that networks of relationships between stakeholders in the network-oriented systems influence a firm's decision to incorporate sustainability and social responsibility. Finally, there exists a positive association between leverage and dynamic productivity change specific to socially undesirable output. This finding is in line with the claim that debt limits investments on socially responsible activities and investments to deal with undesirable outputs due to the obligation to pay interest (Sheikh, 2018).

The results on the firm specific factors associated with dynamic technical inefficiency and productivity growth specific to inputs and investment are outputs are presented as follows. Leverage was positively association with inefficiency specific to material input implying an increase in leverage is associated with an increase in technical inefficiency specific to material input. This result is in line with the argument, as discussed in Vincent et al (2007) and Hossain et al (2005), that firms with higher levels of debts are monitored by creditors to service the debts on time and focus more on debtholders' interest than shareholders' interest to invest on inputs. ROA was negatively associated with dynamic Luenberger indicator specific to variable input. This suggests that an increase in ROA is associated with a decrease in productivity growth specific to variable input. This implies that firms with high levels of profitability have more financial means and may invest in non-rentable inputs. R\&D and technical inefficiency specific to material input were positively associated. A possible explanation for this finding could be that $R \& D$ initiatives divert resources away from investment in direct material inputs. ROA was positively associated with the dynamic Luenberger indicator specific to investment. This indicates that the potential for doing investment in quasi fixed inputs increases with an increase in level of profitability. 
Table 6.1: Regression estimates on factors associated with dynamic inefficiencies and productivity growth

\begin{tabular}{|c|c|c|c|c|c|c|c|c|}
\hline & \multicolumn{5}{|c|}{ Dynamic technical inefficiencies } & \multicolumn{3}{|c|}{ Dynamic Luenberger indicators } \\
\hline & $\begin{array}{l}\text { Socially } \\
\text { responsible }\end{array}$ & Desirable & Undesirable & Material & Labour & Variable input & Investment & Undesirable output \\
\hline Size & $--^{*}$ & - & + & $--^{*}$ & $--^{*}$ & - & + & - \\
\hline Leverage & + & + & - & $+{ }^{*}$ & - & - & - & $-*$ \\
\hline FCF & + & - & + & - & - & + & - & - \\
\hline ROA & + & - & $-*$ & - & - & $-{ }^{*}$ & $+^{*}$ & - \\
\hline R\&D Intensity & $-*$ & - & $-*$ & $+^{*}$ & - & $+^{*}$ & - & + \\
\hline $\begin{array}{l}\text { Market-oriented } \\
\text { dummy }\end{array}$ & $+^{*}$ & - & $+^{*}$ & - & $-^{*}$ & + & -* $^{*}$ & + \\
\hline
\end{tabular}

Note: Asterisks denote statistical significance 


\section{Investment inefficiency and CSR performance}

Chapter 5 aimed to investigate the relationship between CSR and investment inefficiency. Several researchers have investigated benefits of CSR and have found evidence that CSR contributes to improved information quality (Cho et al., 2013, Lopatta et al., 2016). It is also documented that the sources of friction that are crucial in investment inefficiency stems from information asymmetry as a result of poor information (Myers and Majluf, 1984). Building on this line of research, we explore the relationship between CSR and investment inefficiency. We estimate a semiparametric stochastic frontier by modelling the conditional mean of investment inefficiency without imposing any distributional assumptions. The semiparametric stochastic approach is useful to estimate a measure of the degree of financial constraint (investment inefficiency) for each firm and determine the marginal effect of CSR on this measure. This chapter provides strong and robust evidence that higher CSR performance is associated with lower investment inefficiency and demonstrates that CSR is value-increasing. This chapter contributes to the understanding on the economic effects of CSR and provides arguments for regulatory bodies to promote CSR activities. The possible mechanism for presence of negative association between CSR performance and investment inefficiency could be through the role of CSR to provide extra information that reduce information asymmetry and in turn reduce investment inefficiency. This explanation is consistent with the findings in Cho et al. (2013) and Cui et al. (2018) that firms highly involved in CSR activities provide extra non-financial information that helps to reduce information asymmetry and provide a more holistic picture of performance.

\subsection{Data requirements, data sources and methods}

The empirical analysis that aimed to model corporate social responsibility (CSR) within a formal by-production framework (Chapters 3 and 4) was based on a multi-input, multi-output model that requires disaggregated measures of inputs and outputs. We followed the existing literature such as Kapelko et al, 2015(a,b), Oude Lansink et al (2015) in production economics to distinguish inputs such as capital, labour and variable inputs. With respect to outputs, aggregate sales at the firm level is the most commonly available measure of conventional output as it was also shown in Kapelko et al, 2015(a,b), Oude Lansink et al (2015). Inputs or outputs that are traded in well-defined markets are easily measurable. However, there is no widely accepted method for measuring non-marketed outputs namely outputs that are produced but are not traded in a market, like the socially undesirable output and socially responsible output (CSR outputs). In this thesis, we obtained data on CSR variables from 
Sustainalytics. 'Sustainalytics is a globally responsible investment research firm' that is committed to providing investors with a reliable and structured scoring for firms in respect to their environment, social and corporate governance (ESG performance (Sustainalytics,2016). Sustainalytics assesses companies' management systems, practices, policies, and other indicators related to environmental, social, and governance risks. Its data compilation is based on a methodology that identifies specific issues for each industry, scores every issue for each firm belonging to the same industry, and provides ESG ranking that evaluates the relative performance of each firm with respect to their peers in the industry.

The data set provided by Sustainalytics consisted of detailed scores for different ESG indicators, which are particularly useful for the analysis in this study. Their methodology focuses on identifying strengths and weaknesses for every ESG category in which single indicators are organized. The fact that scores for detailed indicators are available together with the distinction of these indicators between favorable/positive and controversial/negative aspects of ESG is instrumental in identifying measures of mitigating CSR outputs (scores for the positive indicators) and measures of undesirable outputs (scores for the negative indicators). The data provided by Sustainalytics were in the form of scores. Sustainalytics chooses a certain (usually quite large) number of indicators across the environment, social, and governance (ESG) dimensions of CSR and assigns with a raw score from 0 to 100 , where 0 denotes a very poor performance and 100 denotes an excellent performance.

Data on desirable, marketable output and conventional inputs were taken from the ORBIS dataset maintained by Bureau van Dijk using the information included in companies' annual financial reports. Sales (in euro) were used as a measure of the desirable, marketed output and were deflated using the industrial price index for outputs. Inputs consisted of two variable inputs and one quasi-fixed input. The two variable inputs were material input, which was measured by costs of materials consumed, and labour input, which was measured by costs of employees. Material input and labour inputs were deflated using the industrial price index for consumer non-durables and labour cost index in manufacturing, respectively. Fixed assets were considered as quasi-fixed input. Gross investments in fixed assets in one year were computed as the starting value of fixed assets in the following year minus the starting value of fixed assets in the current year plus the starting value of depreciation in the following year, and then were deflated using the industrial price index for capital goods.

The data showed quite small variation in CSR measures such as undesirable output and socially responsible output while the variability in conventional inputs and output was quite large. This was in part due to data limitations but also to the fact that the CSR performance of 
firms is much more homogeneous- looked as a minimum standards that every firm strives to achieve. The low variability could also stem from the measurement of dimensions of CSR that are assigned with a raw score from 0 to 100.The low variability in the data negatively affects the discriminatory power of the by-production model. This can be observed from the results in Chapter 3 that $66 \%$ and $62 \%$ of the firms were efficient specific to socially responsible output and undesirable outputs respectively. A future research with diversified CSR measures could improve the discriminatory power of the model in particular and assessment of performance of firms in general.

The empirical analysis in Chapter 5 that aimed to investigate the relationship between CSR and investment inefficiency was based on financial data from the ORBIS database. The data consisted of variables such as capital expenditures (investment), Tobin's Q (market capitalization), sales, the cash flow and fixed assets. In order to control for economic environment that the firm operates in, we obtained data on the growth of real GDP and its lag values from the world bank database.

Regarding the use of methods for the estimation of efficiency and productivity, two main streams of literature have emerged, namely: parametric and non-parametric. The nonparametric approach such as DEA is a mathematical optimization technique that estimates the ability of a firm to obtain maximum output from a given set of inputs (output oriented technical efficiency) or to use minimum inputs from a given set of outputs (input oriented technical efficiency) (Farrel, 1957). It attributes all deviations from the maximum output or minimum input as inefficiency. The parametric method such as Stochastic Frontier Analysis (SFA) allows for variation in output due to random shocks and one-sided shocks (inefficiency) when estimating the ability of a firm to obtain maximum output. However, it requires distributional assumptions which yields a likelihood function whereby the parameters of the distributional components of the noise and inefficiency can be recovered. More recently, there is also an emerging literature on semi-parametric stochastic approaches that does not impose distributional assumptions on the composite error terms (Tran and Tsionas 2009, Parmeter et al.2017).

In this thesis, we utilized both a non-parametric and a semi parametric approaches. The nonparametric approach used DEA to estimate directional distance functions within the dynamic by-production framework. The DEA method allows to integrate multiple outputs including socially responsible outputs and socially undesirable outputs, and capture the trade-offs to provide a more accurate representation of the production process. We chose the nonparametric (DEA) approach since DEA is a more flexible to estimate inefficiency and productivity growth specific to inputs and outputs than the parametric approach(SFA). However, 
DEA estimation with a large number inputs-output variables has a higher probability that the DMUs would be fully technically efficient (Dyson et al. 2001). To address this, it is crucial to ensure the analysis is based on a large set of DMUs and give due care regarding the selected number of variables (Fried et al. 2007).

We utilized a semi parametric approach to investigate the association between CSR and investment inefficiency. The semi-parametric approach is based on a recent advances in efficiency estimation that relax the stringent distributional assumptions on noise and inefficiency in the SFA approach as proposed in Tran and Tsionas (2009) and Parmeter et al. (2017). The choice of semi-parametric approach over the parametric SFA is due to the fact that the former does not require assumption on the inefficiency component and it involves much easier, faster and numerically more robust computation.

\subsection{Policy and business implications}

Companies are facing growing pressure from various stakeholder groups to consider the social and environmental consequences of their operations. As a result, a number of independent advisory firms emerged in the past decades with a mission of setting standards for assessing corporate sustainability even though their methods are criticized for the subjective weighting of the multiple indicators (Belu \& Manescu, 2013). A combined PCA-DEA method (Chapter 2) addresses these shortcomings of the methods used by these advisory firms. A wider adoption of this method is important to improve the construction of composite measures of different applications especially when the measure comprises large number of highly correlated indicators. However, the implementation of the method could be limited by the nature and measurement of CSR variables. When the variability of the measure is low, there will be a situation where many firms are located at the frontier and the differences in performance between firms become less visible.

The third and fourth chapters developed a dynamic by-production framework incorporating CSR into a formal production process that accounts for adjustment costs associated with quasi-fixed inputs. This framework is vital for assessing how firms manage the entirety of their production process. The comparison of the results of the static and the dynamic approach in Chapter 3 showed that ignoring adjustment costs when benchmarking performance may lead to an overestimation of technical inefficiency. More R\&D intensity is associated with higher CSR performance that implies R\&D can be CSR related and product or process innovations can be motivated through CSR. The results of the empirical application to a sample of European food and beverage manufacturing firms showed that there is a decline in dynamic productivity changes mainly due to technical inefficiency change. The business implication of 
this finding is that firms should reorganize their resource use in a way that enhances the utilization of resources.

Results in Chapter 5 shows that implementation of CSR strategies is negatively associated with higher investment inefficiency. An important practical implication can be derived from this result that integrating CSR issues in strategies is crucial to help firms move towards decisions which improve firm growth and safeguard interests of different stakeholders. In addition, this finding provides arguments for regulatory bodies to promote CSR activities. This chapter contributes to the understanding on the value of CSR and provides arguments for regulatory bodies to promote CSR activities.

\subsection{Future research}

This dissertation developed tools and generated insights that can help to accurately benchmark firms' performance in view of CSR activities. Conventional production models cannot fully accommodate CSR in the production process. More recently, it has been proposed to divide the production process in two sub-technologies, i.e. a by-production approach. We extend the by-production approach to integrate CSR in the production process and account for adjustment costs in quasi fixed assets using the two sub-technologies allows for more flexibility in the substitution of the outputs, inputs and externalities. There are, however, future avenues of research that could be further explored.

One avenue for future research is to extend our work by estimating shadow prices of the inputs and outputs to understand the value of CSR in the dynamic by-production framework. This helps to quantify the value of engaging in CSR activities and prioritize the most valuable CSR activities for the firm. The proposed production framework uses directional distance functions (DDFs) representing a flexible way to evaluate performance(efficiency) of DMUs. Permitting the selection of a direction towards the efficient frontier is often useful in empirical applications. Future research that integrates CSR in the multiple input-output settings could endogenize the directional vector) where data-driven and objective directional vector is used in the estimation as introduced by Färe et al, (2013) and Zofio et al (2012). This permits the heterogeneity of DMUs and their diverse contexts that may influence their input and/or output mixes (Daraio and Simar, 2017.) 


\subsection{Main Conclusions}

The main conclusions of this dissertation are:

- The multi-dimensional construct of corporate sustainability that comprises a large number of highly correlated indicators can be captured into a single composite measure using a combined PCA and DEA framework (Chapter 2).

- The dynamic by-production approach developed in this dissertation accounts for adjustment costs and it can be used to benchmark firm performance in the presence of corporate social responsibility (Chapters 3-4).

- Ignoring adjustment costs may lead to an overestimation of technical inefficiency. (Chapter 3).

- The overestimation of technical inefficiency in the static production technology was varies from $13.1 \%$ for material input, $26.6 \%$ for labour input to $40 \%$ for undesirable output for labor input. (Chapter 3).

- Material input, labor input and undesirable output can be contacted by $13.5 \%, 16.3 \%$ and $11 \%$ respectively while desirable output can be expanded by $77.1 \%$, socially responsible output by $4.1 \%$ and the potential of doing investment by $585 \%$ of the capital stock (Chapter 3).

- Material input, labor input, capital input and undesirable output can be contacted by $26.6 \%, 21.7 \%, 42.9 \%$ and $11.6 \%$ respectively while desirable output and socially responsible output can be expanded by $24.3 \%$ and $5.1 \%$ respectively under the static by-production approach (Chapter 3).

- Technical inefficiency change is the main contributor to the negative productivity growths specific to variable input and undesirable output (Chapter 4).

- The average annual dynamic productivity growth associated with variable input, undesirable output and investment were $-0.003,-0.027$ and +0.135 respectively. These results indicate that, while producing the same quantity of marketable and socially desirable outputs, the use of variable input increased by $0.03 \%$, the production of undesirable output increased by 0.027 and the potential for doing investment in capital increased by $2.7 \%$ of the capital stock per year during the sample period. (Chapter 4 ).

- Leverage is positively associated with the Luenberger indicator specific to undesirable output (Chapter 4).

- A better CSR performance is associated with lower investment inefficiency (Chapter 5)

- Median estimated gradients of conditional investment inefficiency for CSR using partly linear model was -0.715 with negative upper and lower quartiles (Chapter 5 ). 


\section{References}

Adler, N., Yazhemsky, E., 2010. Improving discrimination in data envelopment analysis: PCADEA or variable reduction. European J. Operat. Res. 202 (1), 273-284.

Ball, V.E., Färe, R., Grosskopf, S., Hernandez-Sancho, F., Nehring, R., 2002a. The environmental performance of the U.S. agriculture sector. In: Ball, V.E, Norton, G. (Eds.), Agricultural Productivity, Measurement and Sources of Growth. Kluwer Academic Publishers.

Belu, C. \& Manescu, C. (2013). Strategic corporate social responsibility and economic performance. Applied Economics, 45:19, 2751-2764,

Chambers, R.G.,Färe,R.,2008.A 'calculus' for data envelopment analysis .J.Prod. Anal. 30,169-175.

Cherchye, L., Moesen, W., Puyenbroeck, T., 2004. Legitimately diverse, yet comparable: on synthesizing social inclusion performance in the EU. JCMS: J. Common Market Stud. 42 (5), 919-955

Cho, S. Y., Lee, C., and Pfeiffer Jr, R. J. (2013). Corporate social responsibility performance and information asymmetry. Journal of Accounting and Public Policy, 32(1):71-83.

Cui, J., Jo, H., and Na, H. (2018). Does corporate social responsibility affect information asymmetry? Journal of Business Ethics , 148(3):549-572

Dakpo, K. H. (2016). On modeling pollution-generating technologies: a new formulation of the by-production approach(No. 913-2016-72292).

Dakpo, K.H., Jeanneaux, P., Latruffe, L. (2016). Modelling pollution-generating technologies in performance benchmarking: Recent developments, limits and future prospects in the nonparametric framework. European Journal of Operational Research, 2502):347-359.

Dakpo, KH, \& Oude Lansink, AO (2019). Dynamic pollution-adjusted inefficiency under the byproduction or bad outputs. European Journal of Operational Research , 276 (1), 202211.

Daraio, C., Simar, L., 2017. Efficiency and benchmarking with directional distances. A data driven approach. Journal of the Operational Research Society 67, 928-944.

Dong F., Mitchell P.D., Colquhoun J., 2015. Measuring farm sustainability using data envelope analysis with principal components: The case of Wisconsin cranberry. Journal of Environmental Management. 147, 175-183

Dyson, R.G., Allen, R., Camanho, A.S., Podinovski, V.V., Sarrico, C.S. \& Shale, E.A. (2001) Pitfalls and protocols in DEA. European Journal of Operational Research 132(2):245259.

Färe, R., Grosskopf, S., \& Whittaker, G. (2013). Directional output distance functions: endogenous directions based on exogenous normalization constraints. Journal of Productivity Analysis , 40 (3), 267-269.

Färe, R.,Grosskopf,S.,Noh,D.-W.,Weber,W.,2005.Characteristics of a polluting technology: theory and practice. J. Econom. 126, 469-492.

Färe, R., Primont, D., 1995. Multi-Output Production and Duality: Theory and Applications. Kluwer Academic Publishers. 
Farrell, M. J. (1957). The measurement of productive efficiency. Journal of the Royal Statistical Society: Series A (General), 120(3), 253-281.

Fried, H.O., Knox Lovell, C.A., Schmidt, S.S (2007) Efficiency and Productivity In: Fried, H.O., Knox Lovell, C.A., Schmidt, S.S. (Eds.) The Measurement of Productive Efficiency and Productivity Growth, New York, Oxford University Press

Førsund, F. R. (2008). Good modelling of bad outputs: pollution and multiple-output production (No. 2008, 30). Memorandum.

Hatefi, S.M., Torabi, S.A., 2010. A common weight MCDA-DEA approach to construct composite indicators. Ecol. Econ. 70, 114-120.

Hossain, F., Jain, R., \& Govindasamy, R. (2005). Financial structure, production, and productivity: evidence from the US food manufacturing industry. Agricultural economics, 33, 399-410.

Jolliffe, I.T., 2002. Principal component analysis and factor analysis. Principal Comp. Analysis 150-166.

Kapelko, M., Oude Lansink, A., \& Stefanou, S. E. (2015)a. Analyzing the impact of investment spikes on dynamic productivity growth. Omega, 54, 116-124.

Kapelko, M., Oude Lansink, A., \& Stefanou, SE (2015)b. Effect of food regulation on the Spanish food processing industry: a dynamic productivity analysis. PloS one , 10 (6), 0128217.

Kapelko, M., Oude Lansink, A., \& Stefanou, SE (2017). Input - Specific Dynamic Productivity Change: Measurement and Application to European Dairy Manufacturing Firms. Journal of agricultural economics , 68 (2), 579-599.

Lopatta, K., Buchholz, F., and Kaspereit, T. (2016). Asymmetric information and corporate social responsibility. Business \& Society, 55(3):458-488.

Lovell, C.K., Pastor, J.T., Turner, J.A., 1995. Measuring macroeconomic performance in the OECD: a comparison of European and non-European countries. European J.Operat. Res. 87 (3), 507-518.

Myers, S. C. and Majluf, N. S. (1984). Corporate financing and investment decisions when firms have information that investors do not have. Journal of financial economics, 13(2):187-221.

Murty, S., Russell, R. R., \& Levkoff, S. B. (2012). On modeling pollution-generating technologies. Journal of environmental economics and management, 64(1), 117-135.

Oude Lansink, A., Stefanou, S., \& Serra, T. (2015). Primal and dual dynamic Luenberger productivity indicators. European Journal of Operational Research, 241(2), 555-563.

Oude Lansink, A., Verstegen, J., \& Van den Hengel, J. (2001). Investment decision making in Dutch greenhouse horticulture. NJAS-Wageningen Journal of Life Sciences, 49(4), 357-368.

Parmeter, C. F., Wang, H.-J., and Kumbhakar, S. C. (2017). Nonparametric estimation of the determinantsof inefficiency. Journal of Productivity Analysis, 47(3):205-221.

Sheikh, S. (2019). Corporate social responsibility and firm leverage: The impact of market competition. Research in International Business and Finance, 48, 496-510. 
Shephard, R.W., 1970. Theory of Cost and Production Functions. Princeton Uni- versity Press.

Silva, E., Oude Lansink, A. , \& Stefanou, S. E. (2015). The adjustment-cost model of the firm: Duality and productive efficiency. International Journal of Production Economics, 168, 245-256.

Silva, E., \& Stefanou, S. E. (2003). Nonparametric dynamic production analysis and the theory of cost. Journal of Productivity Analysis, 19(1), 5-32.

Tran, K. C. and Tsionas, E. G. (2009). Estimation of nonparametric inefficiency effects stochastic frontiermodels with an application to british manufacturing. Economic Modelling, 26(5):904-909.

Vincent Mok, Godfrey Yeung, Zhaozhou Han \& Zongzhang Li (2007) Leverage, Technical Efficiency and Profitability: an application of DEA to foreign-invested toy manufacturing firms in China, Journal of Contemporary China, 16:51, 259-274

Zhou, P., Ang B.W., Zhou D.Q., 2010. Weighting and aggregation in composite indicator construction: a multiplicative optimization approach. Soc Indic Res. 96, 169-81.

Zofio, J. L., Pastor, J. T., \& Aparicio, J. (2013). The directional profit efficiency measure: on why profit inefficiency is either technical or allocative. Journal of Productivity Analysis, 40(3), 257-266. 


\section{Summary}

Corporate social responsibility (CSR) defines a set of corporate practices that improve the social and environmental standards of firms operating in markets. CSR shifts corporate goals from value maximization for shareholders towards a broader, multi-stakeholder satisfaction. The rise in firms' interest of adopting CSR is a result of the growing pressure from various stakeholder groups on firms to consider the social and environmental consequences of its operations. In this respect, there is a need to develop tools and generate insights that help accurately benchmark firms' performance in the presence of CSR. This dissertation developed tools and generated insights that help to accurately benchmark firms' performance in the presence of CSR. The overall objective of this thesis was to assess the relationship between CSR and firm performance with a focus on the European food and beverage industry. This overall objective was met by addressing the following specific objectives:

- To assess corporate sustainability performance in the European food and beverage industry,

- To estimate dynamic inefficiency in the presence of socially responsible and undesirable output in the European food and beverage industry,

- To estimate input- and output-specific productivity change in the presence of socially responsible and undesirable output in the European food and beverage industry,

- To assess the relationship between corporate social responsibility and investment inefficiency.

Chapter 2 developed a composite indicator to measure corporate sustainability. Although many indicators exist that capture the different dimensions of sustainability, a composite indicator that integrates across all indicators is important as it helps to summarize multidimensional issues and to provide synthesized information. Corporate sustainability assessment requires evaluating a large number of highly correlated indicators. This chapter discussed and evaluated a method that builds on a combination of principal component analysis and data envelopment analysis for developing a composite indicator of corporate sustainability. Principal component analysis(PCA) is used to remove correlations among the indicators and reduce the dimension of corporate sustainability. The aggregation of indicators using Data Envelopment Analysis(DEA) reduces the subjectivity that is implicit in composite indicators when aggregation is performed. The method is illustrated for companies in the European food and beverages sector, using data from Sustainalytics. 
Chapter 3 developed a dynamic by-production framework that specifies a technology set to integrate corporate social responsibility (CSR). This is with the aim to provide a useful framework to benchmark performance, accounting for resources diverted from the production of desirable outputs(conventional outputs) to socially responsible outputs as well as the mitigation effects of socially responsible output. The framework captures the trade-offs between outputs and helps provide a more accurate representation of the production process when evaluating performance. We derived inefficiency estimates related to the generation of CSR outputs and focuses on the comparison between a static and a dynamic framework. The empirical results of the third chapter provide insight into inefficiency related to the generation of CSR outputs and confirm the importance of dynamic framework that accounts for adjustment costs in quasi-fixed inputs. Ignoring adjustment costs in the by-production model leads to an overestimation of technical inefficiencies. The average inefficiencies specific to material input, labor input, socially responsible output, and undesirable output in the static production technology were overstated by 13.1, 26.6, 1.0 and 0.6 percentage points, respectively. Under the dynamic by-production approach, material input, labor input and undesirable output can be contacted by $13.5 \%, 16.3 \%$ and $11 \%$ respectively while desirable output can be expanded by $77.1 \%$, socially responsible output by $4.1 \%$ and the potential of doing investment by $585 \%$ $\left(29.255^{\star} 0.2^{*} 100\right)$ of the capital stock. Regarding the factors that determine dynamic technical inefficiency, firm size, profitability $(R O A), R \& D$ intensity and network oriented dummy tend to negatively associated with dynamic inefficiency specific to CSR variables.

Chapter 4 contributed to the efficiency and productivity literature by evaluating productivity change that accounts for the role of corporate social responsibility in the production process. The production model integrates corporate social responsibility in the production framework and it represents the transformation of multiple inputs into desirable (marketed), socially responsible and undesirable outputs, in a dynamic context where we account for adjustment costs in quasi-fixed inputs. We estimated input and output-specific productivity change that accounts for the role of corporate social responsibility and adjustment costs in quasi-fixed inputs. Measuring productivity change helps to evaluate performance over time. We decomposed productivity change into the contributions of technical change, technical inefficiency change and scale inefficiency change to provide insights into the sources of productivity change. The chapter illustrated the method using sample data of European food and beverage manufacturing firms. The empirical results of this chapter show that the use of variable input has increased, on average per year by $0.03 \%$, the production of undesirable output has increased by 0.027 and the potential for doing investment in capital has increased by $2.7 \%$ of the capital stock while still producing the same quantity of (marketable) output. The decline in dynamic Luenberger indicators is mainly due to technical inefficiency change. Hence, 
firm should focus on strategies that that improve utilization of resource use. Regarding the factors that determine dynamic Luenberger indicators, leverage and profitability $(\mathrm{ROA})$ tend to associated with dynamic Luenberger indicators. Leverage and dynamic Luenberger indicator specific to socially undesirable output were positively associated. This result is inline with the argument, as in (Sheikh, 2018), that debt limits investments on socially responsible activities to address undesirable output. ROA was positively associated with the dynamic Luenberger indicator specific to investment indicating the potential for doing investment in quasi fixed inputs increases with the level of profitability.

Chapter 5 proposed the use of semi-parametric stochastic frontier analysis to examine whether CSR is associated with investment inefficiency. The stochastic frontier approach appropriately characterizes CSR as having a downward pull on firm level investment inefficiency. We applied the approach to a sample of European listed companies, providing robust evidence on the relationship between CSR and investment inefficiency. The estimated coefficient of CSR is negative and statistically significant indicating that a higher CSR performance is associated with lower investment inefficiency. This result is consistent with the claim that high CSR firms are characterized by low information asymmetry and high stakeholder solidarity, which may represent a source of competitive advantage and helps to reduce investment inefficiency.

Chapter 6 presents the synthesis of the main results along the following main lines: (1) aggregation method, (2) by-production model of corporate social responsibility, (3) dynamic inefficiency and productivity growth, (4) determinants of productivity and efficiency, (5) Investment inefficiency and CSR performance. Subsequently, the chapter provides the implications of the results, and finalizes by outlying possible directions for future research.

From this dissertation the following conclusions were drawn:

- The multi-dimensional construct of corporate sustainability that comprises a large number of highly correlated indicators can be captured into a single composite measure using a combined PCA and DEA framework (Chapter 2).

- The dynamic by-production approach developed in this dissertation accounts for adjustment costs and it can be used to benchmark firm performance in the presence of corporate social responsibility (Chapters 3-4).

- Ignoring adjustment costs may lead to an overestimation of technical inefficiency. (Chapter 3).

- The overestimation of technical inefficiency in the static production technology was varies from $13.1 \%$ for material input, $26.6 \%$ for labour input to $40 \%$ for undesirable output for labor input. (Chapter 3). 
- Material input, labor input and undesirable output can be contacted by $13.5 \%, 16.3 \%$ and $11 \%$ respectively while desirable output can be expanded by $77.1 \%$, socially responsible output by $4.1 \%$ and the potential of doing investment by $585 \%$ of the capital stock (Chapter 3).

- Material input, labor input, capital input and undesirable output can be contacted by $26.6 \%, 21.7 \%, 42.9 \%$ and $11.6 \%$ respectively while desirable output and socially responsible output can be expanded by $24.3 \%$ and $5.1 \%$ respectively under the static by-production approach (Chapter 3).

- Technical inefficiency change is the main contributor to the negative productivity growths specific to variable input and undesirable output (Chapter 4).

- The average annual dynamic productivity growth associated with variable input, undesirable output and investment were $-0.003,-0.027$ and +0.135 respectively. These results indicate that, while producing the same quantity of marketable and socially desirable outputs, the use of variable input increased by $0.03 \%$, the production of undesirable output increased by 0.027 and the potential for doing investment in capital increased by $2.7 \%$ of the capital stock per year during the sample period. (Chapter 4 ).

- Leverage is positively associated with the Luenberger indicator specific to undesirable output (Chapter 4).

- A better CSR performance is associated with lower investment inefficiency (Chapter 5)

- Median estimated gradients of conditional investment inefficiency for CSR using partly linear model was -0.715 with negative upper and lower quartiles (Chapter 5). 


\section{Acknowledgements}

Completion of this thesis would not have been possible had I not been supported by so many colleagues, friends and family. I would like to express my gratitude to all who brought an input for the successful completion of the thesis.

First and foremost I wish to thank my promoter Prof. dr. Alfons Oude Lansink. He has been there providing his heartfelt support, guidance, motivation and suggestions at all times in my quest for knowledge. He has given me all the freedom to pursue my research, while silently and non-obtrusively ensuring that I do not deviate from the core of my research. Without his able guidance, this thesis would not have been possible and I shall eternally be grateful for his assistance.

I would like to express my gratitude to my co-promotor Dr. Xudong Rao who has been contributing significantly to my training as an independent researcher. He has also given me all the freedom to explore my initiatives. Xudong, thanks for your confidence in my work, and for your encouragement and insightful comments.

I acknowledge the contribution of Dr. Christopher F. Parmeter for his kind guidance during my research visit at the University of Miami. I am grateful for his valuable comments on the fifth chapter of the thesis.

I would also like to extend my appreciation to my former and current colleagues at Business Economics Group of WUR including Anne, Jeannette, Nurul, Tariku, Daniel, Jamal, Dikky, Esmee, Gumi, Marlous, Thomas, Jaap, Yann, Frederic, Kevin, Thomas, Xiaomei, Kirstin and Beshir. Anne and Jeannette, I am grateful for your support with admin issues and with my personal life.

My appreciation also goes to the Ethiopian community at WUR including Dessu, Neli, Beshir, Netsi, Mahder, Aby, Saba, Eskie, Engu, Moke, Aziza, Mame, Hanan, Beyetim, Betty, Abe, Zedo, Tesfish, Shambie, Gilbert, Etatu and Zinu for your company and care especially during the time of my wife's pregnancy and after Maya's arrival. A big thank you to my closest friends Alemtsi, Dangi, Goitish, Aman, Getu, Mule, Ashe, Yitibe, Yirgish and Mok for sending me messages and keeping in touch with encouraging talks. Furthermore, a special thanks to Beteseb: Mekdi, Abu, Meku, Firu, Betty, Jose, Kal and Asrat for your sincere friendship and great times we spent together. 
I would like to express my gratitude to my family. Thank you Abaye, Emaye, Neneye, Hiwote and Abushe for giving me your unconditional love and confidence in my capabilities to accomplish this goal. Abaye and Emaye, I cannot imagine myself at this stage without your care and encouragement since childhood. Neneye, thank you for your encouraging words to stand firm and keep the journey until completion.

Finally, finishing this PhD was made possible because of the unconditional love, sacrifices, and support of my wife Tigest. Tgye, thank you for everything, for being so understanding and for putting up with me through the toughest moments of my life. My angel Maya, you bring bliss in our life! Thank you for showing mama (and baba) that there are also other pleasant dimensions of life. 
Curriculum vitae 


\section{About the author}

Tadesse Engida was born in Shoa, Ethiopia, on 07 April 1985. In July 2006, he completed his Bachelor study in Business Education at Mekelle University (Ethiopia). In the same year, he joined Mekelle University (Ethiopia) as a graduate assistant and worked for a year and half. In May 2008, he started his MA study in Development Management at Ruhr Universität Bochum (Germany) and completed in December 2009. Thereafter, he returned to Mekelle University and continued his teaching and research career until August 2015. In September 2015, he started his PhD research at the Business Economics Group of Wageningen University \& Research. He was a visiting scholar for one month (August 4- September 4 2018) at University of Miami, USA. 


\section{Peer reviewed publications}

Engida, T. G., Rao, X., Berentsen, P. B., \& Lansink, A. G. O. (2018). Measuring corporate sustainability performance-the case of European food and beverage companies. Journal of Cleaner Production, 195, 734-743.

Adane, YG, Engida, TG, Asfaw, YA, Azadi, H., \& Passel, SV (2018). Determinants of internal governance quality: Evidence from corporations in Ethiopia. Cogent Economics \& Finance, $6(1), 1537051$.

Haile, A., Engida T.G., \& Tesfay, H. (2014). Financial Performance Analysis of Selected Commercial Banks in Ethiopia. Ethiopian Journal of Business and Economics (The), 4(2), 251-282.

Engida, T. G., \& Baisa, G. A. (2014). Factors Influencing taxpayers' compliance with the tax system: An empirical study in Mekelle City, Ethiopia. eJournal of Tax Research, 12(2).

\section{Conference proceedings}

Engida, T. G., Rao, X. and Oude Lansink, A. G. J. M. (2019). Dynamic Productivity Change in the Presence of Corporate Social Responsibility (CSR). Contribution presented at the 8th EAAE PhD Workshop, June 10-12, 2019, Swedish University of Agricultural Sciences, Uppsala, Sweden

Engida, T. G., Rao, X. and Oude Lansink, A. G. J. M. (2018). A dynamic by-production framework to examine inefficiency specific to corporate social responsibility. Contribution presented at the AAEA Annual Meeting, Augest 5- 7, 2018, Washington DC, USA.

Engida, T. G., Rao, X. and Oude Lansink, A. G. J. M. (2018). A dynamic by-production framework to examine inefficiency specific to corporate social responsibility. Contribution presented at the North American Productivity Workshop X, June 12-15, 2018, Miami, USA.

Engida, T. G., Rao, X., Berentsen, P. B. M. and Oude Lansink, A. G. J. M. (2017). Measuring corporate sustainability performance- the case of European food and beverage companies. Contribution presented at the XV EAAE Congress, "Towards Sustainable Agrifood Systems: Balancing Between Markets and Society", August 29th - September 1st, 2017, Parma, Italy.

Engida, T. G., Rao, X., Berentsen, P. B. M. and Oude Lansink, A. G. J. M. (2017). Measuring corporate sustainability performance- the case of European food and beverage companies. Contribution presented at the 15th European Workshop on Efficiency and Productivity Analysis (EWEPA) 2017, June $12^{\text {th }}$ - June $15^{\text {th }}$ 2017, London, UK. 
Tadesse Getacher Engida

Wageningen School of Social Sciences (WASS)

Wageningen School

Completed Training and Supervision Plan

\begin{tabular}{llll}
\hline Name of the learning activity & Department/Institute & Year & ECTS
\end{tabular}

\section{A) Project related competences}

Organisation of the Agribusiness, BEC

WUR

2015

6

31306

Advanced Agricultural Business

WUR

2016

6

Economics, BEC 30306

Advanced Econometrics , AEP 60306

WUR

2016

6

Theory and Practice of efficiency \&

WASS

2017

6

productivity measurement: Static and

dynamic analysis

Advanced microeconomics, UEC 32306

WUR

2019

6

Info-Metrics

WASS

2019

2

B) General research related competences

Introduction course

WASS

$2016 \quad 1$

PhD Competence Assessment

WGS

2016

0.3

The Essentials of Scientific Writing and

WGS

2017

Presenting

$\mathrm{BEC}$ PhD discussion group

WUR

2015-

'Measuring corporate sustainability performance- the case of European food and beverage companies'.

$15^{\text {th }}$ European Workshop

2019

on Efficiency and

Productivity Analysis

(EWEPA), London, UK

'A dynamic by-production framework to AAEA Annual Meeting, 2018 1 examine inefficiency specific to corporate Washington DC, USA social responsibility'

\section{C) Career related competences/personal development}

Teaching (Agricultural Business and

WUR

Economics (BEC-51806) and Advanced

business economics (BEC-30306),

practical) and Thesis Supervision
2015 , 


\section{Colophon}

The research described in this thesis was financially supported by the Netherlands Organisation for International Cooperation in Higher Education(NUFFIC).

Financial support from the Business Economics Group of Wageningen University for printing this thesis is gratefully acknowledged. 
